\author{
UNIVERSIDADE DE SÃO PAULO \\ Faculdade de Medicina de Ribeirão Preto \\ PÓS-GRADUAÇÃO EM IMUNOLOGIA BÁSICA E APLICADA
}

O papel da enzima glicolítica piruvato quinase M2 (PKM2) na sinalização via IL-17A em queratinócitos e patogênese da psoríase

GABRIEL AZEVEDO PÚBLIO

RIBEIRÃO PRETO

2020 


\author{
UNIVERSIDADE DE SÃO PAULO \\ Faculdade de Medicina de RibeIRÃo Preto \\ PÓS-GRAduAÇÃo EM IMUNOLOGIA BÁSICA E APLICADA
}

Versão Corrigida

\title{
O papel da enzima glicolítica piruvato quinase M2 (PKM2) na sinalização via IL-17A em queratinócitos e patogênese da psoríase
}

\section{GABRIEL AZEVEDO PÚBLIO}

DISSERTAÇÃO APRESENTADA AO PROGRAMA DE PÓS-GRADUAÇÃO EM IMUNOLOGia BÁSicA E APLICAdA dA FACULdAdE DE MEDICINA de Ribeirão Preto da Universidade de SÃo PaUlo para obtençÃo do títUlo de Mestre em CIÊNCIAS, NA ÁREA DE CONCENTRAÇÃO: IMUNOLOGIA BÁSICA E APLICADA.

Orientador: Prof. Dr. José Carlos Farias Alves Filho

RIBEIRÃO PRETO 
AUTORIZO A REPRODUÇÃO E DIVULGAÇÃO TOTAL OU PARCIAL DESTE TRABALHO, POR QUALQUER MEIO CONVENCIONAL OU ELETRÔNICO, PARA FINS DE ESTUDO E PESQUISA, DESDE QUE CITADA A FONTE.

Públio, Gabriel Azevedo

O papel da enzima glicolítica piruvato quinase M2 (PKM2) na sinalização via IL-17A em queratinócitos e patogênese da psoríase

- Ribeirão Preto, 2020.

$91 \mathrm{f}$.

Dissertação apresentada à Faculdade de Medicina de Ribeirão Preto da Universidade de São Paulo para a obtenção do título de Mestre em Ciências. Área de Concentração: Imunologia Básica e Aplicada. Faculdade de Medicina de Ribeirão Preto da Universidade de São Paulo.

Orientador: Prof. Dr. José Carlos Farias Alves Filho

Palavras-chave: Piruvato Quinase M2, Psoríase, Queratinócito, IL-17A 
Gabriel AZeVedo Públio

O papel da enzima glicolítica piruvato quinase M2 (PKM2) na sinalização via IL$17 \mathrm{~A}$ em queratinócitos e patogênese da psoríase

DISSERTAÇÃO APRESENTADA AO PROGRAMA DE PÓS-GRADUAÇÃO EM IMUNOlogia BÁsica e Aplicada da Faculdade de Medicina dE Ribeirão Preto da Universidade de SÃo PaUlo PARA obtençÃo do título de Mestre em CiÊnCIAS, NA ÁREA de CONCENTRAÇÃo: IMUNOLOGIA BÁSICA E APLICADA.

APROVADO EM: DE DE

\section{BANCA EXAMINADORA}

Prof. Dr. José Carlos Farias Alves Filho

Faculdade de Medicina de RiBeIRÃo PRETO - USP

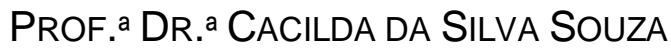

Faculdade de Medicina de RibeiRÃo PRETO - USP

Prof. Dr. Marco Aurélio Ramirez Vinolo

UNIVERSIDADE ESTADUAL DE CAMPINAS - UNICAMP 
Dedico esse trabalho a minha família e amigos por todo apoio e carinho 


\section{AGRADECIMENTOS}

A minha família, em especial a meu pai Washington, minha mãe Selma e meu irmão Afonso e meu gato Nino por todo o apoio durante todos esses anos.

Ao meu orientador, Prof. Dr. José Carlos Farias Alves Filho, pela orientação e por ter me dado a oportunidade de realizar esse trabalho.

A meus coorientadores, Dr. Flavio Protásio Veras e Dra. Nerry Tatiana Cecílio, pelos ensinamentos, apoio, paciência e por me guiar durante esse projeto.

Aos professores Fernando de Queiroz Cunha e Thiago Mattar Cunha, por compartilharem a estrutura do laboratório e a expertise de seus grupos de pesquisa durante a execução desse trabalho.

A Prof. Katiucha Uzzun Sales e ao pós-graduando Gabriel Villiord Vieira, pelos ensinamentos, ajuda na realização dos experimentos de biologia molecular, por oferecer a estrutura de seu laboratório para a clonagem do plasmídeo CRISPR e por nos ceder as células da linhagem HaCat.

Aos meus colaboradores e amigos do laboratório de inflamação e dor (LID), Cesar, Douglas, Eduardo, Bruno, Carlos, Marcos, Thainá, Paula, Stella, Amanda, Joao Paulo, Timna, Juliana, Leticia, Daniele, Raphael, Paulo, André, Raissa, Rose, Talita.

Ao apoio dos técnicos de laboratório, em especial: Sérgio Rosa (Serginho), Ana Kátia, Diva, leda, Gil, Juliana, Marcela.

Ao programa de pós-graduação em Imunologia Básica e aplicada e a secretaria do programa Ana.

As agências de fomento, CNPq, CAPES, FAPESP e CRID pelo apoio financeiro

E a todos de que participaram de alguma maneira desse trabalho 
"Deixo Sísifo no sopé da montanha! Encontramos sempre o nosso fardo. Mas Sísifo ensina a fidelidade superior que nega os deuses e levanta os rochedos. Ele também julga que tudo está bem. Esse universo enfim sem dono não Ihe parece estéril nem fútil. Cada grão dessa pedra, cada estilhaço mineral dessa montanha cheia de noite, forma por si só um mundo. A própria luta para atingir os píncaros basta para encher um coração de homem. É preciso imaginar Sísifo feliz." (CAMUS, Albert. O mito de sísifo.) 


\section{RESUMO}

Públio, Gabriel Azevedo. O papel da enzima glicolítica piruvato quinase M2 (PKM2) na sinalização via IL-17A em queratinócitos e patogênese da psoríase. 2020. 91f. Dissertação (Mestrado em Imunologia Básica e Aplicada) - Faculdade de Medicina de Ribeirão Preto, Universidade de São Paulo, Ribeirão Preto, 2020.

A psoríase é uma doença crônica imunomediada que acomete a pele, caracterizada pela ativação e hiperproliferação de queratinócitos em resposta à citocinas, como IL17A. Estudos demonstram que células do sistema imune passam por uma reprogramação metabólica glicolítica (efeito warburg) durante a ativação, a qual é importante para modular as suas funções. Nesse sentido, foi demonstrado que a piruvato quinase M2 (PKM2), uma enzima do metabolismo glicolítico, é essencial para resposta inflamatória em macrófagos e linfócitos, além disso, descrevemos a participação dessa enzima no desenvolvimento da psoríase experimental. Nesse sentido, o objetivo do presente trabalho é investigar os efeitos funcionais e moleculares da PKM2 na ativação de queratinócitos ativados por IL-17A. Primeiramente, observamos um aumento na expressão de PKM2 em uma linhagem de queratinócitos humanos (HaCat) frente a estimulo de IL-17A, visto por qPCR, Western Blot e Imunofluorescência. Em um passo seguinte, utilizamos a tecnologia CRISPR/Cas9 para gerar células HaCat deficientes para PKM2. Frente a ausência dessa enzima observamos uma redução na produção de mediadores inflamatórios como TNF- a e CXCL-1/IL-8 pelas células ativadas por IL-17A, resultando numa menor capacidade de recrutar neutrófilos em um ensaio de quimiotaxia in vitro. Além disso, a ausência de PKM2 nos queratinócitos inibiu a sinalização de NF-KB, avaliado pela translocação a subunidade p65 e pela atividade de NF-kB utilizando Células HaCat-Luc. Mecanisticamente, observamos que a PKM2 está interagindo com as proteínas acessórias ao receptor de IL-17A (IL-17RA), Act1 e TRAF6. Baseado no exposto acima, os resultados desse trabalho ressaltam a importância da PKM2 no desenvolvimento da psoríase, atuando na sinalização de IL-17A em queratinócitos, o que nos permite acreditar que esta molécula seja um potencial alvo terapêutico para tratamento de psoríase.

Palavras-chave: Piruvato quinase M2 (PKM2), Psoríase, Queratinócitos, IL-17A 


\begin{abstract}
Públio, Gabriel Azevedo. The role of the glycolytic enzyme pyruvate kinase M2 (PKM2) on keratinocytes IL-17A signaling and psoriasis pathogenesis. 2020. $91 \mathrm{f}$. Dissertation (Mestrado em Imunologia Básica e Aplicada) - Faculdade de Medicina de Ribeirão Preto, Universidade de São Paulo, Ribeirão Preto, 2020.
\end{abstract}

Psoriasis is a chronic immunomediated skin disease characterized by a hyperproliferation and activation of keratinocytes in response of cytokines, such as IL17A. Recent studies have shown that immune cells undergo a metabolic reprograming known as Warburg effect during activation, this phenomenon is important for their activity. Accordingly, it has been shown that pyruvate kinase M2 (PKM2) a glycolytic enzyme, is essential for macrophages and lymphocytes inflammatory response, also recently our research group described the participation of this enzyme on the development of experimental psoriasis. Therefore, this work aims to investigate the molecular and functional effects of PKM2 during keratinocyte activation. We first observed an increase in PKM2 expression on IL-17A activated human keratinocytes cell line (HaCat). In this context, we utilized the CRISPR/Cas9 technology as a tool to produce PKM2 deficient HaCat cells. In the absence of PKM2 the keratinocytes did not respond to IL-17A stimulation, with a clear reduction on the production of chemokines, such as TNF- $\alpha$ and CXCL-1/IL-18, impacting their capacity to recruit neutrophils in vitro. Beyond that, in the absence of PKM2 there was no NF-kB p65 translocation to the nucleus, seen by the activation of NF-kb reporter HaCat cells. We also demonstrated for the first time the interaction of PKM2 with the proteins Act1 and Traf6, important adaptors proteins in the IL17RA signalling. Taken together, our results show the importance of PKM2 on psoriasis development, acting on II-17A activated keratinocytes. We conclude that PKM2 is a potential therapeutic target that can be use in the treatment of psoriasis.

Keywords: Pyruvate kinase M2 (PKM2), Psoriasis, Keratinocytes, IL-17A 


\section{Lista de Figuras}

Figura 1 - Organização estrutural de queratinócitos na epiderme......................17

Figura 2 - Fisiopatologia da psoríase.

Figura 3 - Modificações pós-traducionais regulam alostéricamente a

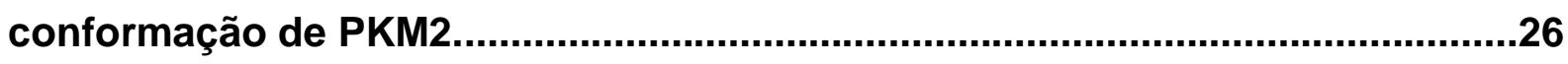

Figura 4 - Geração do plasmídeo CRISPR/PKM2 ................................................33

Figura 5 - IL-17A induz a expressão de PKM2 em queratinócitos in vitro............45

Figura 6 - Padronização da seleção de células transfectadas com o plasmídeo

CRISPR/PKM2. 49

Figura 7 - Geração de linhagem Hacat noucate para PKM2 ...................................50

Figura 8 - PKM2 é necessária na ativação de queratinócitos por IL-17A.............52

Figura 9 - Recrutamento de neutrófilos por queratinócitos é dependente de PKM2. 54

Figura 10 - Deficiência em PKM2 não causa alterações no metabolismo de queratinócitos. .56

Figura 11 - PKM2 é necessária para o translocamento de p65 ao núcleo. 59

Figura 12 - PKM2 é crucial para ativação de NF- $\square$ B por IL-17A em queratinócitos. .60

Figura 13 - Estímulos inflamatórios variados dependem de PKM2. 62

Figura 14 - Deficiência em PKM2 não altera a expressão do receptor para IL$17 \mathrm{~A}$. .64

Figura 15 - PKM2 é importante para a formação da plataforma molecular TRAF6Act1 em queratinócitos ativados por IL-17A. .65

Figura 16 - Participação da PKM2 durante o processo de ativação de queratinócitos. . .73 


\section{Sumário}

1. INTRODUÇÃO

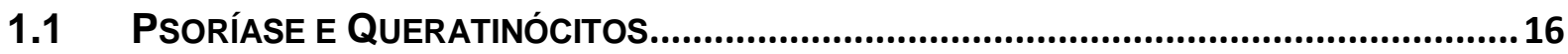

1.2 METABOLISMO CELULAR E SISTEMA IMUNOLÓGICO..................................................21

1.2.1 A PIRUVATO QuINASE M2 (PKM2): ASPECTOS GERAIS ...................................24

1.2.2 A PIRUVATO QuINASE M2 (PKM2): No SISTEMA IMUNolóGICO.........................27

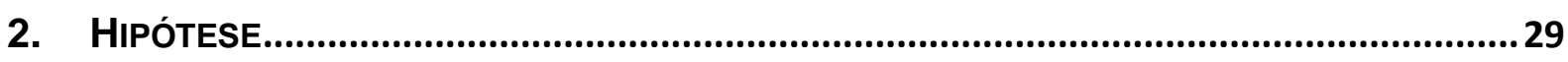

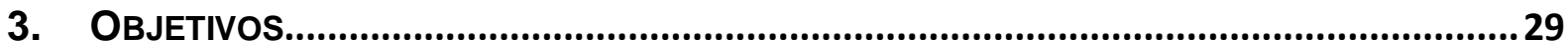

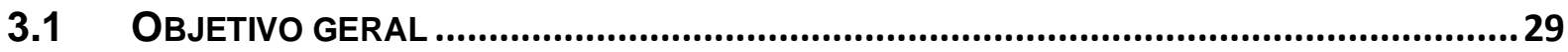

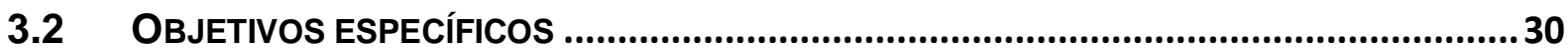

4. MATERIAIS E MÉTODOS ........................................................................................... 30

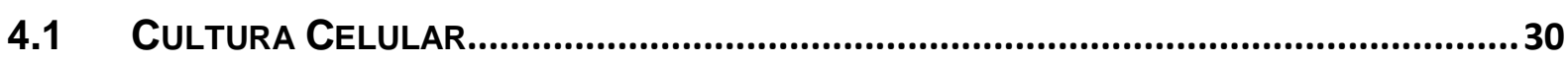

4.2 DESENHO E ESCOLHA do RNA-gUIA PARA O GENE PKM2 …..............................31

4.3 CLONAGEM DO OLIGO DESENHADO NO VETOR E OBTENÇÃo DO PLASMÍDEO..............32

4.4 TRANSFECÇÃo dos Plasmídeos SELECIONAdoS EM CÉlULAS HACAT .....................34

4.5 SeleÇÃo dAS CÉlULAS TRANSFECTADAS COM PLASMÍDEO CRISPR/PKM2 ..........34

4.6 Western Blot .......................................................................................................

4.7 ANÁLISE DA SEQUência do DNA genômico por sequenciamento de nova

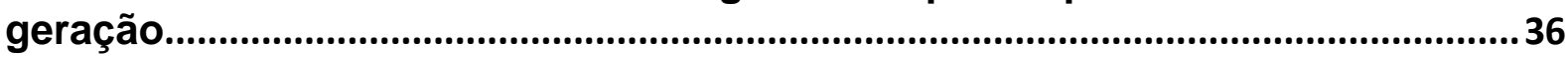

4.8 ENSAIO DE QuIMIOTAXIA DE NEUTRÓfILOS ..........................................................

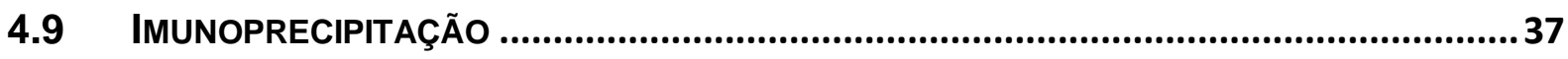

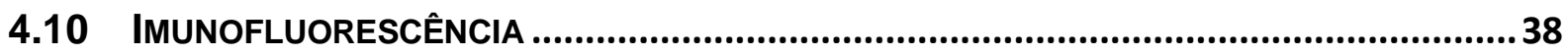

4.11 ANÁLISE DO PERFIL DE CITOCINAS POR ELISA .....................................................39

4.12 ANÁLISE DA EXPRESSÃo gênica...........................................................................39

4.13 ENSAIO de PROLIFERAÇÃo CELULAR ……..........................................................40

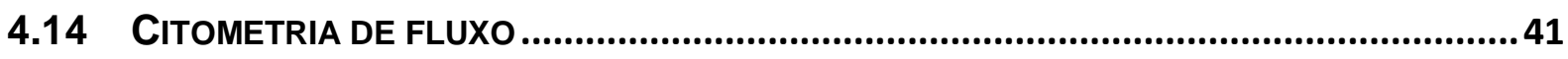

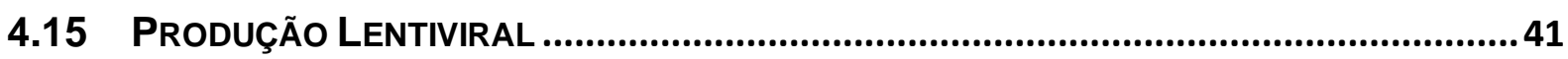

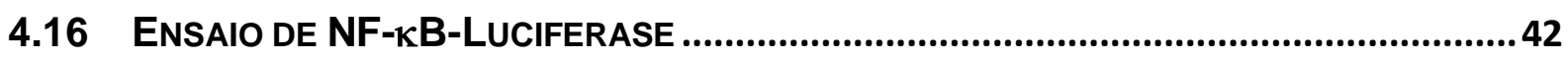

4.17 Dosagem de LACTATO E ConSUMo DE GLICOSE ..................................................42

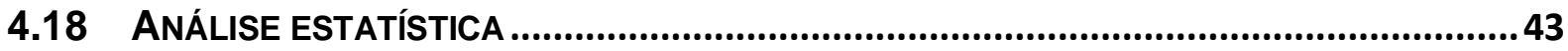

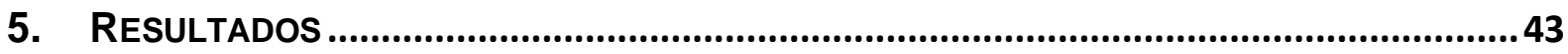

5.1 IL-17A INDUZ A EXPRESSÃO DE PKM2 EM QUERATINÓCITOS IN VITRO. ....................43

5.2 GERAÇão de Queratinócitos nocautes Para A ENZIMA PKM2 PELO MÉtodo

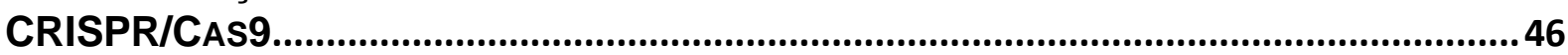


5.3 PKM2 PARTICIPA NO PROCESSO DE ATIVAÇÃO DE QUERATINÓCITOS POR IL-17A .. 51

5.4 QUIMIOTAXIA INDUZIDA POR QUERATINÓCITOS É DEPENDENTE DE PKM2 ................53

5.5 AUSÊNCIA de PKM2 não altera o metabolismo de queratinócitos................55

5.6 ATIVAÇÃO dE NF-KB POR IL-17A EM QUERATINÓCITOS REQUER PKM2 .................57

5.7 VIAS COMUNS DE ATIVAÇÃO DE NF-KB PARECEM SER DEPENDENTES DE PKM2 ....61

5.8 A ENZIMA PKM2 INTERAGE COM MOLÉCULAS ADAPTADORAS DA VIA DE

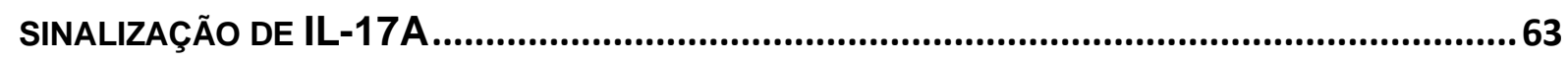

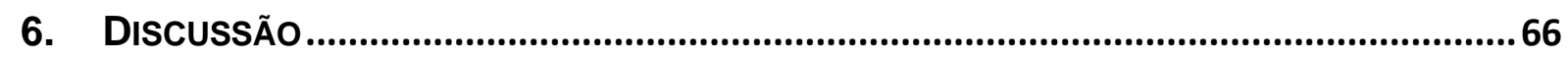

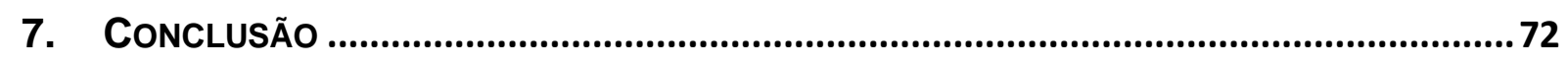

8. REFERÊNCIAS BIBLIOGRÁFICAS .........................................................................74

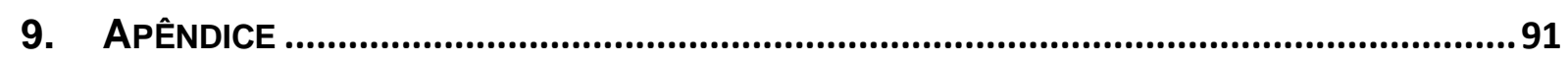




\section{Lista de Abreviaturas}

3'LTR - repetição terminal longa 3 linha

5'LTR - repetição de terminal longa 5 linha

Act1 - NFkB-Activating Protein ACT1

AIM2 - Absent In Melanoma 2

ATP - Adenosina trifosfato

Cas9 - CRISPR associated protein 9

CRISPR - Clustered Regularly Interspaced Short Palindromic Repeats

CXCL-1/IL-8 chemokines - Gro-alpha / Interleucina 8

DAMPs - Padrão molecular associado ao dano

DMEM - Dulbecco's Modified Eagle's Medium

E.coli - Escherichia coli

EDTA - Ethylenediamine tetraacetic acid

EGF - Endotelia Grow Factor

FACs - Citometria de fluxo

GFP - Proteína fluorescente verde

HIF1-a - Fator 1-alfa induzível por hipóxia

HK - Hexoquinase

HMGB1 - proteína box 1 do grupo de alta mobilidade,

IFN- $\alpha$ - Interferon Alfa

IFN- $\mathrm{Y}$ - Interferon Gama

IKKi - IKB quinase induzível

IL-17A - Interleucina 17A

IL17RA - receptor para IL-17A

IL17RC -subunidade de receptor para IL-17A C 
IL17RE - subunidade de receptor para IL-17A E

IL-1 $\beta$-Interleucina 1 beta

IL-22 - Interleucina 22

IL-23 - Interleucina 23

IL-6 -Interleucina 6

IMQ -Imiquimode

K14 -Citoqueratina 14

K16 - Citoqueratina 16

K17 - Citoqueratina 17

K5 - Citoqueratina 5

K6 - Citoqueratina 6

LPS - Lipopolissacarídeo

LUC - Luciferase

MHC - Complexo principal de histocompatibilidade

NF-kB p65 - Factor nuclear kappa B subunidade 65

PAM - Protospacer adjacent motif

PAMPs - Padrões moleculares associados ao patógeno

PBS-T - Phosphate-Buffered Saline Tween

PCR - Reação de caideia da Polimerase

PFK - Fosfofrutoquinase

PK - Piruvato quinase

PKLR - Piruvato quinase L e R

PKM1 - Piruvato quinase M1

PKM2 - Piruvato quinase M2

PMA/I - Forbol 12-miristato 13-acetato e lonomicina 
ROS - Espécie reativa de oxigênio

S100a8 - Proteína A8 de ligação ao cálcio S100

S100a9 - Proteína A9 de ligação ao cálcio S100

STAT3 - Signal transducer and activator of transcription 3

TCA - Ciclo do ácido tricarboxílico

TCR - Receptor de célula T

TGF- $\beta$ - Transforming growth factor beta.

Th1 - T auxiliar 1

Th17 - T auxiliar 17

TMB - Tetrametilbenzidina

TNF- $\alpha$ - Fator de necrose tumoral alfa

TRAF6 - Fator associado ao receptor de TNF

$\triangle P K M 2$ - Nocautes para PKM2 


\section{INTRODUÇÃO}

\subsection{Psoríase e Queratinócitos}

A psoríase é uma doença crônica imunomediada que acomete a pele, caracterizada pela hiperproliferação de queratinócitos e um acúmulo de infiltrado inflamatório. De acordo com dados epidemiológicos estima-se que doença acometa cerca de $3 \%$ da população mundial, apresentando uma taxa elevada de morbidade, perda de produtividade, baixa autoestima e até altos custos econômicos (Christopher E, 2001; Boehncke W. H., 2015). Essa doença contém diferentes apresentações clinicas, como psoríase vulgar, psoríase gutata, psoríase inversa, psoríase pustulosa e psoríase enritrodérmica, as quais, apesar de apresentarem características distintas, podem ocorrer concomitantemente em um mesmo indivíduo (GRIFFITHS et al., 2007; GRIFFITHS; BARKER, 2007). De maneira geral, a psoríase caracteriza-se por uma formação de placas na pele cobertas por escamas brancas (placas psoriáticas) em diferentes regiões do corpo resultando num enrijecimento da pele e eritema (McKee $\mathrm{PH}, 2005)$. O desenvolvimento da doença ocorre pela desregulação da resposta imunológica, resultante da incapacidade dos componentes imunológicos presentes na pele de montar uma reposta imune efetiva, o que leva a inflamção exacerbada e crônica (Krueger JG, 2005)

O tipo celular mais abundante da pele são os queratinócitos, esses se situam predominantemente na epiderme desempenhando funções estruturais sintetizando principalmente queratina, que garante impermeabilidade, elasticidade e resistência a pele, que são importantes para o controle homeostático do órgão (Eckert, 1989). Os queratinócitos se organizam na epiderme em cinco camadas ou estratos: o estrato basal, o estrato espinhoso, o estrato granuloso, o estrato lúcido e estrato córneo 
(Figura 1). Essas camadas se originam logo após a derme, sendo a mais interna o estrato basal. Os queratinócitos seguem por divisão e migração celular da camada mais interna para a mais externa, mantendo algumas células progenitoras no estrato basal enquanto seguem para os estratos subsequentes (Freedberg, 2003). No estrato espinhoso é iniciado o processo de diferenciação celular, onde ocorrem mudanças bioquímicas e morfológicas nos queratinócitos que ao chegar no estrato córneo já se apresentam como células mortas de superfície, sendo composto principalmente de filamentos de queratina (Schoop, 1999). Este processo é altamente regulado e perturbações durante esse processo pode levar a perda de função da barreira epitelial e surgimento de doenças de pele (Eckert, 1989).

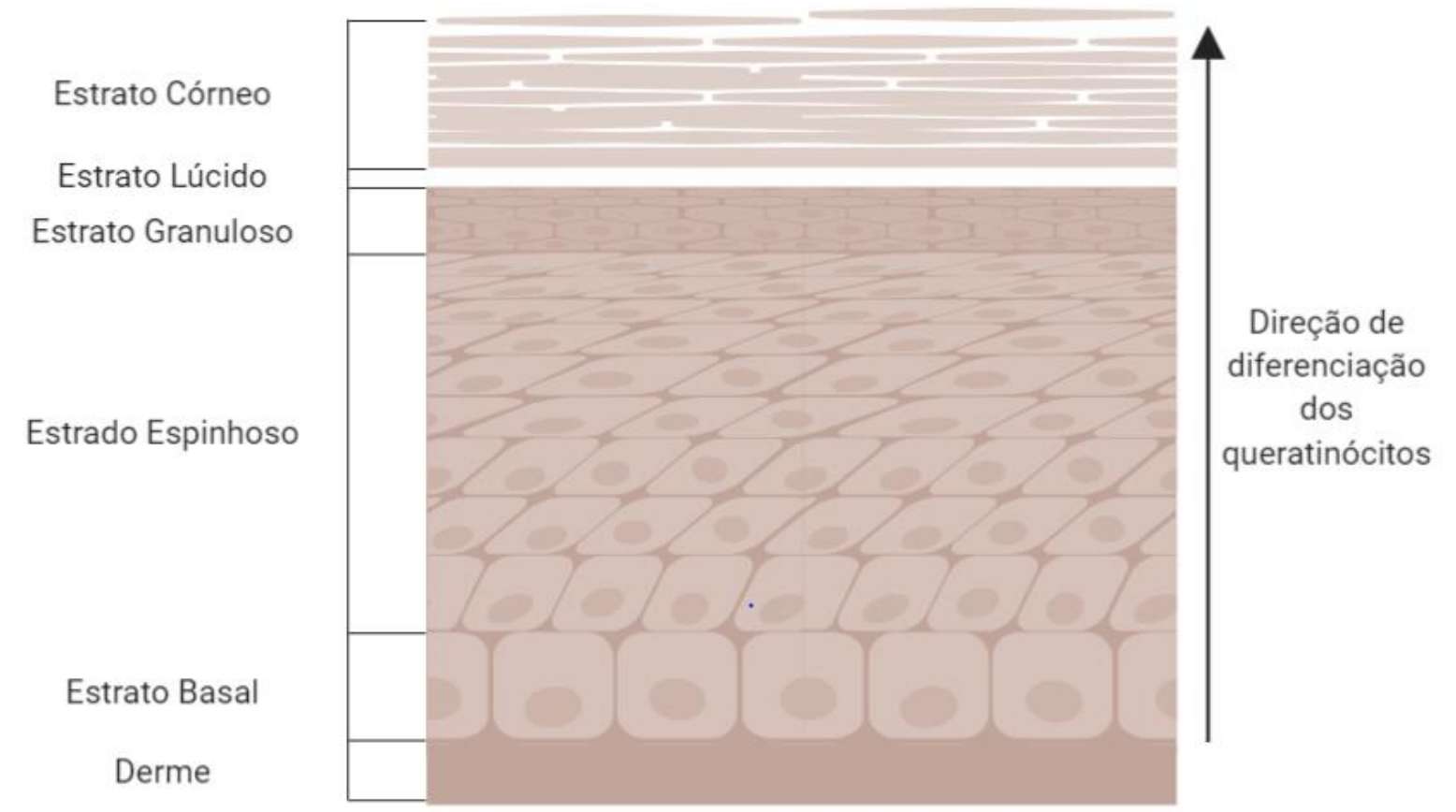

Figura 1 - Organização estrutural de queratinócitos na epiderme. Ilustração representativa da diferenciação de queratinócitos e direção de proliferação da camada mais interna (Estrato Basal) até a mais externa (Estrato Córneo).Adaptado de KIERSZENBAUM, 2008, 311)

Em uma situação de homeostase, a epiderme serve de barreira física protegendo o organismo de agressores externos, porém frente a estímulos estressores os 
queratinócitos podem participar da gênese e manutenção da resposta inflamatória na pele (Barker, 1991). Além disso, foi reportado a capacidade de queratinócitos de produzir quimiocinas e citocinas pró-inflamatórias, como IL-6, IL-8, IL- $\beta$ e TGF- $\alpha$ frente a diversas situações estressantes, tais como exposição à radiação UV, psoríase e reparo tecidual. Também foi reportado a capacidade dos queratinócitos de expressar MHC de classe II, o que os permite interagir diretamente com linfócitos do perfil Th1 (Lu KQ, 2003; Fukuoka M, 1998; Galkowska H, 2006; Samira Tamoutounour, 2019). Essa capacidade permite aos queratinócitos a capacidade de interagir com as células do sistema imunológico, participando assim das respostas imunes que acometem a pele.

Por conter as características supracitadas, os queratinócitos podem atuar tanto na gênese, bem como, na manutenção da psoríase. Embora ainda não esteja bem esclarecido como isso se inicia, sabe-se que os queratinócitos tem a capacidade responder tanto a PAMPs como a DAMPs, possuindo uma série de receptores do tipo toll (Lebre MC, 2007), receptores de citocinas (Junghans et al., 1996, Albanesi et al., 2000, Akaiwa et al., 2001), além de ser capaz de ativar inflamossoma (Kalali BN, 2008; Dombrowski et al., 2011) tornando essas células em sentinelas na pele. Esse processo de ativação dos queratinócitos os leva a um perfil altamente proliferativo, com alterações em seu citoesqueleto e amplificação de receptores de superfície celular. O perfil apresentado por essas células ativadas é de expressão de proteínas de diferenciação e hiperproliferação, como citoqueratinas 5, 6, 14, 16 e 17 (K5, K6, K14, K16 e K17) os quais levam a morte celular e liberação de seu conteúdo celular, resultando em inflamação (Alam H, 2011; Coimbra, 2012; Juráňová et al., 2017).

Uma das principais moléculas ativadoras de queratinócitos num contexto de psoríase é a citocina IL-17A. Sua produção na pele se dá majoritariamente por dois 
tipos celulares, da imunidade adaptativa os linfócitos Th17 e da imunidade inata os linfócitos naturais yర. Para produção de IL-17A, os linfócitos T naives precisam se diferenciar em linfócitos Th17 na periferia, isso se dá após estimulo de TCR mais os segundos sinais de citocinas como IL-6 e TGF- $\beta$. Já os linfócitos $ү \delta$ adquirem a capacidade de produzir IL-17A durante seu desenvolvimento no timo, e começam a produzir esta citocina frente aos estímulos de IL-23 e IL-1 $\beta$, sem necessidade de estimulo de TCR (Cua DJ, 2010; Sutton CE, 2009; Cai Y, 2011, Shibata K 2008).

Ao ocorrer acúmulo de IL-17A na pele, temos a ativação dos queratinócitos por essa citocina, sendo esse o estímulo mais potente para a liberação de quimiocinas como a IL-8. Além disso, essa ativação resulta numa alta taxa proliferativa de queratinócitos, assim como a indução da produção de peptídeos antimicrobianos por essas células, como as proteínas da família S100 e Defensinas (LOWES et al., 2013). Com isso, temos o recrutamento e acúmulo de neutrófilos no sitio de lesão psoriásica por gradiente quimiotático. Ainda não está bem estabelecido na literatura o papel dos neutrófilos na psoríase, porém existem evidências que esta célula estimule a proliferação de queratinócitos e perturbe sua diferenciação na epiderme, o que sugere sua participação no desenvolvimento da psoríase (Henry et al., 2016;Tonello, 2017).

A importância da ativação dos queratinócitos pela citocina IL-17A se dá pela alta expressão de seu receptor (IL-17RA) presente nesse tipo celular. A família de receptores para IL-17A é composta por dímeros de até 5 subunidades, de IL17RA a IL17RE (Aggarwal S, Gurnery, 2002). De maneira curiosa, apesar da expressão de IL17RA se apresentar na maioria das células de mamíferos a resposta a IL-17A ocorre de maneira predominante em células epiteliais (Sara L. Gaffen, 2009). Nos queratinócitos o IL-17RA se apresenta como um dímero de IL17RA e IL17RC, esses 
promovem a sinalização induzida por IL-17A através da proteína adaptadora Act1. A Act1 pode se associa com a proteína inibitória de NF-kB, IKB quinase induzível (IKKi), permitindo a transcrição de proteínas pró-inflamatórias por esse fator transcricional. Independentemente do IKKi, o Act1 também pode promover a ubiquinação de TRAF6 levando à ativação do NF-kB (Chiricozzi et al., 2011; Tonel \& Conrad, 2009; Zhu et al., 2010).

De maneira resumida, temos então a participação dos queratinócitos na fisiopatologia da psoríase esquematizada na Figura 2. A qual observamos a ativação de queratinócitos por um insulto inicial (não determinado), levando a uma proliferação dessas células bem como a produção de quimiocinas e citocinas pro-inflamatórias. Esse microambiente inflamatório leva o recrutamento de neutrófilos que provocam uma maior inflamação e lesão tecidual. Durante essa situação, temos a morte celular de queratinócitos com liberação de ácidos nucleicos livres que são reconhecidos por células dendríticas locais, presentes na derme, as ativando (Takagi H, 2016; Li N 2014; Ganguly D, 2009). Uma vez ativadas, as células dendríticas começam a produzir IFN- $\alpha$, que por sua vez, ativam as células dendríticas mielóides nos linfonodos drenantes culminando na indução da diferenciação de linfócitos T produtores de IL-17A (Lande et al., 2007; Girolomoni G, 2017). Esses subtipos de linfócitos são os principais mediadores que levam ao desenvolvimento da doença (Korn, Bettelli, Oukka, \& Kuchroo, 2009; Cai et al., 2011; Nestle FO, 2009). Os linfócitos ativados migram de volta para a derme onde eles produzem grandes quantidades de IL-17A. Essas citocinas ativam os queratinócitos resultando em uma maior proliferação e maior produção de quimiocinas, levando a um maior recrutamento de células do sistema imune para a lesão, e por consequência a cronicidade da doença. (Carrier Y, 2011; Albanesi C, 2007; Muromoto R, 2016; Torales-cardeña, 
2015).

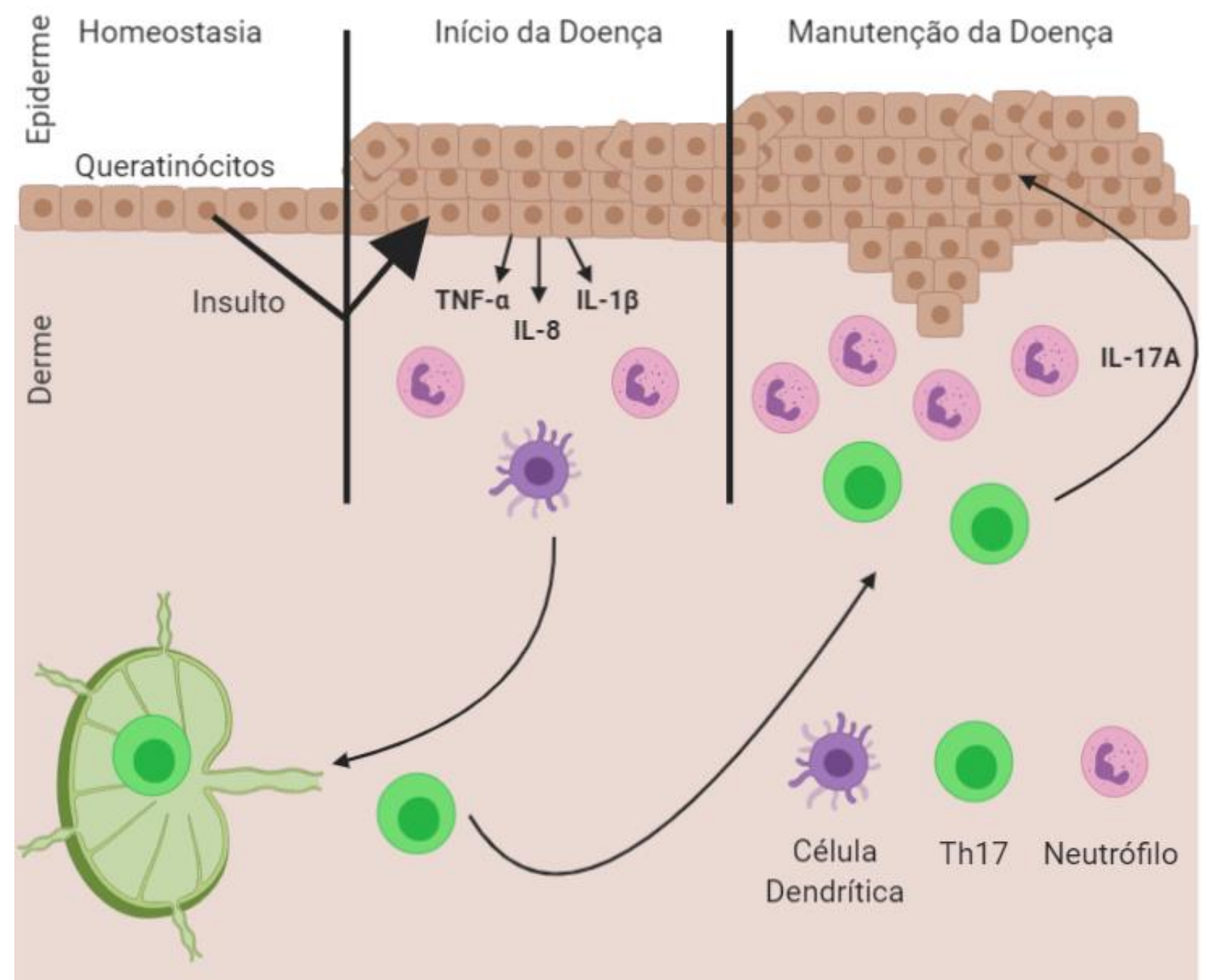

Figura 2 - Fisiopatologia da psoríase. Ilustração esquemática da fisiopatologia da psoríase dando foco na produção de citocinas produzidas pelos queratinócitos assim como sua ativação por IL-17A (Adaptado de Nestle FO, 2009).

\subsection{Metabolismo celular e sistema imunolóGico}

Nossas células estão diariamente realizando diversas reações bioquímicas, reações estas que se intersectam em cadeias e vias complexas que permitem as reações e catabolismo e anabolismo. Catabolismo pode ser entendido como o processo de quebra de moléculas para produção de energia, por exemplo a quebra de glicose durante a respiração celular para formação de ATP. Enquanto o anabolismo é basicamente o processo oposto, utilizando a energia (ATP) para a produção de 
moléculas maiores a partir de moléculas menores. Esses processos relacionados a produção e utilização de ATP é o que chamamos de metabolismo energético ( Lehninger, 2000, p.3).

O metabolismo glicolítico é a via mais importante para geração de energia em células eucarióticas. Essa pode ocorrer de maneira aeróbia bem como anaeróbica. De maneira resumida, a glicólise ocorre em 10 passos catalisado por diversas enzimas especificas, como a hexoquinase (HK), a fosfofrutoquinase (PFK) e a piruvato quinase (PK), convertendo no citoplasma glicose em piruvato, o qual pode seguir para a mitocôndria alimentando o ciclo do ácido tricarboxílico (TCA), ou ser reduzido a lactato em condições de hipóxia (Boiteux, A. \& Hess, B., 1981 ; Dandekar, T. 1999, Erlandsen, H., 2000)

Além da sua importância na geração de energia, a via glicolítica gera diversos metabólitos que alimentam outras vias, por exemplo: a síntese de ácidos graxos pode ser feita a partir de acetil-CoA, proveniente de piruvato; o aminoácido alanina é sintetizado a partir de piruvato; a glicose e a glicose-6-fosfato são intermediários na conversão para outros açucares importantes na síntese de nucleotídeos (Xue-bing Li, Jun-dong Gu \& Qing-hua Zhou, 2015).

Cada vez mais tem se demonstrado que o metabolismo celular apresenta outros papéis-chave nas atividades celulares além de anabolismo e catabolismos. Foi descrito na literatura a capacidade de metabolitos gerados atuarem como segundo mensageiros em vias de sinalização intracelular, o que pode modular a atividade de células do sistema imune (Palsson-McDermott, 2013; Galván-Peña, 2014; Shi, 2011). Isto se mostra claro durante o efeito Warburg, em que temos um aumento da glicose aeróbica, que está estritamente ligado ao perfil de resposta imune celular (GalvánPeña, 2014; Shi, 2011). 
O efeito Warburg, descrito por Otto Warburg em 1927, demonstrou que células cancerígenas apresentavam um perfil altamente glicolítico mesmo em condições de hipóxia, e que isto estava ligado à sua alta capacidade proliferativa (Warburg O, 1927). As células tumorais parecem ter a capacidade de "reprogramar" seu metabolismo, com deslocamento do uso de piruvato na fosforilação oxidativa presente no TCA, para produção final de lactato (West AP, 2011; O'Neil LA, 2016). Isso ocorre por um aumento na expressão de genes relacionados a glicólise, como transportadores e enzimas, levando a uma maior captação de glicose assim como maior catabolismo celular. Dessa maneira, a célula consegue uma rápida produção de energia assim como material biossintético, como intermediários metabólicos para produção de proteínas, nucleotídeos e componentes de membrana, permitindo uma rápida proliferação celular (Dong G, 2016).

Como brevemente mencionado anteriormente, o efeito Warburg também se apresenta em células do sistema imune. Isso já foi demonstrado em macrófagos, os quais quando ativados pela via clássica, o qual determina o fenótipo M1, é necessário que ocorra uma reprogramação metabólica, com um aumento da glicólise aeróbica, de maneira similar ao observado em celular tumorais, em contra partida isso não ocorre em macrófagos ativados de maneira alternativa, o que determina o fenótipo M2 (Galván-Peña, 2014). Concordando com isso, observamos alterações metabólicas polarizantes de maneira similar em linfócitos $T$, na qual foi observado a necessidade da glicólise aeróbica durante a diferenciação para o perfil Th17, o qual está relacionada a respostas pró-inflamatórias, enquanto isso não se mostra necessário durante a diferenciação para o perfil T regulador, o qual está relacionado a regulação da inflamação (Palsson-McDermott, 2013;L. Z. Shi et al., 2011). 
De maneira similar, existem evidências que sugerem que queratinócitos apresentem mudanças em seu metabolismo frente a ativação. Queratinócitos infectados por Staphylococcus aureus, apresentam uma maior expressão de HIF1-a, um importante fator de transcrição do efeito Warburg, e de maneira concordante mudanças em seu metabolismo energético, assim como uma maior produção de IL$1 \beta$ (Wickersham M, 2017). De maneira similar, também foi descrito a capacidade dos queratinócitos apresentam maior expressão de HIF1-a frente a outras situações estressantes, como a exposição a raios UV ou durante psoríase (Cho, 2012). Concordando com a importância do metabolismo glicolítico para ativação de queratinócitos, foi demonstrado que a inibição do transportador de glicose Glut 1 nessas células se mostrou benéfico em modelo experimental de psoríase (Zhuzhen Zhang, 2018).

Uma enzima metabólica que cada vez mais tem se demonstrado importante para esse processo de reprogramação metabólica é a enzima piruvato quinase M2 (PKM2), a qual foi descrita importante tanto em células tumorais como células no sistema imune, apresentando funções glicolíticas e não glicolíticas (Dong G, 2016; PalssonMcDermott, 2015).

\subsubsection{A PIRUVATO Quinase M2 (PKM2): ASPECtOS GERAIS}

A enzima metabólica Piruvato Quinase (PK) participa na via glicolítica catalisando a última reação desta via, de fosfoenolpiruvato em piruvato. Ela se apresenta em mamíferos em quatro isoformas distintas, sendo elas a L, R, M1 e M2 (Imamura K, 1972). A expressão das isoformas $L$ e $R$ são dadas pelo gene $P K L R$ expresso pelo fígado e eritrócitos respectivamente, já as isoformas M1 e M2 são codificadas pelo gene PKM se diferenciando a partir do processo de splicing alternativo do transcrito 
primário de RNA do gene PKM, o qual contém as sequencias codificadoras de cada isoforma a partir do exon 9, para PKM1, e 10, para a PKM2 (YANG; LU, 2015).

A PKM1 é uma enzima expressa constitutivamente em tecidos que demandam de uma alta taxa bioenergética, como músculo, coração e cérebro. Essa apresenta uma alta afinidade por seu substrato (fosfoenolpiruvato) com conformação fixa de tetrâmero e uma rápida atividade de piruvato quinase e não é passível de modificações alostéricas. Por outro lado, sua isoforma PKM2 é altamente expressa em tecidos com alta taxa de proliferação, como células embrionárias, células tronco, tumorais e células do sistema imunológico (Yang, 2013; Mazurek, 2011). Esta apresenta, quando comparada a isoforma $M 1$, baixa atividade basal tendo sua atividade controlada alostericamente por modificações pós-traducionais, mudando entre duas conformações ativas, uma dimérica e outra tetramérica (Figura 3) (Dong G, 2016; Israelsen and Vander Heiden, 2015). 


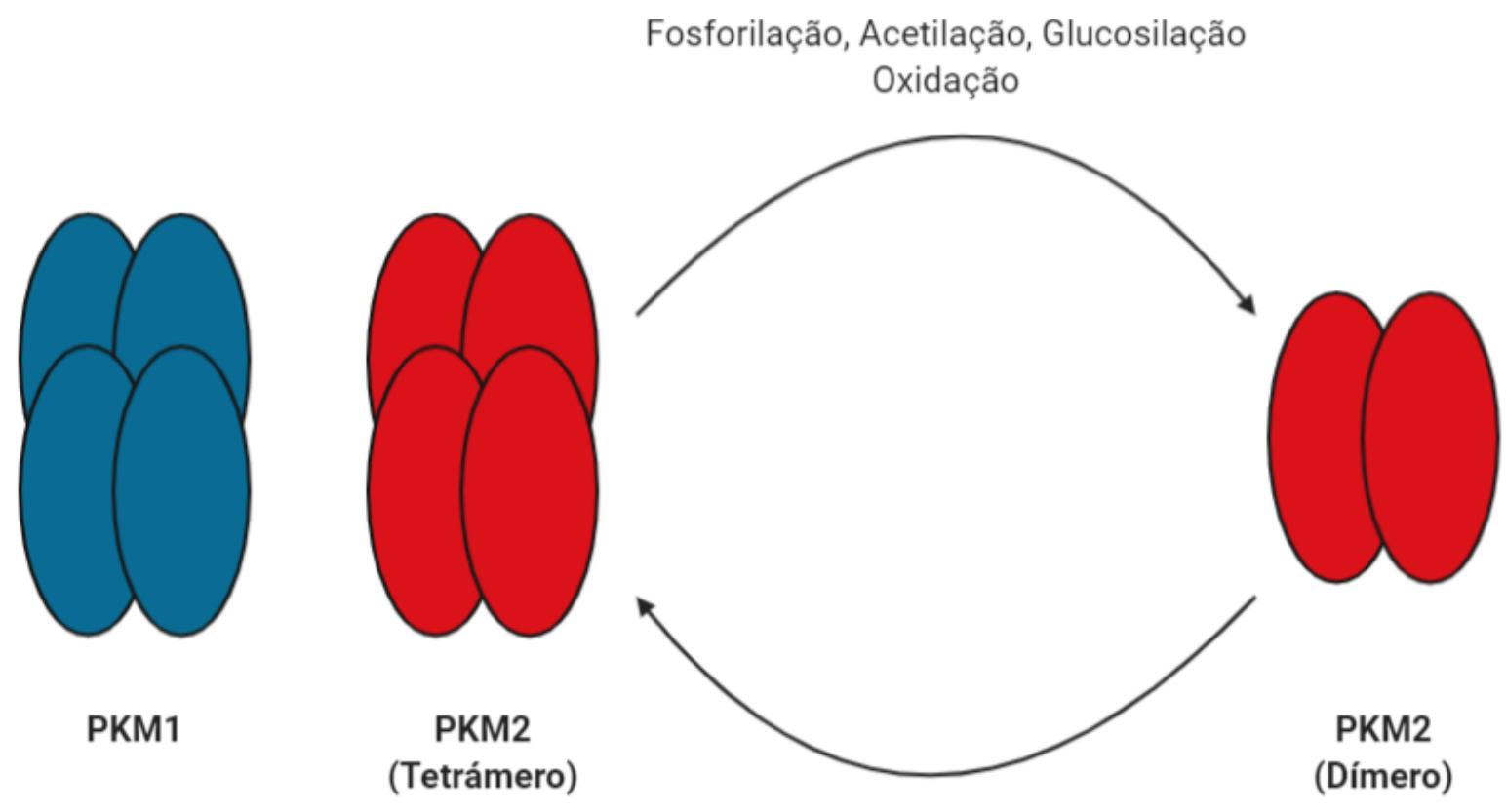

Frutose 1,6 Bifosfato, Serina

Figura 3 - Modificações pós-traducionais regulam alostéricamente a conformação de PKM2. Ambas PKM1 e PKM2 apresentam uma conformação tetramérica ativa, porém frente modificações pós-traducionais como fosforilação, acetilação, glicosilação e oxidação PKM2 pode se dimerizar (Adaptado de Dong G, 2016).

Essas diferentes conformações apresentadas pela PKM2 garantem capacidade funcional distinta, sendo esse processo altamente regulado tanto por produtos metabólicos, como aminoácidos, como por vias de sinalização celular e esses juntos coordenam a atividade da PKM2 (Anastasiou D., 2012; Abhishek Bhardwaj, 2016; Christofk HR, 2008; Chaneton B, 2012; Israelsen, 2015). Em sua conformação tetramérica, a PKM2 apresenta uma rápida capacidade glicolítica similar a sua isoforma M1, já em sua conformação dímérica, sua função foi primeiramente descrita como um co-ativador transcricional do fator transcricional HIF-1 $\alpha$, interagindo com o mesmo fisicamente (Palsson-McDermott, 2015). Além disso, a conformação dimérica da PKM2 não atua somente como um co-ativador transcricional, mas 
também podendo agir como uma proteína quinase fosforilando fatores transcricionais como STAT3, assim regulando a transcrição gênica (Gao X, 2012). Também foi demonstrado a importância da PKM2 dimérica no citoplasma, na qual estabiliza a sinalização do receptor de EGF, promovendo o crescimento de células epiteliais (Y-C Yang, 2016).

Embora já existam evidências do papel da PKM2 na modulação do sistema imune, conforme descritos adiante, ainda pouco se sabe do mecanismo pelo qual essa enzima exerce suas funções, o que torna interessante seu estudo no contexto de doenças imunes, como a psoríase.

\subsubsection{A Piruvato Quinase M2 (PKM2): No sistema ImUnológico}

Conforme supracitado, a enzima PKM2 pode apresentar diferentes funções dependente de sua conformação, funções essas metabólicas e não metabólicas. Podemos observar a importância metabólica dessa enzima tanto em células tumorais como em células do sistema imunológico, na qual foi descrita como reguladora do metabolismo através do efeito Warburg, garantindo um rápido fluxo de energia e intermediários glicolíticos para sintetizar os ácidos nucléicos, aminoácidos e lipídeos, que são importantes tanto para a proliferação celular como para a geração de biomoléculas necessárias para se iniciar o processo inflamatório (Yang W, 2012; Pouyssegur J, 2006; Gao X, 2013; Alves-Filho \& Palsson-McDermott, 2016).

Enquanto a função não metabólica, foi demonstrado a importância de PKM2 na imunidade inata, na qual foi capaz de interagir diretamente com HIF-1 $\alpha$ e atuar como co-fator transcricional promovendo a transcrição de genes relacionados com a glicose aeróbica em macrófagos classicamente ativados (Palsson-Mcdermott et al., 2015; Yang et al., 2014). Curiosamente, ao se inibir a PKM2 nesses macrófagos, esses 
mostraram menor produção de IL-1 $1 \beta$, e menor polarização para o subtipo M1 frente ao estimulo de LPS (Palsson-McDermott, 2015). Também já foi demostrado que o silenciamento de PKM2 resultou numa diminuição na secreção de HMGB1 em macrófagos ativados, um grupo de citocinas inflamatórias secretadas em casos tardios de sepse, o que além de diminuir a produção de lactato, conferia uma maior proteção a camundongos a sepse letal (Yang, 2015). Além disso, esse mesmo grupo de pesquisa mostrou que a PKM2 participava do processo de ativação de inflamassomas, como NLRP3 e AIM2, que são importantes sensores citoplasmáticos no combate a infecções intracelulares (XIE et al., 2016).

A PKM2 também se demonstrou importante para o desenvolvimento de doença arterial coronariana, sendo essa considerada uma síndrome inflamatória crônica caracterizada pela migração de monócitos no espaço subendotelial causada pela deposição de colesterol. Os monócitos aumentam seu perfil glicolítico se diferenciando para o macrófagos M1, aumentando sua produção de ROS e de citocinas pró-inflamatórias, como IL-6 e IL1 $\beta$, causando lesão tecidual e agravamento da doença (Shirai et al., 2016).

Já imunidade adaptativa foi demonstrado a importância da PKM2 durante a diferenciação de células T CD4, em que sua inibição resulta em menor diferenciação para perfis pró-inflamatórios, como Th1 e Th17 (Michihito Kono, 2019; Damasceno, 2018, tese de doutorado). A menor diferenciação para o perfil Th17 causada pela ausência de PKM2, mostrou-se benéfica durante 0 desenvolvimento de encefalomielite autoimune experimental, na qual animais nocautes específicos a essa enzima em linfócitos $\mathrm{CD}^{+}$, desenvolveram menor doença e maior sobrevida (Damasceno, 2018, tese de doutorado). 
Também existem evidencias de que a PKM2 participa no processo de ativação e proliferação de queratinócitos. Existe um estudo em que a inibição farmacológica de PKM2 em uma linhagem de queratinócitos humano imortalizado (HaCat), inibiu a produção de VEGF pela mesma, frente ao estimulo de IL-17A (Xu, 2014). Nosso grupo de pesquisa também demonstrou que a PKM2 está altamente expressa na epiderme da pele lesionada de pacientes psoriásicos, assim como na epiderme de camundongos submetidos a psoríase experimental por IMQ, e que animais deficientes a essa enzima nos queratinócitos desenvolviam menos a doença (Veras, 2018, tese de doutorado). Embora o estudo supracitado tenha demonstrado a importância da PKM2 no desenvolvimento da psoríase, não ficou claro o mecanismo pela qual a mesma atua nos queratinócitos. Portanto, o seguinte trabalho visou aprofundar o conhecimento sobre o papel da PKM2 durante a ativação de queratinócitos num contexto de psoríase, e investigar a fundo os mecanismos envolvidos nesse processo.

\section{HIPÓTESE}

Como hipótese, a PKM2 participa da patogênese da psoríase pela ativação de queratinócitos via IL-17A pela interação com sua sinalização, contribuindo para o desenvolvimento e manutenção da doença.

\section{OBJETIVOS}

\subsection{OBJETIVO GERAL}

Este estudo tem por objetivo geral investigar a participação da PKM2 na ativação de queratinócitos por IL-17A. 


\subsection{OBJetivos específicos}

3.2.1 Avaliar in vitro o perfil de expressão de genes relacionados à ativação de queratinócitos, frente a um estimulo de IL-17A

3.2.2 Geração de queratinócitos nocautes para PKM2 ( $\triangle \mathrm{PKM} 2)$ e avaliar seu efeito funcional num contexto inflamatório

3.2.3 Investigar o papel funcional de PKM2 no processo de ativação de queratinócitos frente ao estimulo de IL-17A

3.2.4 Avaliar como a ausência de PKM2 impacta nas vias de resposta a IL-17.

\section{MATERIAIS E MÉTODOS}

\subsection{Cultura Celular}

A linhagem de queratinócitos humanos imortalizados, chamada HaCat, vem sendo cada vez mais utilizada em estudos in vitro sobre a patofisiologia e homeostasia da pele. A utilização dessas células para esse tipo de estudo se deve, principalmente, ao fato de que elas mantêm as características morfofuncionais dos queratinócitos humanos. Além disso, apresentam crescimento rápido e fácil cultivo, se tornando uma importante ferramenta de estudo (Boukamp, 1988). Essa linhagem de queratinócitos foi utilizada no presente trabalho e gentilmente cedida para esse estudo pela Profa. Dra. Katiuchia Uzzun Sales (Departamento de Biologia Celular e Molecular FMRP/USP). As células após o descongelamento foram expandidas e mantidas em meio de cultura DMEM (Dulbecco's Modified Eagle's, Thermo Fisher Scientific Waltham, MA, EUA) com alta concentração de glicose (4,5 g/L) e suplementado com soro bovino fetal $10 \%$, penicilina $(100 \mathrm{U} / \mathrm{mL})$, L-glutamina $(2 \mathrm{mM})$ e gentamicina $(0,2$ $\mathrm{mg} / \mathrm{mL}$ ), a $37^{\circ} \mathrm{C}$ e $5 \% \mathrm{CO}_{2}$. As células em questão foram utilizadas até um número máximo de 10 passagens. No dia anterior a transfecção as células foram mantidas no mesmo meio, excluindo-se a gentamicina, a qual se mostrou impactar na proliferação 
desta célula, assim sua exclusão conservou um maior número de células viáveis Antes dos experimentos as células foram testadas para micoplasma,

\subsection{Desenho e escolha do RNA-guia PARA O GENE PKM2}

A escolha da região gênica para ser alvo da endonuclease Cas9 foi direcionada ao éxon crítico para realizar o nocaute. Portanto, analisamos a sequência codificante do gene PKM, o responsável pela produção da PKM2 após o processo de splicing alternativo codificando o éxon 10 para a nossa enzima de interesse (Figura 4a). Em um banco de dados presente no site do NCBI (https://www.ncbi.nlm.nih.gov/gene/5315) obtivemos a sequência de todos os éxons envolvidos na transcrição do gene da PKM (Gene ID: 5315). As regiões de dissimilaridade entre as isoformas PKM1 e PKM2 foram encontradas com o auxílio do software SnapGene (GSL Biotech, Chicago, IL), dessa maneira nós obtivemos as regiões específicas para a PKM2. Em posse da sequência de interesse, utilizamos a ferramenta online para busca de RNAs guias para o alvo em questão (Optimized Crispr Desing: http://crispr.mit.edu) (Figura 4b). Esse software, denominado CRISPR design tool, é uma ferramenta online desenvolvida pelo grupo de pesquisa liderado pelo Prof. Feng Zhang do MIT (Massachusetts Institute of Technology). Ela ajuda pesquisadores a desenharem RNAs guia funcionais ao sistema CRISPR. Ao informar à ferramenta uma sequência de DNA (entre 23 e 500 pares de bases) e o genoma ao qual essa sequência pertence, com base em um algoritmo, a sequência informada é escaneada para encontrar possíveis RNAs guias (20 nucleotídeos seguidos por uma sequência PAM: NGG). Feito isso, a mesma ferramenta irá procurar por possíveis regiões de off targets (pareamentos não específicos) por todo o genoma do organismo escolhido, destacando a especificidade das sequências guias encontradas. A própria 
ferramenta fornece um ranking no qual o número de regiões off target bem como a especificidade de um RNA guia são consideradas. O resultado então é apresentado com cada guia encontrado em uma lista, as classificando com base no número de off targets encontrados, as apresentando em ordem a uma pontuação (score) de 0 a $100 \%$ indicando, aproximadamente, a confiabilidade da atividade com o alvo de cada guia (Feng Zhang, 2014). À sequência escolhida (score = 92), foram inseridos nucleotídeos adicionais as suas extremidades (5' e 3') (overhangs) para que houvesse complementaridade ao vetor na qual essa sequência foi posteriormente inserida (Figura 4c - Topo).

\subsection{Clonagem do oligo desenhado no Vetor e obtenção do PLASmídeo}

Em posse do oligo sintetizado, o mesmo foi clonado no vetor pX459 (plasmídeo \#62988, Addgene), o qual contém a sequência da enzima Cas9, do gene de resistência a puromicina para posterior seleção em células de mamíferos (ambos sob o controle do mesmo promotor - U6), além do gene de resistência a ampicilina para propagação em bactéria já clonados (Figura 4c - Direita). Brevemente, o vetor px459 foi digerido pela enzima Bbsl (New England Biolabs, MA, USA) durante 4 horas a $37^{\circ} \mathrm{C}$. Em seguida, as extremidades livres do vetor foram desfosforiladas, para evitar sua auto-ligação, utilizando a enzima fosfatase alcalina rSAP (Shrimp Alkaline Phosphatase - New England Biolabs) por 1 hora a 37ํㅡ (Figura 4c - Meio). Após esses processos, tanto a enzima de digestão quanto a fosfatase foram inativadas a $65^{\circ} \mathrm{C}$ por 20 minutos. O oligo sintetizado foi fosforilado em suas extremidades pela enzima T4 polinucleotídeo quinase (New England Biolabs) e em seguida ligado ao vetor pela enzima T4 DNA ligase (New England Biolabs) a temperatura ambiente por 4 horas (Figura 4c - Baixo). Bactérias E.coli DH5-a quimiocompetentes foram 
transformadas com o plasmídeo oriundo das reações citadas acima. As colônias obtidas pela seleção dessas bactérias em meio LB sólido (código L3522 - SigmaAldrich), contendo ampicilina (100 $\mathrm{g} / \mathrm{mL}$ - InvivoGen) foram coletadas e cresceram overnight em meio LB liquido contendo ampicilina. No dia seguinte os plasmídeos foram purificados pelo método de MiniPrep, seguindo as instruções do fabricante (Qiagen - Hilden, Germany).

a)

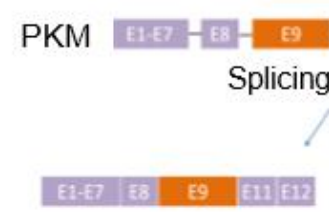

PKM1 b)

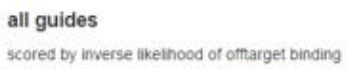

scored by inwerse likelinood of otharget binding

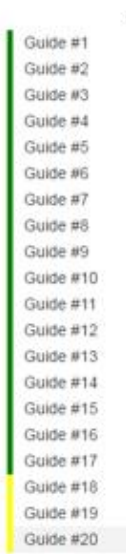

guide $\# 20$ quality seore: 28

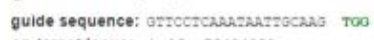
on-target locus: cha15:- 72494823 number of oftrarget sites: 265 (18 are in genes)

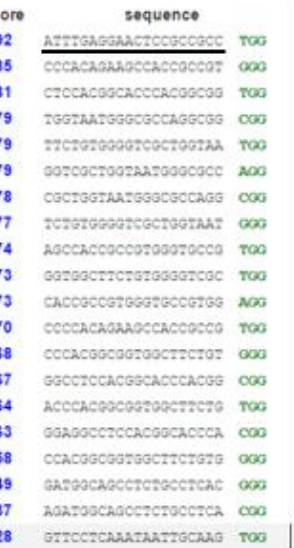

sequence

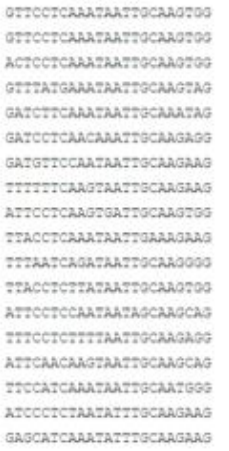

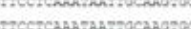

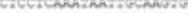
eascatcuntazzrocasanas

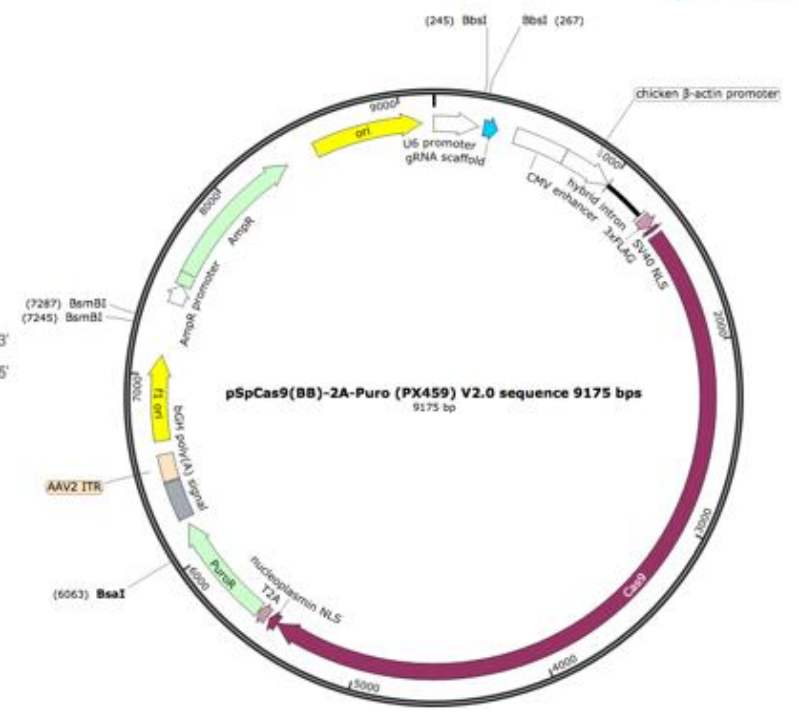

c)

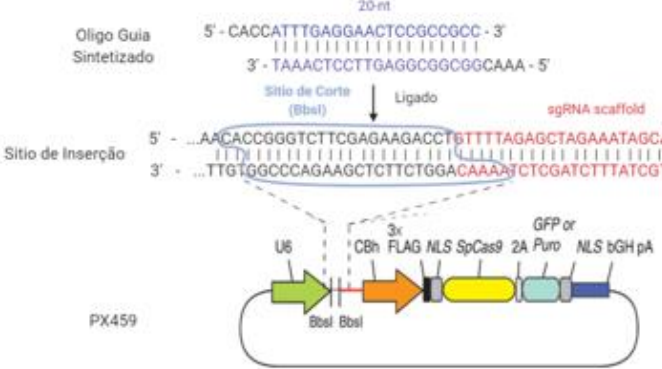

Figura 4 - Geração do plasmídeo CRISPR/PKM2. (a) Esquema representando o fenômeno de Splicing alternativo do gene da PKM, o qual utiliza do éxon 9 exclusivo para PKM1 e éxon 10 exclusivo para PKM2. (b) Escolha da sequência do RNA guia, 
baseado no éxon 10 do gene PKM, foi identificada utilizando ferramenta disponível no

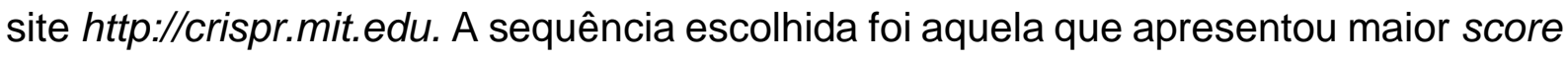
(menor quantidade de off targets $\mathrm{x}$ maior grau de especificidade). (c) Desenho do CRISPR/Cas9: Topo: Desenho do oligo selecionado possuindo over-hangs para a enzima Bbsl. Meio: Digestão do vetor pX459 pela ação da enzima Bbsl e inserção do oligo. Baixo: Vetor contendo a endonuclease Cas9 e o gene de resistência a puromicina. A direita o esquema do Vetor CRISPR pX459 (Addgene) ao qual foi inserido o RNA guia.

\subsection{Transfecção dos plasmídeos selecionados em células HaCat}

Queratinócitos da linhagem HaCat foram cultivados em meio DMEM high glucose $10 \%$ soro fetal bovino até atingirem $70-80 \%$ de confluência em seguida foram tripsinizadas e lavadas com PBS contendo $0,5 \%$ de BSA para a inativação da tripsina, em seguida ressuspendidas $\left(1-5 \times 10^{6}\right.$ células) em $100 \mu l$ do tampão Cell line Nucleofector Solution $V$. A essa solução foi adicionado $5 \mu \mathrm{gg}$ do plasmídeo CRISPR/PKM2 + plasmídeo repórter pMaxGFP. Essa solução foi transferida para cubetas e a eletroporação foi realizada utilizando o protocolo U-020 (Nucleofector I

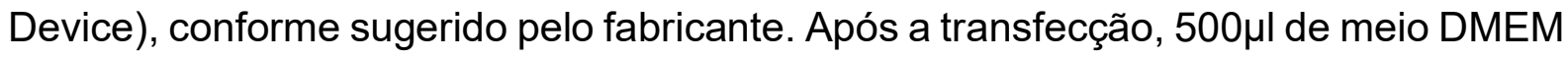
high glucose $10 \%$ soro fetal bovino foram imediatamente adicionados e as células foram plaqueadas. A eficiência da transfecção foi avaliada por microscopia de fluorescência, 48 horas após a transfecção, através da expressão de GFP contida no vetor controle.

\subsection{Seleção das cÉluLAS tRANSFECtAdAS COM PLASMídeO CRISPR/PKM2}


O vetor pX495 utilizado para a clonagem apresenta gene de resistência para puromicina sob o controle de um promotor de expressão em eucariotos, assim células HaCat que foram transfectadas com o plasmídeo CRISPR/PKM2 foram selecionadas em meio DMEM na presença desse antibiótico. A concentração ótima de puromicina para células HaCat foi determinada através da realização de uma curva de morte, onde $1 \times 10^{5}$ células não transfectadas foram incubadas com uma concentração crescente (de 0,5 a $5 \mu \mathrm{g} / \mathrm{ml}$ ) de puromicina (código A1113803 - Thermo Fisher) em uma placa de 24 poços, assim, determinando a concentração mínima de antibiótico necessária para matar todas as células não transfectadas por um período de 3-7 dias. Após 3 a viabilidade dessas células foi avaliada pela utilização Resazurina (código R7017 - Sigma-Aldrich) adicionada em cada poço. Após um período de incubação de 4 horas foi realizada a leitura da absorbância $590 \mathrm{~nm}$ em um leitor de microplacas (FlexStation® 3 - Molecular Devices).

\subsection{Western Blot}

As amostras provenientes de cultura celular foram lisadas com tampão RIPA (25 mM Tris-HCL pH 7,6, 150mM NaCl, 1\% NP-40, 1\% deoxicolato de sódio, 0,1\% SDS) adicionado de coquetel de inibidores de proteases (código 5872- Cell Signaling). Uma alíquota do extrato foi separada para dosagem proteica pelo kit BCA (SigmaAldrich, St. Louis, MO, USA) e após o cálculo da concentração proteica, quantidades equitativas das amostras foram aplicadas em gel de poliacrilamida (12\%) na presença de SDS e posteriormente transferidas para membrana de nitrocelulose (GE Healthcare, Little Chalfont, UK). As membranas foram bloqueadas com leite desidratado 3\% (Nestlé) por 1h a temperatura ambiente e posteriormente incubadas 
com anticorpos monoclonais anti-PKM2 (código3198s - Cell Signaling), anti-PKM1 (código 7067S - Cell Signaling), anti- Cytokeratin 14 (código ab7800 - Abcam), anticytokeratin (código C5992 - Sigma), GAPDH (código 5174P - Cell Signaling), anti-NFkB p65 (código sc-372 - Santa Cruz Biotechnology), anti-Act1 (código sc-398161 Santa Cruz Biotechnology), anti-traf6 ( código AF3284 - R\&D systems) durante toda a noite, nas concentrações sugeridas pelos fabricantes. Em seguida, as membranas foram lavadas com TBS-Tween e incubadas com os anticorpos secundários conjugados a peroxidase, adequados ao anticorpo primário nas concentrações sugeridas pelo fabricante. As membranas foram reveladas com kit de quimioluminescência (ECL, GE lifescience) como descrito no manual de instruções. As imagens foram obtidas no equipamento ChemiDoc ${ }^{\mathrm{TM}} \mathrm{XRS}+$ Transilluminator (BioRadLaboratories, Hercules, CA, USA) e analisadas com o auxílio do software ImageLab (Bio-Rad) e posteriormente fotodocumentadas.

\subsection{ANÁLISE DA SEQUência do DNA genômico por sequenciamento de nova geração}

O DNA genômico foi isolado de clones de células transfectadas e não transfectadas. O éxon 10 do gene PKM responsável por codificar a PKM2 foi amplificado por PCR, utilizando primers específicos para essa sequência. O produto da PCR desses clones foi analisado por sequenciamento de última geração (MiSeq Illumina - San Diego, CA, USA). Os resultados obtidos através do sequenciamento foram analisados com o auxílio do programa SnapGene. 


\subsection{Ensaio de Quimiotaxia de NeUtrófilos}

Neutrófilos humanos foram isolados a partir de sangue periférico de indivíduos saudáveis, esses foram coletados em tubo contendo anticoagulante EDTA e pipetadas cuidadosamente em uma curva de Percoll (GE Healtcare) de concentrações $72 \%, 63 \%, 54 \%$ e $45 \%$. Posteriormente, as amostras foram centrifugadas por 30 minutos, a $650 \mathrm{~g}$ em temperatura ambiente. Em seguida, as células polimorfonucleares foram isoladas e lavadas em meio Hanks, e ressuspendida em meio RPMI-1640 suplementado com $0.1 \%$ de BSA e contadas em câmara de Neubauer.O ensaio de quimiotaxia foi realizado numa câmera de 48 poços (Neuro Probe) contendo uma membrana com poros de policarbonato de $5 \mu \mathrm{m}$ separando em duas fases a câmara. Na parte inferior foi adicionado o meio condicionado (CM) de células HaCat Ctrl ou $\triangle \mathrm{PKM} 2$ estimuladas ou não com IL-17A, após um período de $24 \mathrm{~h}$ de cultura. Na parte superior foi adicionado os neutrófilos isolados $\left(5.10^{4}\right)$ e encubados a $37^{\circ} \mathrm{C}, 5 \% \mathrm{CO}_{2}$, por 1 hora permitindo sua migração. O número de neutrófilos foi determinado por contagem de 5 poços escolhidos de maneira aleatória usando microscopia ótica. Os resultados expressos são em número de neutrófilos por campo.

\subsection{IMUNOPRECIPITAÇÃO}

Para imunoprecipitação, células Hacat foram centrifugadas a $4^{\circ} \mathrm{C}$ (200 rpm por 5 minutos) e o pellet obtido foi lisado em uma solução de imunoprecipitação $(0,5 \%$ Triton X-100, 20mM HEPES (pH 7.4), 150nM NaCl, 12.5 mM b-glycerofosfato, $1.5 \mathrm{mM}$ MgCl2, 10 mM NaF, 1 mM Ortavanato de Sódio e inibidor de protease (Roche). Em seguida esse lisado de células foi homogeneizado com anti-Act1, para formar o 
complexo com a proteína de interesse por 3 horas a $4^{\circ} \mathrm{C}$. Logo após foram seguidas as instruções do kit Pierce ${ }^{\mathrm{TM}}$ Classic Magnetic IP/Co-IP da TermoFisher scientific.

\subsection{IMUNOFLUORESCÊNCIA}

Queratinócitos da linhagem HaCat $\left(1 \times 10^{5}\right.$ células $)$ foram plaqueados em lamínulas para aderência por duas horas em estufa a $37^{\circ}$ com $5 \%$ de $\mathrm{CO} 2$. Em seguida foram realizadas lavagens com PBS para retirada de células não aderidas. Após essa etapa, os queratinócitos foram incubados com anticorpo monoclonal coelho anti-PKM2 humano (código ab116271 - AbCam, Cambridge, MA, USA), anticorpo policlonal coelho anti-NF-kB p65 (código sc-372 - Santa Cruz Biotechnology), anticorpo camundongo anti-Act1 (código sc-398161 - Santa Cruz Biotechnology), anticorpo cabra anti-traf6 ( código AF3284 - R\&D systems), por 1 hora à temperatura ambiente. Decorrido o período de incubação as células foram lavadas cinco vezes com PBS e então incubadas com anticorpo secundário anti-coelho, anti-camundongo, anti-cabra conjugado a Alexa594 (Life Technologies - Carlsbad, CA, EUA) por 1 hora +a temperatura ambiente. Após a incubação as células foram lavadas 10 vezes de 5 minutos cada uma e rapidamente em água purificada em Mili-Q e montadas com Prolong Gold que contém o marcador nuclear DAPI (ProLong Gold Antifade Mountant com DAPI - Thermo Fisher Scientific). O material foi analisado em microscópio de fluorescência DMI 6000B (Leica Microsystems- Wetzlar, Germany). As imagens foram adquiridas utilizando os microscópios de fluorescência Leica365 FX (Leica Microsystems), confocal Nikon Eclipse Ti2 (Nikon) confocal Axio Observer combined with LSM 800 (Carl Zeiss Microscopy). 


\subsection{ANÁLISE DO PERFIL DE CITOCINAS POR ELISA}

Células HaCat foram incubadas na presença de IL-17A (100 ng/mL), por 24 horas em estufa a $37 \stackrel{\circ}{\circ} 5 \%$ de $\mathrm{CO}_{2}$. Decorrido o período de incubação 0 sobrenadante dessas células foi coletado e armazenado a $-70 \stackrel{\circ}{\mathrm{C}}$ até o momento do uso. Em uma placa de 96 poços foi adicionado anticorpo anti-IL-8 e anti-TNF-a (código 210-TA - R\&D systems). A placa foi mantida durante uma noite a $4^{\circ} \mathrm{C}$. Em seguida, a placa foi lavada uma vez com solução tamponada com fosfato $0,6 \mathrm{M}, \mathrm{pH} 7,2$, contendo 0,05\% de Tween 20 (PBS-T) e, incubada por 2 horas (temperatura ambiente), com uma solução de bloqueio constituída de PBS acrescido de BSA 5\% (PBS-BSA 5\%). Aos poços, foi adicionado, em duplicata, a citocina de interesse recombinante para obtenção de curva padrão, de acordo com as instruções do fabricante, ou as amostras do sobrenadante de cultura de HaCat seguindo-se incubação à 4 graus por toda a noite. A placa foi lavada 5 vezes com PBS-T 0,05\% e o anticorpo de detecção foi adicionado; a placa foi incubada à temperatura ambiente por 1 hora. $\mathrm{O}$ anticorpo de detecção consiste do anticorpo biotinilado específico para a citocina testada, adicionado de avidina conjugada à peroxidase, previamente incubados por 15 minutos. Após nova etapa de lavagens foi adicionada a solução reveladora constituída de tetrametilbenzidina (TMB). A reação foi bloqueada após 20 minutos com ácido sulfúrico $2 \mathrm{~N}$ e a leitura realizada a $450 \mathrm{~nm}$ em leitor de microplacas (FlexStation® 3 Molecular Devices).

\subsection{ANÁLISE dA EXPRESSÃo gênica}

A extração do RNA foi realizada utilizando o kit RNeasy Mini Kit 250 (Qiagen) de acordo com as instruções do fabricante. Em seguida, uma alíquota de $1 \mu$ foi 
utilizada para determinação da concentração de RNA total, através de leitura em NanoDrop (Thermo Fisher Scientific) e 500 ng do RNA extraído foi utilizado para a conversão em cDNA utilizando o kit High Capacity (Life Technologies). O cDNA foi utilizado para a quantificação da expressão dos genes de interesse para humanos (K14, S100a8, S100a9, PKM2 e PKM1, tabela 1), e do gene de expressão constitutiva (GAPDH) por PCR em tempo real utilizando Sybr ${ }^{\circledR}$ Green Master Mix (Thermo Fisher Scientific) como repórter da amplificação. A reação quantitativa em tempo real foi realizada no aparelho StepOne Real-Time PCR System (Applied Biosystems). Os resultados foram analisados através do método de $2^{-\Delta \Delta} \mathrm{ct}$.

Tabela 1: Sequência de primers utilizados

\begin{tabular}{|c|c|c|}
\hline Gene & Sense (5'-3') & Anti-sense (5'-3' \\
\hline GAPDH & AGGGCTGCTTTTAACTCTGGT & CCCCACTTGATTTTGGAGGGA \\
\hline KRT14 & GGCCTGCTGAGATCAAAGACTAC & CACTGTGGCTGTGAGAATCTTGTT \\
\hline S100a8 & AGACCGAGUGUCCUCAGUA & UACUGAGGACACUCGGUCU \\
\hline S100a9 & GCAGCUGGAACGCAACAUA & UAUGUUGCGUUCCAGCUGC \\
\hline PKM2 & ATCGTCCTCACCAAGTCTGG & GAAGATGCCACGGTACAGGT \\
\hline PKM1 & TCACTCCACAGACCTCATGG & GAAGATGCCACGGTACAGGT \\
\hline
\end{tabular}

\subsection{Ensaio de Proliferação celular}


Queratinócitos da linhagem HaCat Ctrl ou $\triangle \mathrm{PKM} 2$ foram cultivados conforme descrito no item 4.1. Essas células foram marcadas com CellTraceViolet (Invitrogen Cat. C34557, 1:2000). Após o preparo, estas foram plaqueadas em placas a uma confluência de $1 \times 10^{5}$ células. Após 2 dias de cultura foi avaliada a proliferação dessas células de acordo com decaimento do CellViolet por citometria de fluxo.

\subsection{Citometria DE FLUXO}

Para caracterização e análise da expressão do receptor para IL-17A (IL17RA) em células HaCat Ctrl e $\triangle \mathrm{PKM} 2$, estas foram ressuspendidas em $100 \mu \mathrm{L}$ de PBS com albumina bovina sérica (BSA) a 1\% e incubadas com Fc block (para bloquear ligações inespecíficas) por 30 minutos a $4^{\circ} \mathrm{C}$. Em seguida, as células foram marcadas com anticorpo monoclonal específico ao receptor conjugados a fluorocromo (1:200) (CD217 (IL-17Ra) Monoclonal Antibody (J10MBS), PE, eBioscience ${ }^{\mathrm{TM}}$ ). As células foram quantificadas através do equipamento FACS Verse e Canto II (BD Bioscience).

\subsection{Produção Lentiviral}

Para a produção lentiviral células Hek 293T phoenix foram transfectadas pelo método Lipofectamine ${ }^{\mathrm{TM}} 3000$, seguindo as recomendações do fabricante. Para nosso objetivo foi utilizado o plasmídeo de expressão pHAGE NFkB-TA-LUC-UBC-GFP-W (addgene \#49343), o qual continha o gene que expressa a proteína luminescente Luciferase, controlado pelo sitio promotor do fator transcricional NFkB, assim como a sequência codificante para o gene GFP controlado pelo promotor constituvo UBC permitindo a separação das células transfectadas. A sequência desses genes é 
flanqueada pelos sítios 5'LTR e 3'LTR, os quais permitem a inserção da sequência no genoma de células de eucarióticas. O plasmídeo também contém uma sequência Psi, responsável pela sinalização da sequência de empacotamento. Foi juntamente transfectadas um plasmídeo empacotador psPAX2 (addgene \# \#12260), o qual garante a expressão das proteínas Gag, Pol, Tat e Ver, e o plasmídeo de envelope pMD2.G (addgene \#12259), responsável pela produção da glicoproteína G do VEV.

Uma vez produzido os vírus, seguindo as instruções do método Lipofectamine $^{\text {TM }} 3000$, foi despejado o sobrenadante das células Hek 293T phoenix produtoras de lentivirus sobre a cultura de células HaCat Ctrl ou $\triangle \mathrm{PKM} 2$. As células HaCat positivamente transfectadas foram separadas por sorting de células GFP positivas.

\subsection{ENSAIO DE NF-KB-LUCIFERASE}

Uma vez obtida as células HaCat Ctrl NF-kB-Luc e HaCat $\triangle$ PKM2 NF-kB-Luc, descritas acima, foi realizado um ensaio "repórter" de Luciferase. Essas células geradas foram incubadas na presença de IL-17 (100 ng/mL), IL-22 (100 ng/mL), Zymozan (10 $\mathrm{\mu g} / \mathrm{mL}$ ), LPS (100 ng/mL) ou IMQ (código401020 - Calbiochem) (5 $\mu \mathrm{g} / \mathrm{mL}$ ) por 24 horas, em seguidas lavadas 3 vezes com PBS e lisadas com luciferase lysis buffer (Promega). A atividade de Luciferase foi medida utilizando o kit luciferase assay system (Promega) seguindo as instruções do fabricante.

\subsection{Dosagem de Lactato e Consumo de Glicose}

Os ensaios de consumo de glicose e produção de lactato foram realizados a partir do sobrenadante da cultura celular de células HaCat, e determinados pelo uso 
dos kits de ensaio enzimáticos de dosagem de Lactato (Bioclin - K084-5.3) e consumo de Glicose Monoreagente (Bioclin - K082-3) seguindo as recomendações do fabricante (Bioclin).

\subsection{ANÁlise estatística}

A análise estatística foi realizada por ANOVA, através do Teste de Comparação Múltipla de Bonferroni e Teste $t$ não paramétrico com nível de significância estabelecido em $5 \%$ ( $p$-value<0,05). A análise estatística e os gráficos foram construídos utilizando o programa computacional GraphPad prism (GraphPad Software, San Diego, CA, EUA).

\section{Resultados}

\subsection{IL-17A INDUZ A EXPRESSÃO DE PKM2 EM QUERATINÓCITOS IN VITRO.}

Uma vez descrita a alta expressão de PKM2 na pele lesionada de pacientes psoriásicos, e que sua ausência em queratinócitos resulta menor doença em modelo experimental, torna-se valido observar a participação dessa enzima durante a ativação frente ao est00EDmulo de IL-17A. Com esse intuito, incubamos uma linhagem de queratinócitos humanos imortalizado (HaCat), na presença ou não dessa citocina, e após um período de 24 horas foram coletadas amostras de mRNA para PCR em tempo real, amostras de proteína para imunoblot e feita a análise da expressão de PKM2 por imunofluorescência (Figura 5a). Pudemos observar que frente ao estímulo de IL17A, houve um aumento na expressão do mRNA de PKM2, assim como no marcador de ativação e proliferação de queratinócito citoqueratina 14 (K14), porém não ouve alteração na expressão da isoforma PKM1 (Figura 5b). De 
maneira similar, pode-se observar um aumento na expressão da proteína total de PKM2 por Imunoblot, e corroborando os dados anteriores a expressão da proteína PKM1 se manteve inalterada, a proteína GAPDH foi usada como um controle de quantidade de proteína utilizada nesse experimento (Figura 5c). Por fim, a marcação de PKM2 por imunofluorescência nos mostra uma expressão basal da enzima, que após o estimulo de IL-17A, é aumentando de maneira similar ao observado na pele de pacientes e camundongos psoriásicos (Figura 5d). 
a)

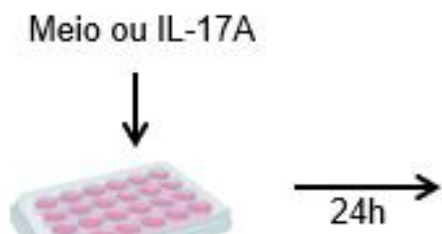

Células HaCat

b)

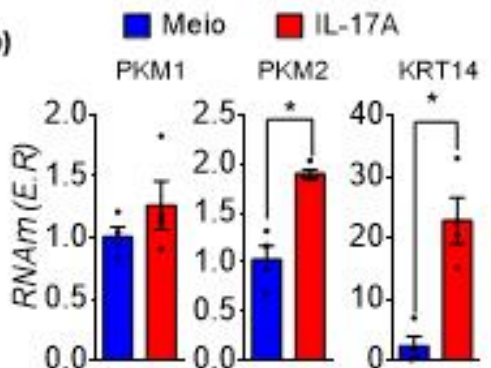

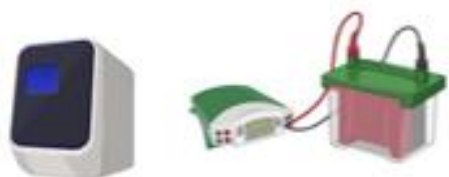

Imunoblot

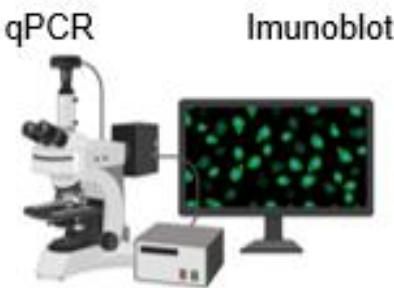

Imunofluorescência

c)

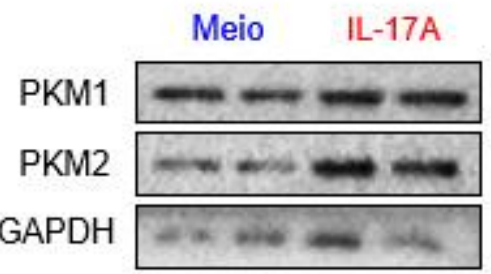

d)

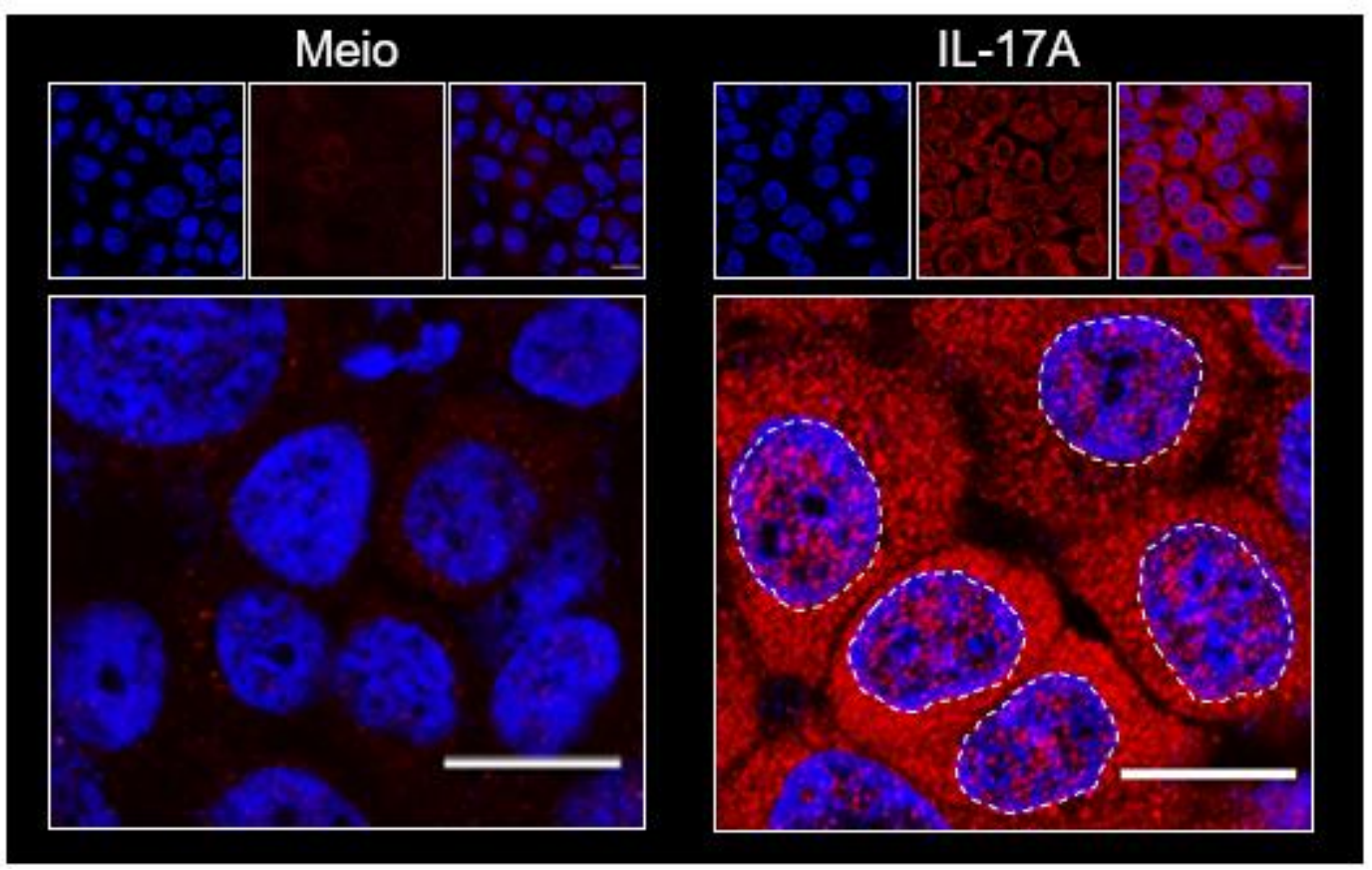

Figura 5 - IL-17A induz a expressão de PKM2 em queratinócitos in vitro. (a) Esquema do protocolo experimental realizado na linhagem de queratinócitos humanos (HaCat) ativadas por IL-17A (100 ng/ml). (b) Expressão relativa de RNAm de PKM1, PKM2 e KRT14 após estimulo com IL-17A. Os gráficos representam a média \pm SEM $(\mathrm{n}=4)$ de três experimentos independentes. (c) Análise da expressão proteica de PKM2, PKM1 por Imunoblot após estimulo com IL17A. GAPDH foi usado como um controle de quantidade de proteína. (d) Imunofluorescência das células HaCat, marcadas por PKM2 (vermelho) e DAPI (Azul). Barra de escala $20 \mu \mathrm{m}$. 


\subsection{Geração de Queratinócitos nocautes PARA A ENZIMA PKM2 PELO MÉTODO CRISPR/CAS9}

Para aprofundar nossos estudos sobre o mecanismo pelo qual a PKM2 participa na ativação de queratinócitos utilizamos da ferramenta CRISPR/Cas9 na geração de uma linhagem nocaute a essa enzima. A utilização de ferramentas para realizar modificações de maneira específica nos genes é considerada fundamental no estudo funcional de um determinado gene em contextos fisiológicos e patológicos ( $\mathrm{Ma}$ $Y, 2014)$. Nesse sentido, o recente sistema CRISPR/Cas9 tem se demonstrado vantajoso para a realização dessas modificações precisas em células eucarióticas, sendo um sistema de fácil customização e de alta eficiência (Ran FA. 2013). De maneira resumida, o sistema CRISPR/Cas9 edita o genoma de células eucarióticas a partir de RNAs guia complementares ao gene-alvo contido no DNA genômico, a sequência alvo deve estar up-stream a pequenas sequências especificas (de 2 a 6 pares de bases) conhecidas como sequências PAM (Protospacer Adjacent Motif) presentes no gene, assim permitindo o reconhecimento dá endonuclease Cas9. Após esse reconhecimento ocorre a clivagem na dupla fita de DNA, ativando o sistema de reparo presente na própria célula podendo ocorrer erros como a inserção e/ou deleção de nucleotídeos, deslocando o quadro de leitura do genoma (frameshift mutation) e consequentemente no nocaute do gene especifico. (Ran FA, 2013; Jinek et al., 2012; Cong et al., 2013). O desenho e obtenção do plasmídeo CRISPR/PKM2 está descrito na sessão de materiais e métodos dessa dissertação (Tópico 4.2).

Uma vez obtido o plasmídeo CRISPR/PKM2, foi necessário realizar as padronizações de quantidade de antibiótico efetivo para posterior seleção das células positivamente transfectadas, assim como padronizações do método de transfecção, 
uma vez que esses processos não estavam bem estabelecidos em nosso laboratório. Para isso foram cultivadas células HaCat em placas de 24 poços na presença de concentrações crescentes do antibiótico Puromicina, a qual o plasmídeo CRISPR garantia resistência, variando de $0,5-5 \mu \mathrm{g} / \mathrm{ml}$ por um período de 3 dias. No último dia, foi adicionado a cultura Resazurina (Sigma-Aldrich), como maneira de inferir viabilidade celular (Anoopkumar-Dukie S, et al. 2005). Concomitantemente, foram feitas imagens por microscopia ótica para análise qualitativa da viabilidade dessas células. Foi observado que 3 dias de cultura a uma concentração de $2 \mu \mathrm{g} / \mathrm{ml}$ de puromicina eram necessários para eliminar qualquer células que não recebesse o gene de resistência ao antibiótico (Figura 6a). Para transfectar as células HaCat encontramos como método mais eficiente a nucleoporação utilizando o sistema AMAXA nucleofector (Lonza- Basel, Switzerland). Por esse método, utilizamos três

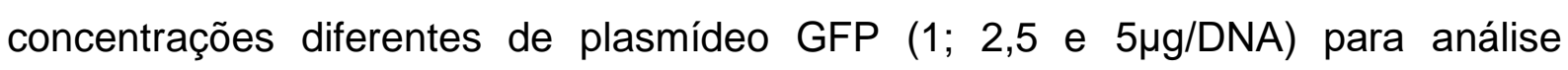
observacional de efetividade na transfecção por microscopia de fluorescência. Essa análise foi realizada com auxílio do software ImageJ. Das concentrações testadas, a qual mostrou melhores resultados foi a concentração de $5 \mu \mathrm{g} / \mathrm{DNA}$ (Figura 6b)

Após feitas as padronizações as células HaCat foram devidamente transfectadas com o plasmídeo CRISPR/PKM2 e selecionadas na presença de puromicina. Foi coletada a amostra proteica dessas células, assim como de células HaCat não transfectadas como controle (Ctrl), e feito o ensaio de Imunoblot. Observamos a ausência da enzima PKM2 nas células transfectadas quando comparadas as células controle, porém todas mantiveram a expressão de sua isoforma PKM1, inferindo na especificidade na deleção do gene PKM2 (Figura 7a). Por sequenciamento de nova geração observamos o tipo de mutação que ocorreu frente a transfeção com o plasmídeo CRISPR/PKM2. Nela encontramos a inserção de 
uma Citosina ao éxon codificador à proteína PKM2, mutação conhecida como InDel (Insertion/Deletion) , que acarretou no deslocamento no quadro de leitura da proteína e consequentemente na tradução de uma proteína não funcional, frequentemente produto do aparecimento de um stop códon prematuro, a qual é rapidamente degradada (Figura 7b). 
a)

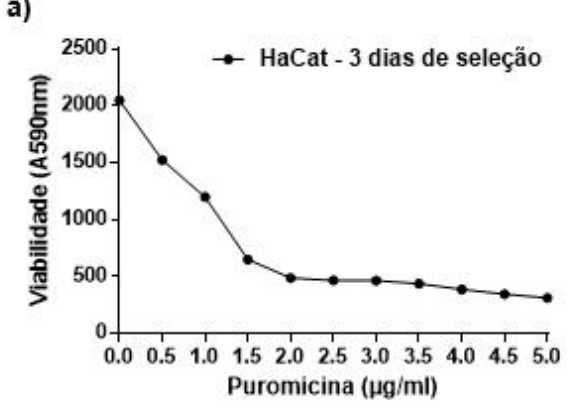

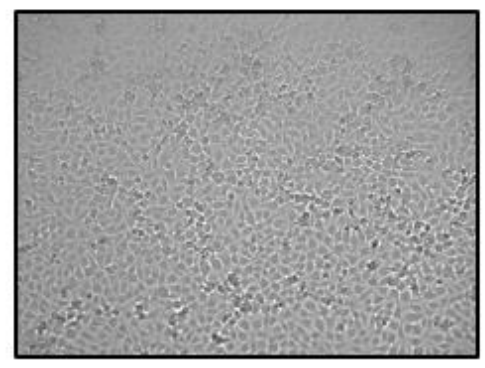

Ctrl

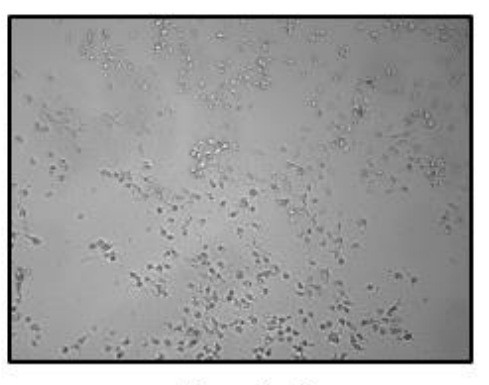

$2 \mu \mathrm{g} / \mathrm{ml}$

b)

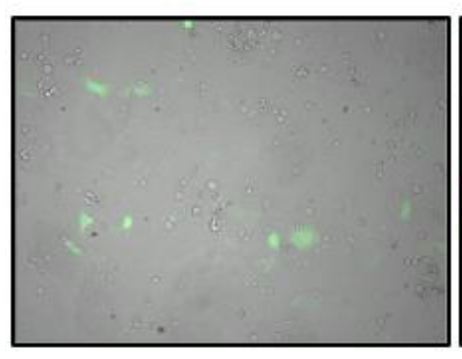

$1 \mu \mathrm{g} / \mathrm{DNA}$

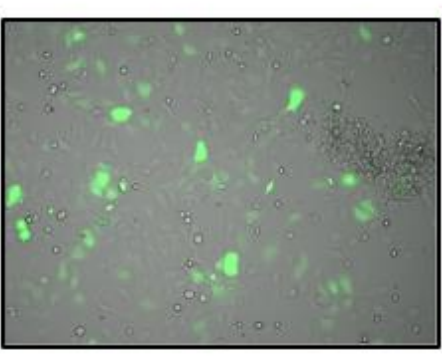

$2,5 \mu \mathrm{g} / \mathrm{DNA}$

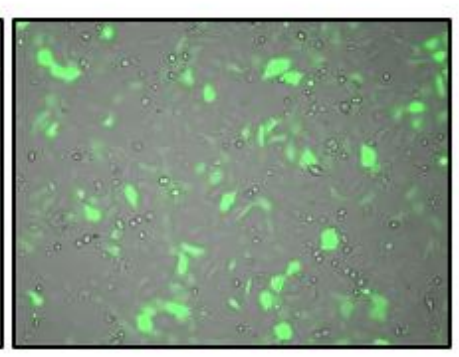

$5 \mu \mathrm{g} / \mathrm{DNA}$

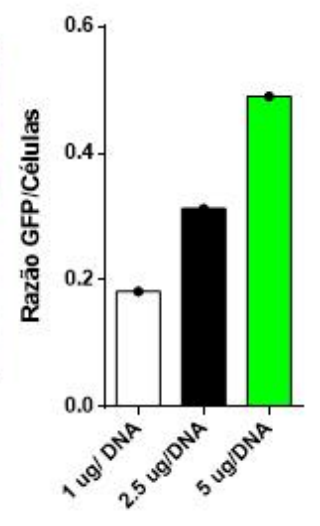

Figura 6 - Padronização da seleção de células transfectadas com o plasmídeo CRISPR/PKM2. (a) Curva de morte de células Hacat $\left(1 \times 10^{5}\right)$ incubadas na presença de concentrações crescentes de puromicina durante 3 dias. Seguido de leitura de absorbância (590nm), da reação dessas células com Resazurina (Sigma-Aldrich), inferindo a viabilidade dessas células. Feita também imagens de microscopia de luz das células não tratadas (Controle) e na presença de $2 \mu \mathrm{g} / \mathrm{ml}$ de puromicina. (b) Sobreposição de Imagens de microscopia de fluorescência (GFP) e de luz de cultura de células HaCat 48 horas após a transfecção do plasmídeo CRISPR/PKM2 e plasmídeo GFP. Escala: 50um. Imagens são representativas de 3 experimentos independentes. Quantificação relativa de células fluorescentes verdes pelas células presentes no campo, feito pelo software ImageJ. 
a)

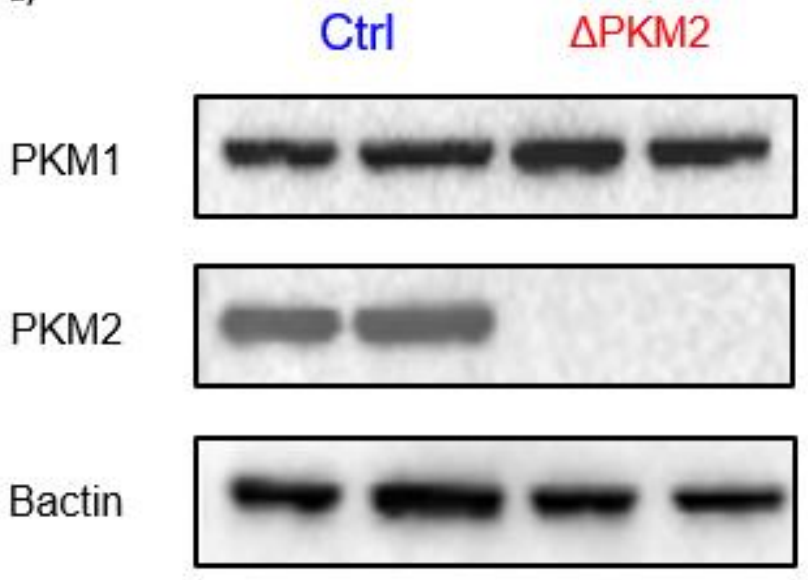

b)
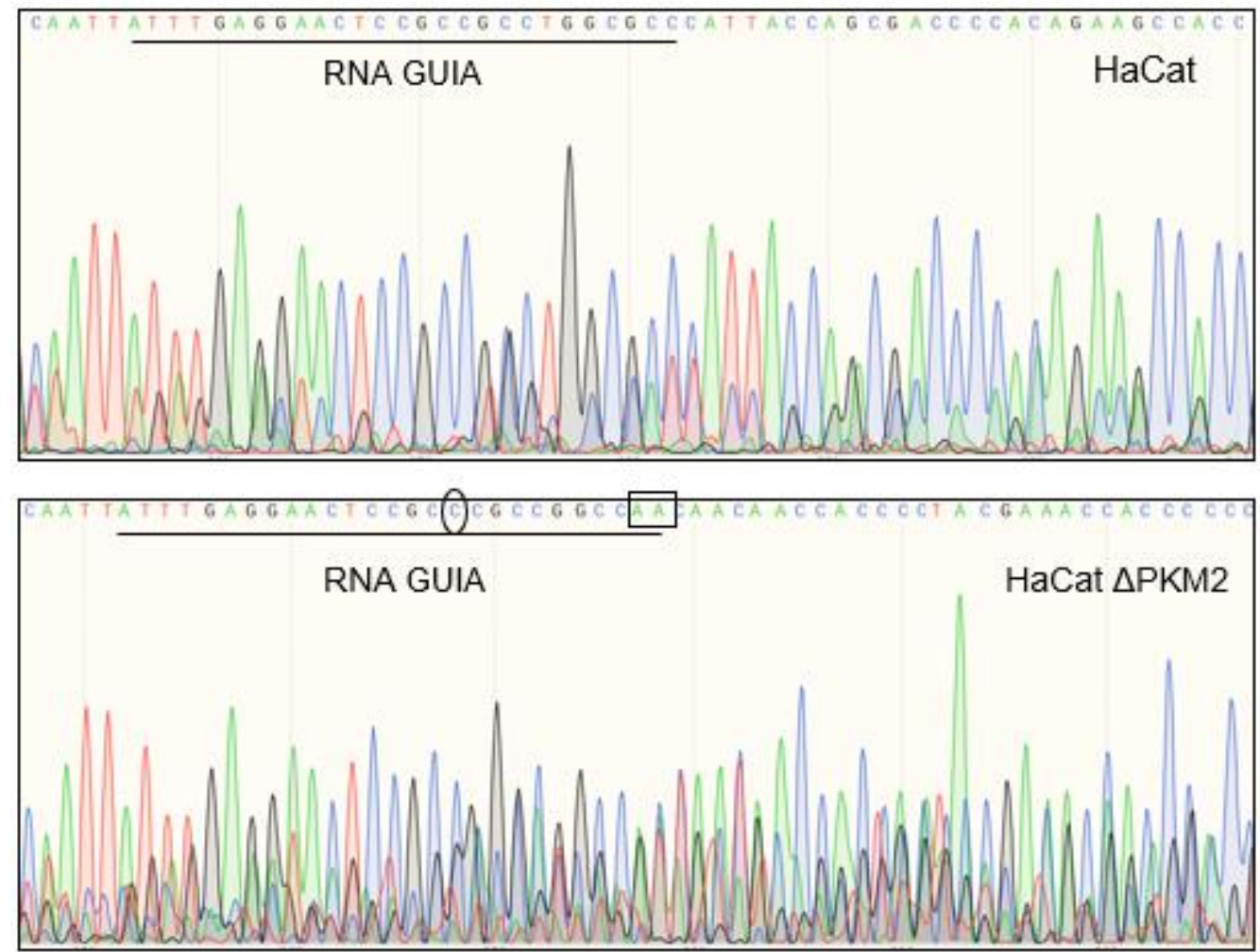

Figura 7 - Geração de linhagem Hacat noucate para PKM2. (a) Análise da expressão proteica de PKM2 e PKM1 em células Hacat (Ctrl) ou células Hacats após transfecção e seleção ( $\triangle \mathrm{PKM} 2)$. GAPDH foi usado como um controle de quantidade de proteína. (B) Eletroferograma representativo do sequenciamento do éxon 10 do gene PKM, variando entre os nucleotídeos circulados. Mutação resultante de inserção de um nucleotídeo $\mathrm{C}$, causando uma alteração no quadro de leitura, evidente nas posições dos nucleotídeos representados no quadrado preto. 


\subsection{PKM2 PARTICIPA NO PROCESSO DE ATIVAÇÃO DE QUERATINÓCITOS POR IL-} 17A

Para observar o impacto da PKM2 sobre o processo de ativação de queratinócitos, utilizamos as células HaCat nocaute para PKM2 ( $\triangle \mathrm{PKM} 2)$ geradas e as incubamos na presença de IL-17A por $24 \mathrm{~h}$, em seguida coletamos amostras de mRNA para qPCR, assim como proteína para Imunoblot, e avaliamos a produção de quimiocinas por essas células. Observamos que, mesmos frente ao estímulo de IL17A, os queratinócitos deficientes para PKM2 não expressavam genes relacionados à ativação de queratinócitos, isso ficou claro quando comparados os níveis de mRNA dos genes da família S100 (S100a8 e S100a9) e de KRT14, quando comparados a expressão de um queratinócito competente (Figura 8a). De maneira surpreendente não foram detectados níveis proteicos de K14 nos queratinócitos deficientes a PKM2, porém a expressão de outras citoqueratinas como $5 / 6$, que estão relacionadas a estrutura celular se mantiveram inalteradas (Figura 8b). Concordando com os dados anteriores, os queratinócitos $\triangle \mathrm{PKM} 2$ não produziram níveis detectáveis de TNF$\alpha$ assim como de CXCL-1/IL-8, enquanto queratinócitos controle mantinham a produção dessas citocinas aumentada frente ao estimulo de II-17A (Figura 8c). 

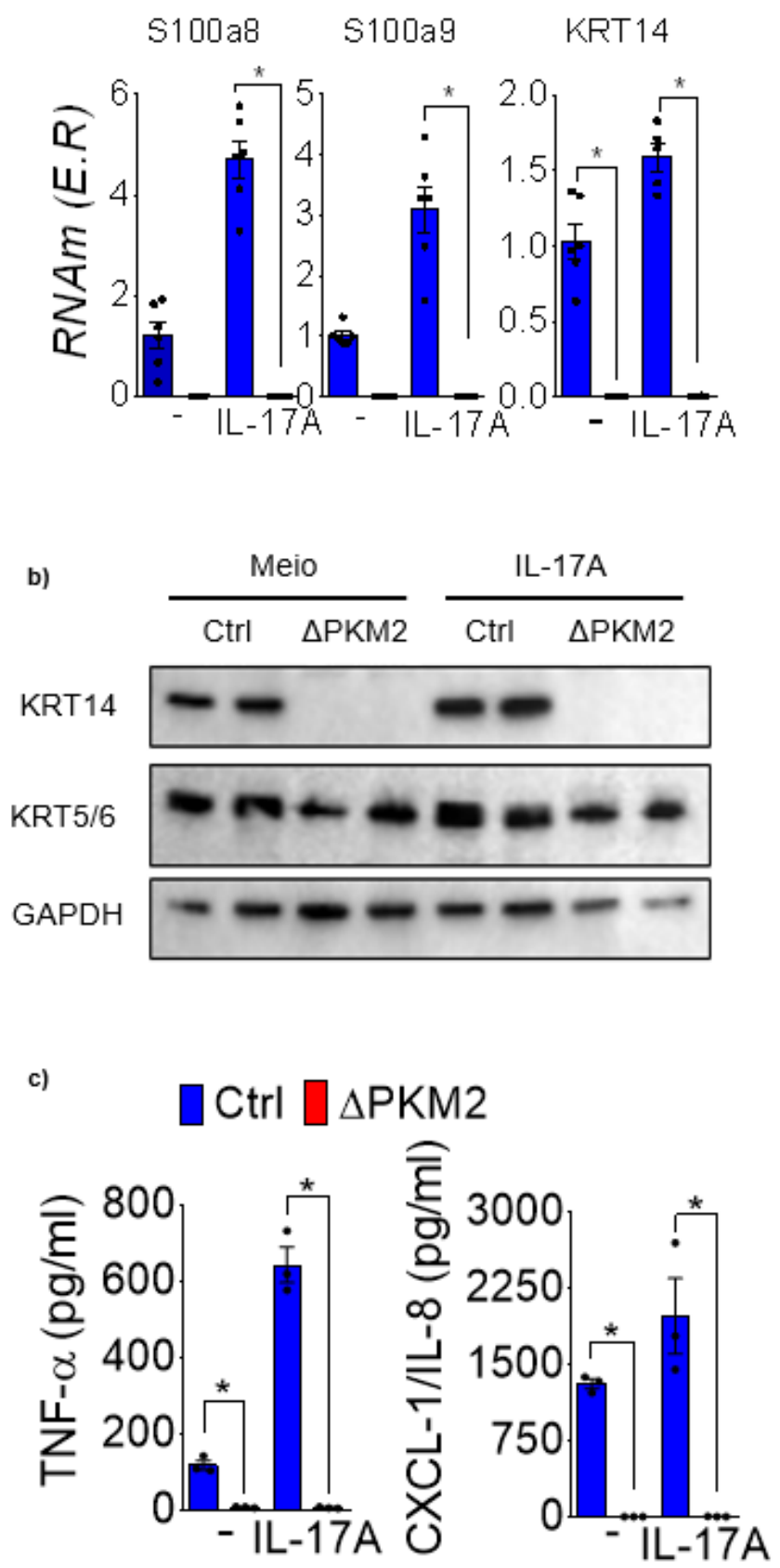

Figura 8 - PKM2 é necessária na ativação de queratinócitos por IL-17A. (a) Expressão relativa de RNAm de S100A8, S100A9 e KRT14 em células HaCats Ctrl ou $\triangle$ PKM2 após estimulo com IL-17A. Os gráficos representam a média \pm SEM $(n=6)$ de três experimentos independentes. ${ }^{*} P<0.05$. (b) Análise da expressão proteica de KRT14 e KRT5/6 em células HaCat Ctrl ou $\triangle$ PKM2 por Imunoblot após estimulo com IL-17A. GAPDH foi usado como um controle de quantidade de proteína. (c) Dosagem de TNFa e CXCL1/IL-8 no sobrenadante da cultura de HaCat Ctrl ou $\triangle P K M 2$, quando ativadas por IL-17A. Os gráficos representam a média $\pm \operatorname{SEM}(n=3)$ de três experimentos independentes. ${ }^{*} P<0.05$. 


\subsection{QUIMIOTAXIA INDUZIDA POR QUERATINÓCITOS É DEPENDENTE DE PKM2}

Uma vez que na ausência de PKM2 os queratinócitos não respondiam ao estimulo de IL-17A, nos perguntamos se isso teria algum impacto funcional durante $o$ processo inflamatório, portanto realizamos um ensaio de quimiotaxia de neutrófilos in vitro. Para tal cultivamos células HaCat Ctrl e $\triangle \mathrm{PKM} 2$ durante 24 horas na presença de IL-17A, o meio condicionada dessas culturas foram coletado e adicionados em uma câmara de uma placa de transwell. Concomitantemente, neutrófilos humanos foram isolados de sangue periférico de indivíduos saudáveis, e utilizando a mesma placa de de transwell, nos quais os neutrófilos coletados foram adicionados na câmara oposta à do meio condicionado (Figura 9a). Após uma hora foi contado o número de neutrófilos que migraram para a câmara contendo o meio condicional dos queratinócitos, vimos que frente ao estimulo de IL-17A queratinócitos Ctrl foram capazes de promover a quimiotaxia desses neutrófilos, porém as células $\triangle \mathrm{PKM} 2$ não foram capazes de induzir essa quimiotaxia (Figura 9b). Sugerindo uma participação dessa enzima na capacidade funcional de queratinócitos para promover quimiotaxia de neutrófilos. 
a)

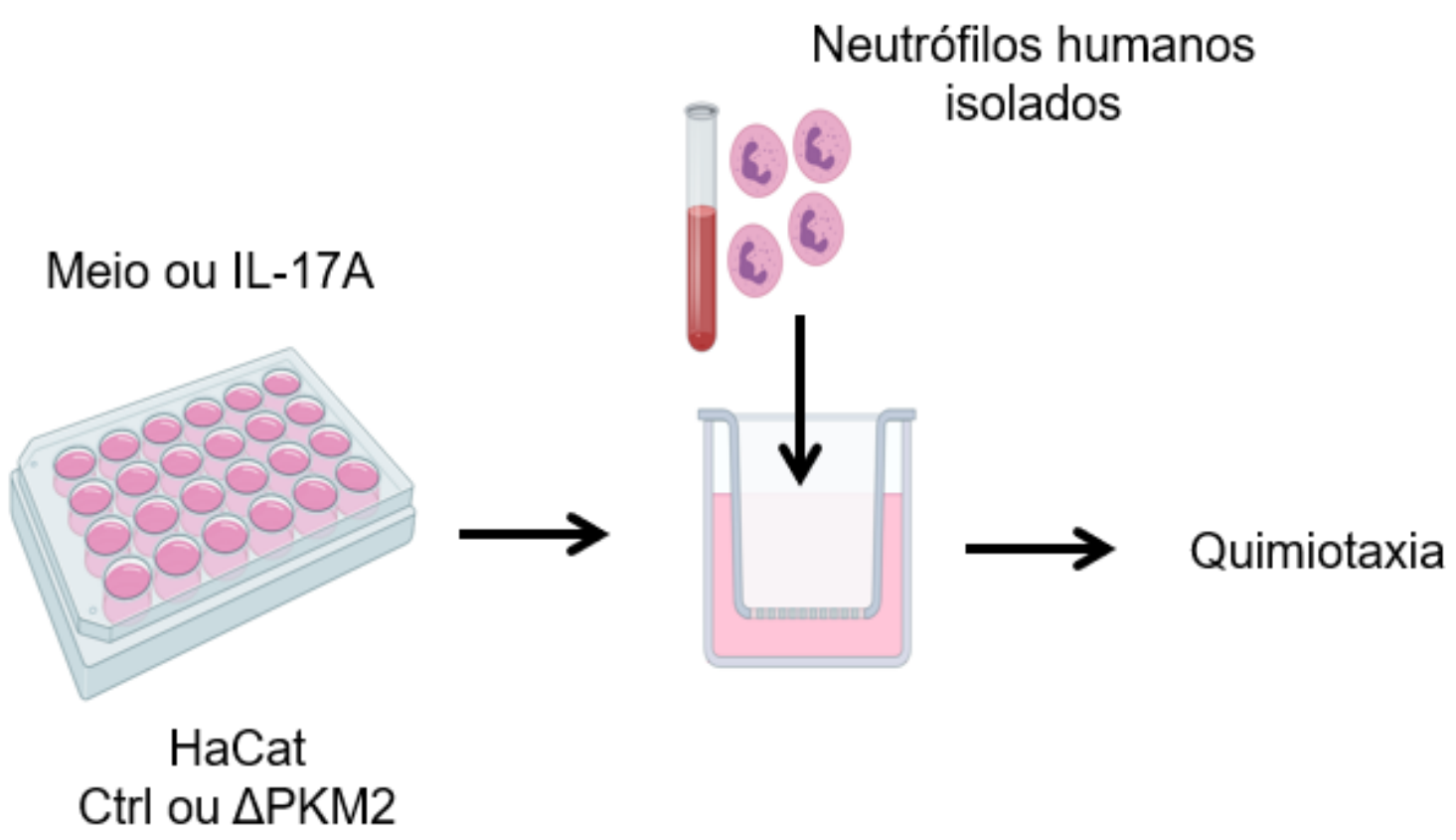

b)
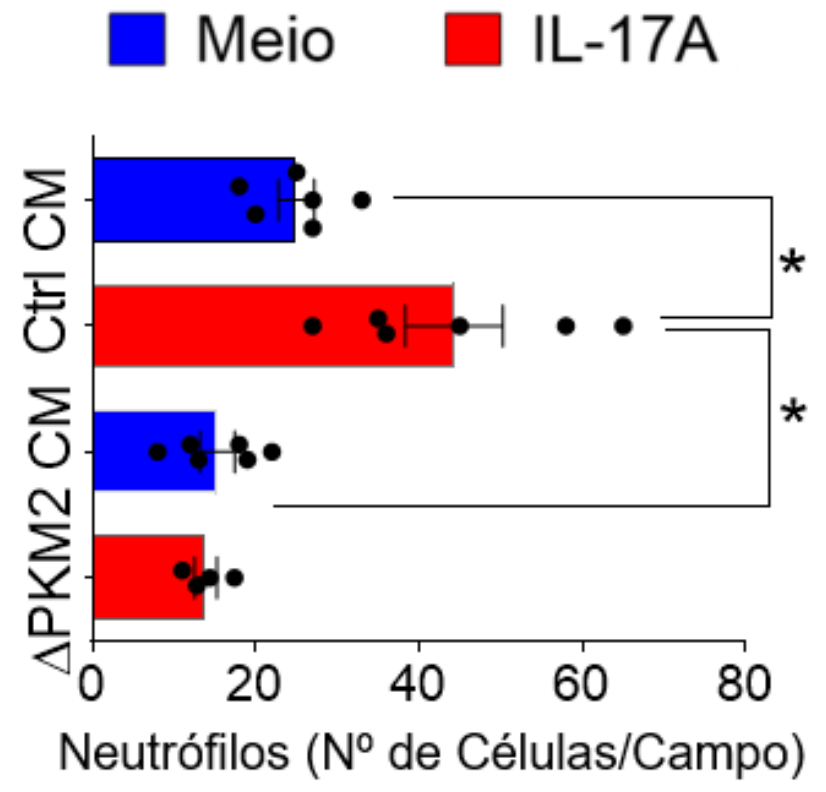

Figura 9 - Recrutamento de neutrófilos por queratinócitos é dependente de PKM2. (a) Representação esquemática do protocolo de quimiotaxia de neutrófilos, utilizado o meio condicionado de células HaCat Ctrl ou $\triangle \mathrm{PKM} 2$, quando ativadas por IL-17A como estimulo quimioatraente. (b) Quimiotaxia de neutrófilos humanos para o meio condicionado $(\mathrm{CM})$ provenientes de células HaCat $\mathrm{Ctrl}$ ou $\triangle \mathrm{PKM} 2$, quando ativadas por IL-17A usando uma câmera de transwell. Os gráficos representam a média \pm SEM $(\mathrm{n}=6)$ de dois experimentos independentes. ${ }^{*} P<0.05$. 


\subsection{AUSÊNCIA de PKM2 não altera o metabolismo de queratinócitos}

Em um próximo passo, nos perguntamos se a ausência de resposta das células deficientes para PKM2 era um reflexo de possíveis alterações metabólicas presentes nessas células. Já é muito bem reportado o papel dessa enzima modulando o metabolismo permitindo o crescimento e proliferação de células tumorais (Christofk HR, 2008; Vander Heiden MG, 2010; Zhou CF, 2012). Surpreendentemente, mesmo na ausência de PKM2, não houveram alterações significativas na proliferação celular, mesmo em uma condição de ativação por IL-17A (Figura 10a). Da mesma maneira, não houveram alterações nos níveis de consumo de glicose e produção de lactado na cultura dessas células (Figura 10b), sugerindo que a PKM2 não apresenta um papel metabólico durante a ativação dessas células. 
a)

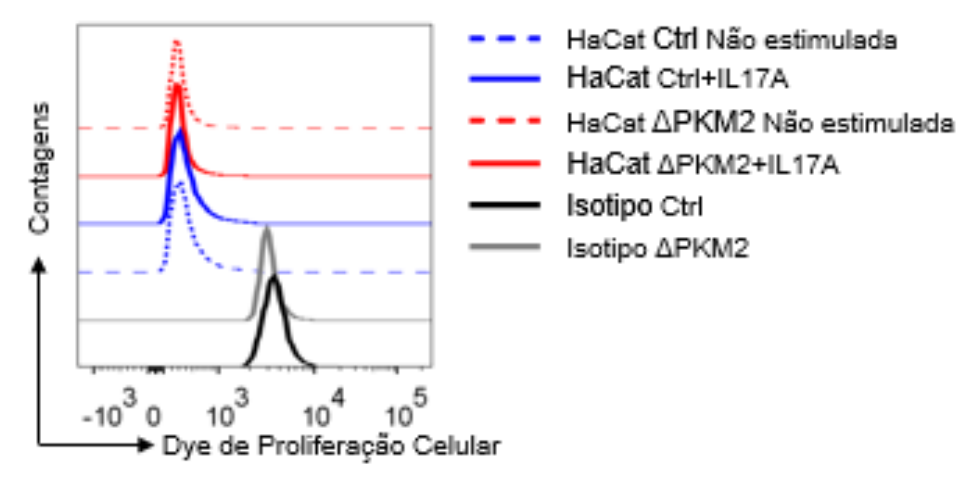

$\square \mathrm{Ctrl} \square \Delta \mathrm{PKM} 2$

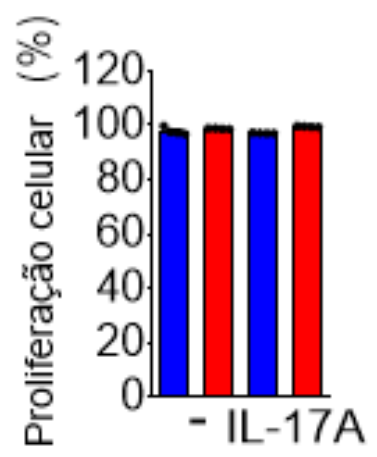

b)

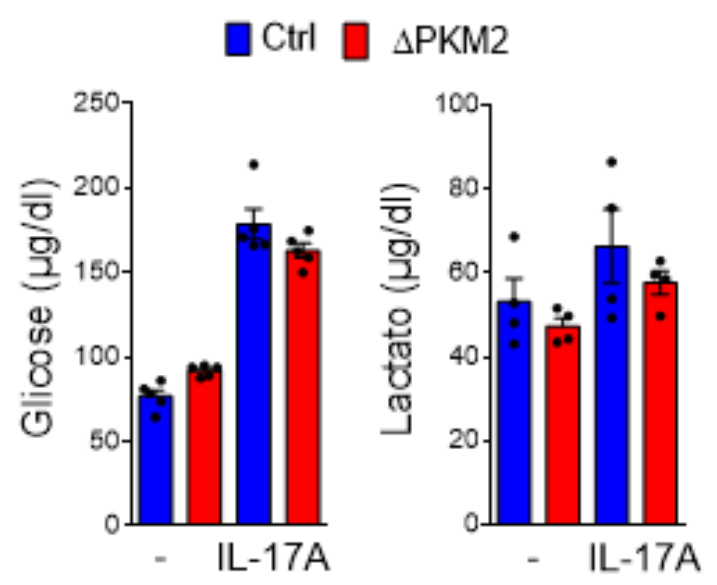

Figura 10 - Deficiência em PKM2 não causa alterações no metabolismo de queratinócitos. (a) Proliferação celular avaliado por FACS, acompanhando o decaimento de um corante nuclear inferindo na proliferação celular de células HaCat Ctrl ou $\triangle \mathrm{PKM} 2$ após estimulo com IL-17A durante um período de 48 horas. Células Ctrl ou $\triangle$ PKM2 recém incubadas com corante nuclear foram usadas como controle (Isotipo). Proliferação celular do mesmo experimento demonstrado em porcentagem de células viáveis. (b) Dosagem de Glicose ou Lactato no sobrenadante da cultura de HaCat Ctrl ou $\triangle \mathrm{PKM} 2$, quando ativadas por IL-17A Os gráficos representam a média $\pm \operatorname{SEM}(n=5)$ de quatro experimentos independentes. 


\subsection{AtivaÇão de NF-KB POR IL-17A em QUeratinócitos REQUeR PKM2}

Uma vez que não observamos alterações no metabolismo glicolítico procuramos avaliar outras funções realizadas pela PKM2, visto que essa pode apresentar papeis não metabólicos. Sabendo que uma das principais vias ativadas frente ao estimulo de IL-17A é a via do NF-kB, e a ativação dessa via é importante para a produção de mediadores inflamatórios por queratinócitos durante a psoríase (Yao Z, 1995; Wang M, 2018), e que uma vez ativado esse fator transcricional se transloca para o núcleo, onde desempenha sua função (Sen R, 1986; Baeuerle P, 1988)nos perguntamos se este fator transcricional estava esta se translocando para o núcleo. Portanto avaliamos a capacidade de translocação para o núcleo de p65, subunidade do NF-kB (Chen FE, 1998), nos queratinócitos $\triangle P K M 2$. Por ensaio de fracionamento nuclear, onde foram separadas amostras proteicas de citoplasma e núcleo dos queratinócitos Ctrl e $\triangle \mathrm{PKM} 2$, seguido de Imunoblot dessas amostras, ficou clara a ausência de p65 no núcleo de células deficientes a PKM2 (Figura 11a). De forma similar, observamos por Imunofluorescência o mesmo fenômeno, no qual queratinócitos Ctrl frente ao estimulo de IL-17A apresentavam uma maior colocalização de p65 com o núcleo, o que não ocorreu nos queratinócitos $\triangle \mathrm{PKM} 2$ (Figura 11b).

Para avaliar de maneira quantitativa a ativação de NF-kB nós construímos células repórter para atividade desse fator transcricional. Para isso utilizamos de um plasmídeo lentiviral que continha quatro copias do sitio de ligação ao NF-kB localizadas upstream promotor TA (TAp). Downtream de TAp se encontra o gene repórter Luciferase, assim como o gene GFP controlado pelo promotor constitutivo de mamíferos UBC (Figura 12a). Essa combinação nos permitiu separar por citometria 
de fluxo as células positivamente transfectadas pela expressão de GFP, além de quantificar em tempo real os níveis de ativação dos genes controlados por NF-kB a partir da expressão de Luciferase. Portanto, células HaCat Ctrl assim como HaCat $\triangle$ PKM2 foram transduzidas com esse plasmídeo NF-kB-luc-GFP, e por microscopia de fluorescência sobreposta a microscopia de luz pudemos avaliar a eficiência da transdução desses genes nessas células (Figura 12b). Uma vez essas células geradas, elas foram separadas por sorting pela expressão de GFP, e cultivadas na presença de IL-17A. Células HaCat Ctrl NF-кB-luc apresentaram um aumento da atividade de NF-kB frente ao estímulo de IL-17A, visto pelo aumento de luminescência produzida por essas células, o mesmo não foi observado em células HaCat $\triangle \mathrm{PKM} 2$ NF-кB-luc, a qual manteve uma expressão basal de Luciferase mesmo frente ao estímulo de IL-17A (Figura 12c). 
a)

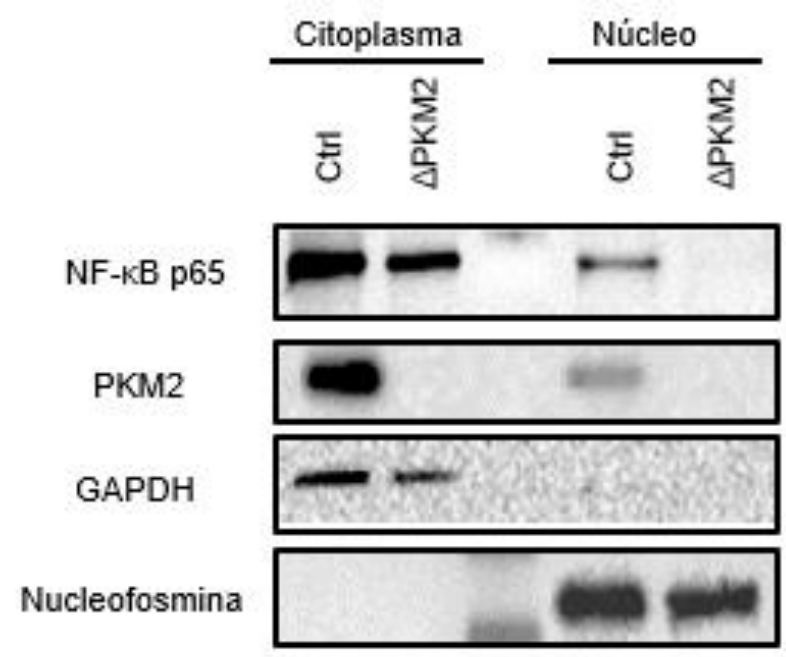

b)

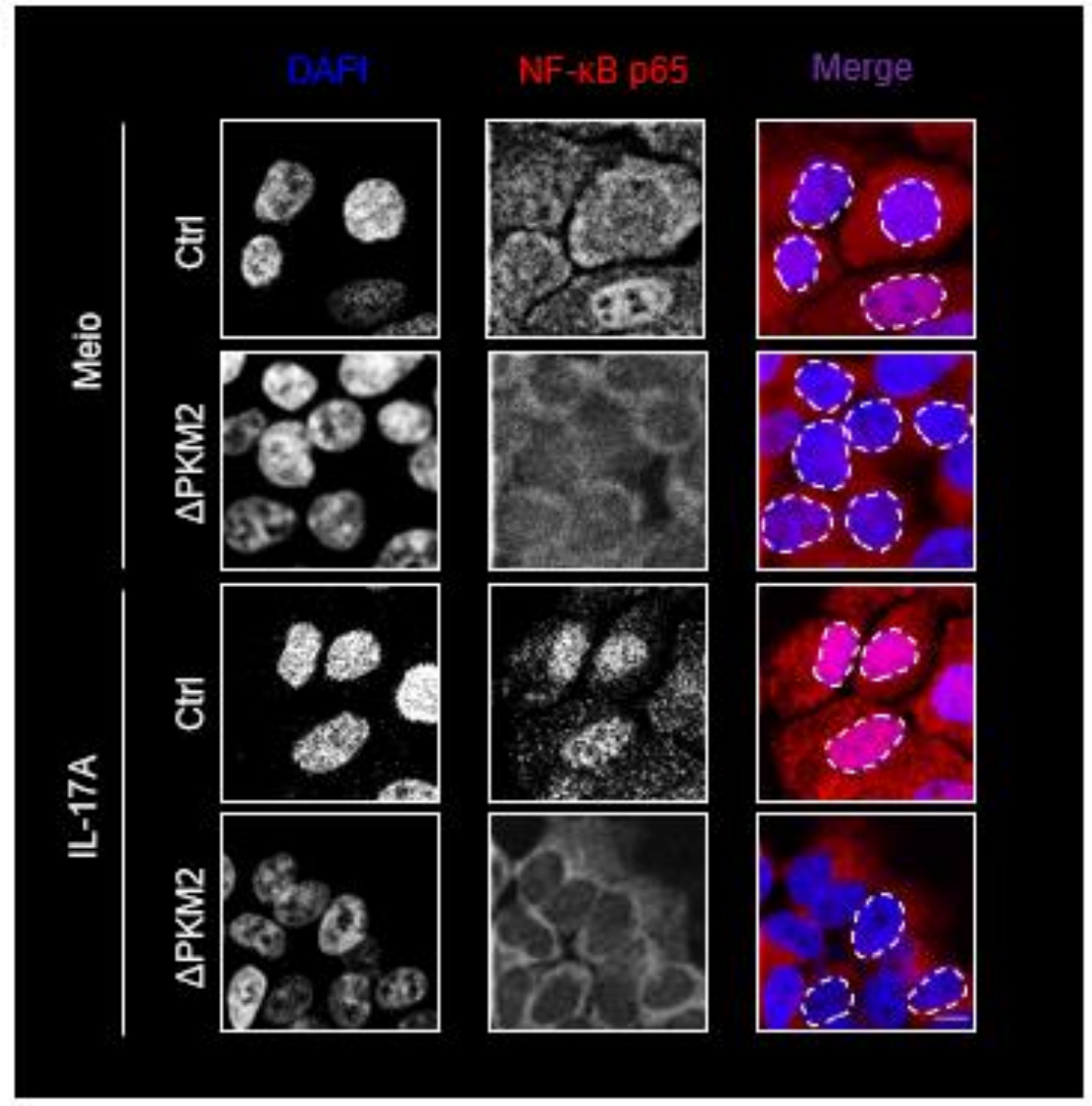

Figura 11 - PKM2 é necessária para o translocamento de p65 ao núcleo. (a) Fracionamento de proteínas presentes no e citoplasma/núcleo de células HaCat Ctrl ou $\triangle \mathrm{PKM} 2$, seguido de análise por Imunoblot da subunidade p65 de NF-kB e PKM2. GAPDH e Nucleofosmina foram usados como um controle de quantidade de proteína presentes no citoplasma e núcleo respectivamente. (b) Análise de ativação de NF-kB por imunofluorescência das células HaCat Ctrl ou $\triangle \mathrm{PKM} 2$ após estimulo com IL-17A, marcadas por p65 (vermelho) e DAPI (Azul). Barra de escala $20 \mu \mathrm{m}$. 
a)

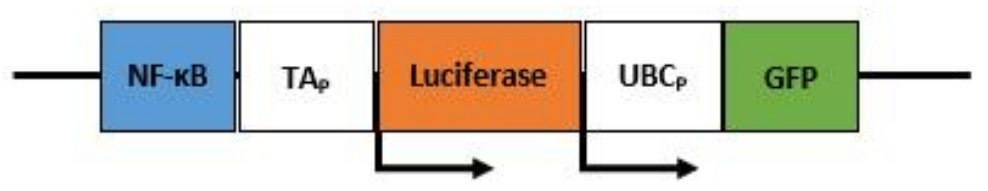

b)

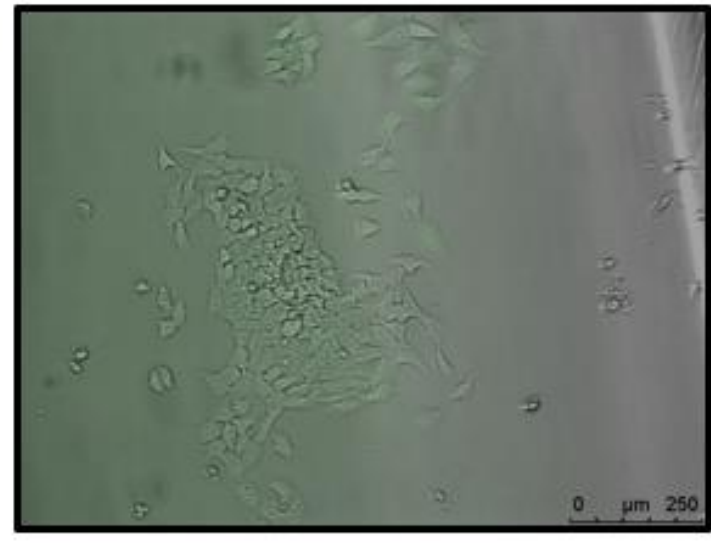

HaCat Ctrl

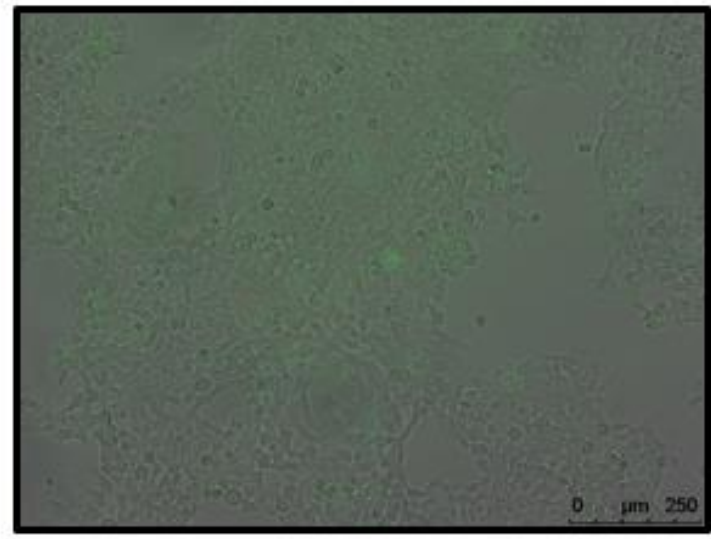

HaCat $\triangle \mathrm{PKM} 2$

c)

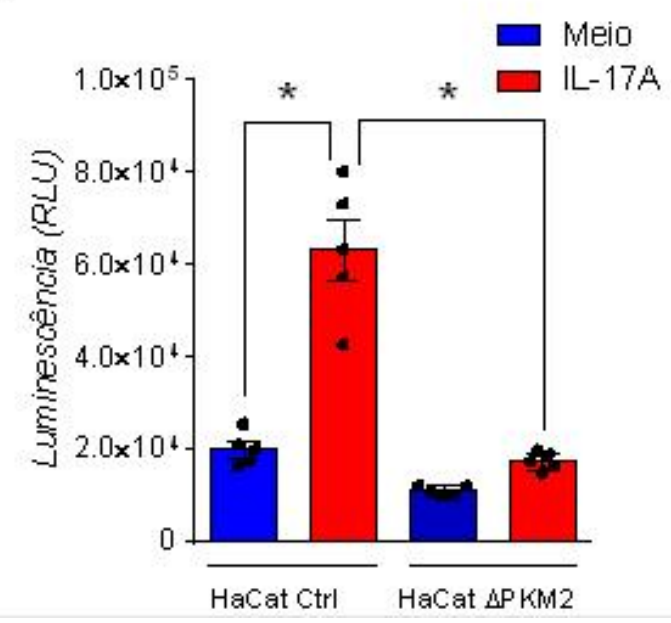

Figura 12 - PKM2 é crucial para ativação de NF-kB por IL-17A em queratinócitos. (a) Representação esquemática do plasmídeo lenti-NF-kB-luc-GFP, sendo a expressão do gene da Luciferase controlado pela atividade promotora de NF- $\kappa B$, e o gene de GFP sendo expresso constitutivamente por atividade do promotor (UBC). (b) Sobreposição de Imagens de microscopia de fluorescência (GFP) e de luz de cultura de células HaCat Ctrl ou $\triangle$ PKM2 48 horas após a transdução do lenti-NF-kB-luc-GFP. Escala: $250 \mu \mathrm{m}$. Imagens são representativas de 2 experimentos independentes. (c) Quantificação relativa de luminescência por células HaCat Ctrl ou $\triangle P K M 2$ transduzidas por lenti-NF-кB-luc-GFP após estimulo com IL-17A.. 


\subsection{VIAS COMUNS DE ATIVAÇÃo DE NF-KB PARECEM SER DEPENDENTES DE PKM2}

Na pele psoriática os queratinócitos enfrentam um ambiente inflamatório rico em estímulos pró-inflamatórios, que levam a atividade de NF-kB. Nos questionamos se estímulos diferentes ao do IL-17A eram capazes provocar resposta na deficiência da enzima PKM2. Portanto incubamos células HaCat Ctrl e $\triangle \mathrm{PKM} 2$, na presença de IL-17A, IL-22 e um estimulo não especifico de PMA e lonomicina (PMA/I), após 24 horas coletamos o sobrenadante dessas células e dosamos a produção de IL-8. Pudemos ver que a células deficiente a PKM2 não responderam ao estimulo de II-22, porém essa mostrou produção de IL-8 frente ao estímulo de PMA/I (Figura 13a). Nos perguntamos se esse estimulo de PMA/l promoveria a ativação de NF-אB mesmo na ausência de PKM2, para responder essa pergunta utilizamos das células repórter para $\mathrm{NF}-\mathrm{kB}$ e as incubamos frente a diversos estímulos, porem a atividade de NF-kB só foi

perceptível nas células $\triangle \mathrm{PKM} 2$ frente ao estimulo de PMA/l (Figura 13b). É interessante ressaltar que dentre os estímulos testados (IL-17A, IL-22, Zymozan, IMQ, LPS) todos compartilham de moléculas adaptadoras da família TRAF downstream ao seu receptor, com exceção do estímulo com PMA, que ativa diretamente a enzima PKC fosforilando IKB e permitindo a translocação de NF-kB para o núcleo (Steffan NM, 1995; Phillip J. Robinson, 1992). 
a)

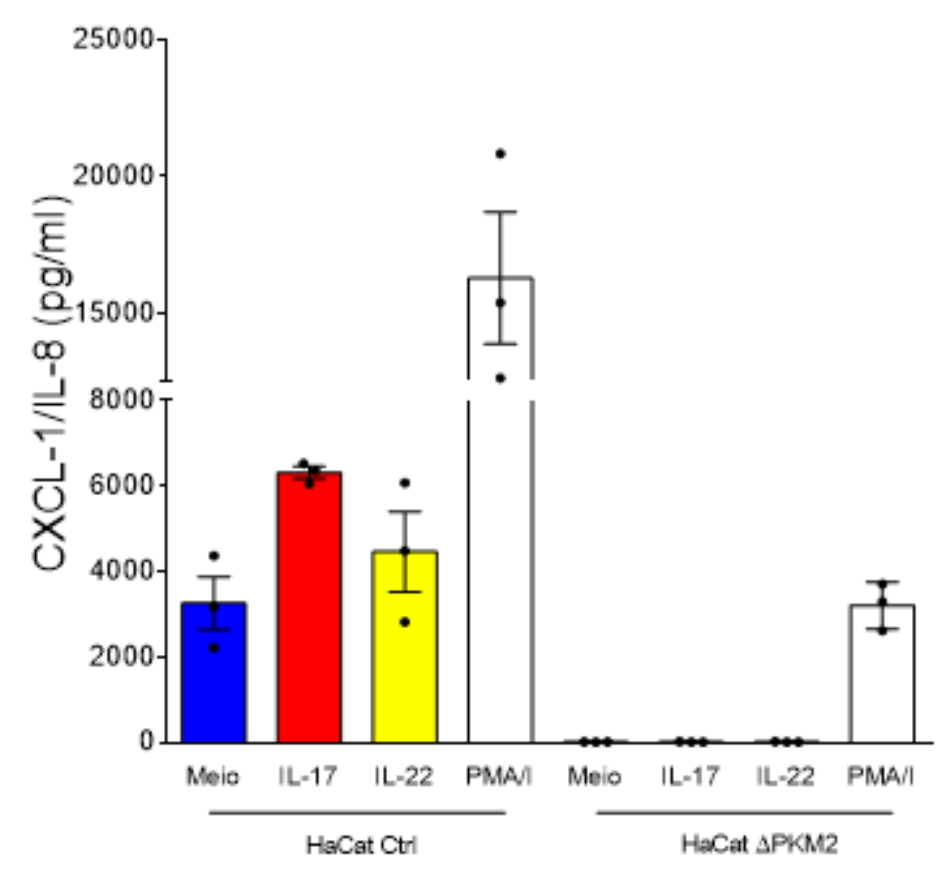

b)

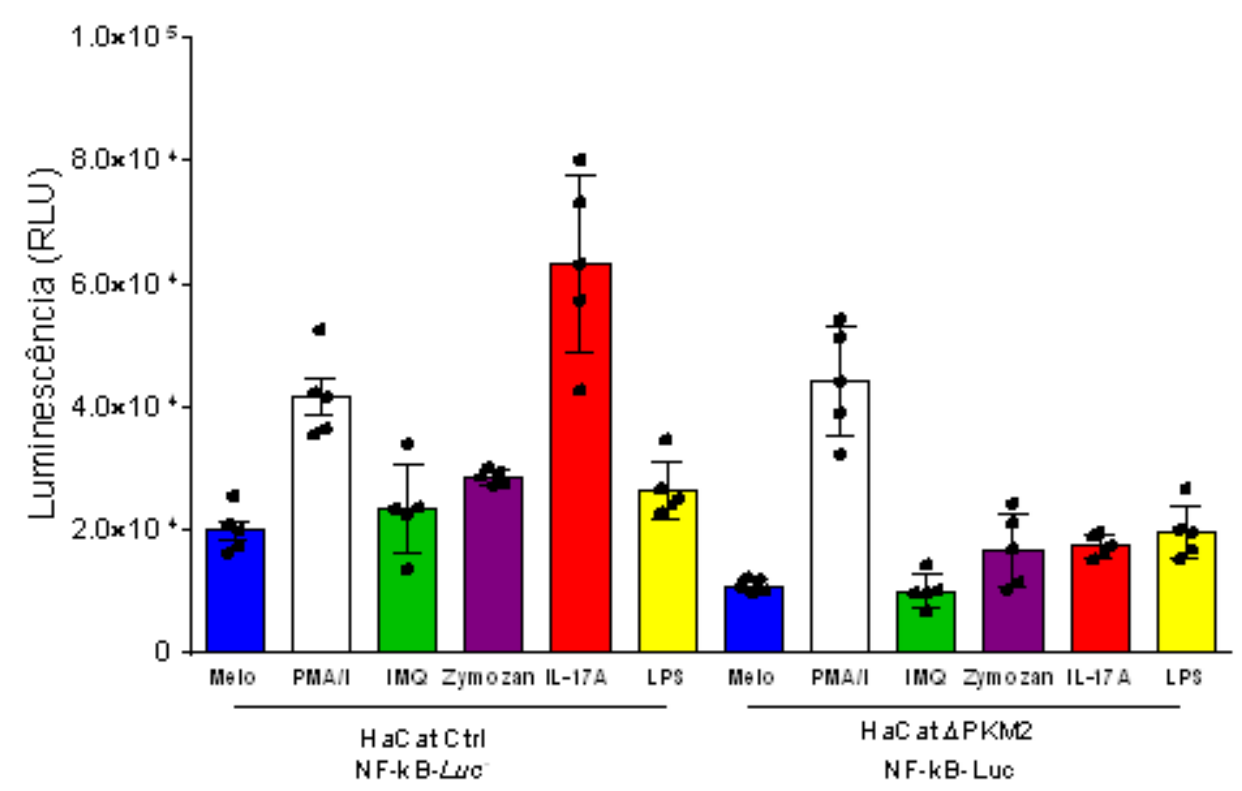

Figura 13 - Estímulos inflamatórios variados dependem de PKM2 (a) Dosagem de CXCL1/IL-8 no sobrenadante da cultura de HaCat Ctrl ou $\triangle$ PKM2, após estimulo de IL-17 ou IL-22 ou PMA/I. (b) Quantificação de luminescência por células HaCat Ctrl

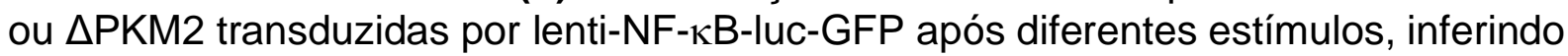
na atividade de NF-kB. Os gráficos de (a) representam a média $\pm \operatorname{SEM}(n=3)$ de três experimentos independentes. Os gráficos em (b) representam a media $\pm \operatorname{SEM}(n=5)$ de 12 experimentos independente. 


\subsection{A ENZIMA PKM2 INTERAGE COM MOLÉCULAS ADAPTADORAS DA VIA DE SINALIZAÇÃo DE IL-17A}

Uma vez que os queratinócitos $\triangle \mathrm{PKM} 2$ não eram responsivos aos estímulos de IL-17A, começamos a investigar em qual parte da via de sinalização dessa molécula PKM2 estava participando. Começamos analisando a expressão de seu receptor (IL-17RA) nos queratinócitos, uma vez que PKM2 pudesse estar regulando sua expressão tornando-o não responsivo a esse estímulo. Analisando a expressão de IL17RA por qPCR não foram perceptíveis diferenças nos níveis de mRNAs produzidos entre as células Ctrl e as $\triangle \mathrm{PKM} 2$ (Figura 14a). E de maneira similar, por análise de citometria de fluxo (FACs) dessas células marcadas com anti-IL17RA, não foram encontradas alterações na expressão do receptor (Figura 14b).

Como não havia alterações na expressão de IL17RA, procuramos verificar a interação de PKM2 com moléculas adaptadoras necessárias para a sinalização via IL17A. Portanto realizamos um ensaio de Imunoprecipitação para a proteína adaptadora Act1, na qual foram extraídas proteína de cultura de queratinócitos estimulados ou não por IL-17A. Pudemos observar a interação da enzima PKM2 com as moléculas adaptadoras Act1 e Traf6, encontradas downtream a IL17RA durante a sinalização por IL-17A (Figura 15a). Sabe-se que após o estímulo com IL-17A, a proteína adaptadora Act1 recruta Traf6 formando uma plataforma molecular capaz de fosforilar IKB e permitir a translocação de NF-кB para o núcleo (Qian Y., 2007; Schwandner R, 2000), portanto procuramos observar a interação de PKM2 na formação dessa plataforma molecular necessária para a ativação de NF-кB. Por imunofluorescência observamos essa interação nos queratinócitos após o estímulo com IL-17A, na qual temos uma co-localização dessas proteínas durante o estímulo, o que não foi visto nos queratinócitos $\triangle \mathrm{PKM} 2$ (Figura 15b). 
a)

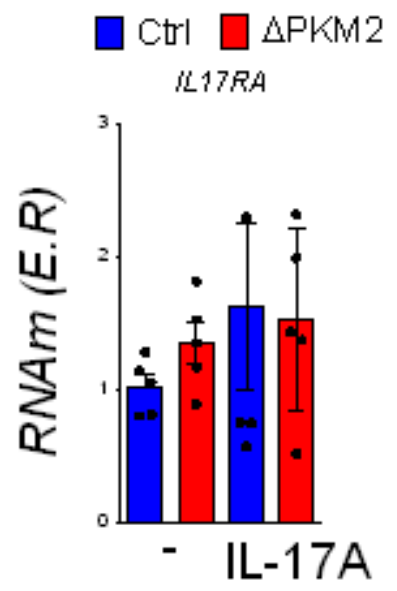

b)

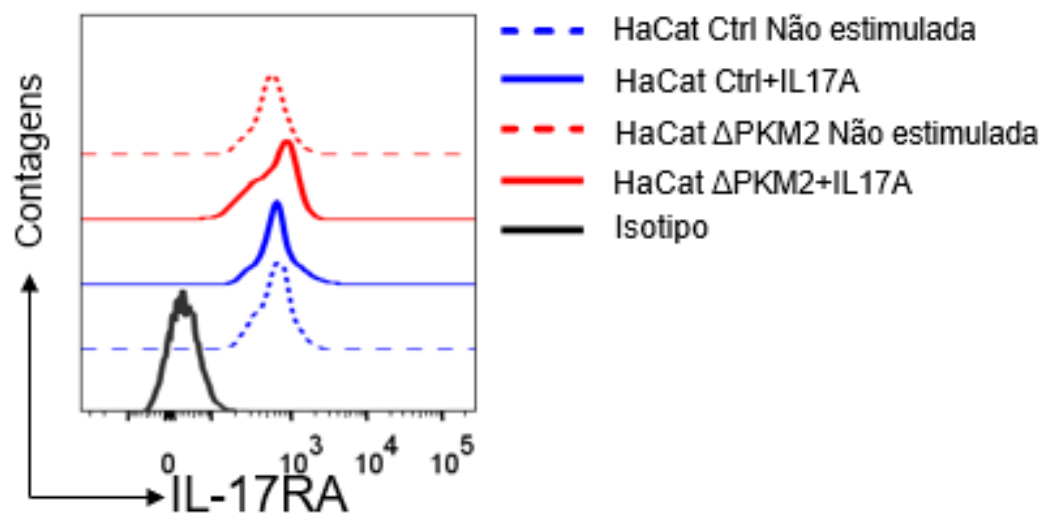

c)

Ctrl $\square \triangle \mathrm{PKM} 2$

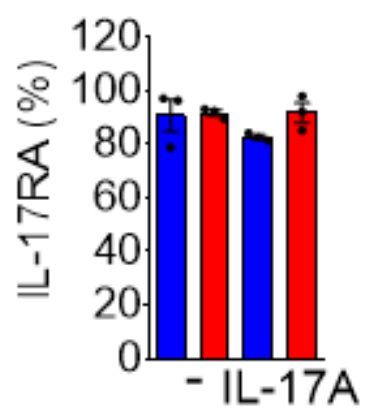

Figura 14 - Deficiência em PKM2 não altera a expressão do receptor para IL-17A (a) Expressão relativa de RNAm de IL-17RA em células HaCats Ctrl ou $\triangle P K M 2$ após estimulo com IL-17A. (b) Expressão de IL17RA avaliado por FACS, de células HaCat Ctrl ou $\triangle$ PKM2 após estimulo com IL-17A marcadas com anti-IL17RA fluorescente. Células também foram marcadas com anti-IgG como controle (Isotipo). (c) Porcentagem de células expressando IL17RA por citometria de fluxo do mesmo experimento. 
a)

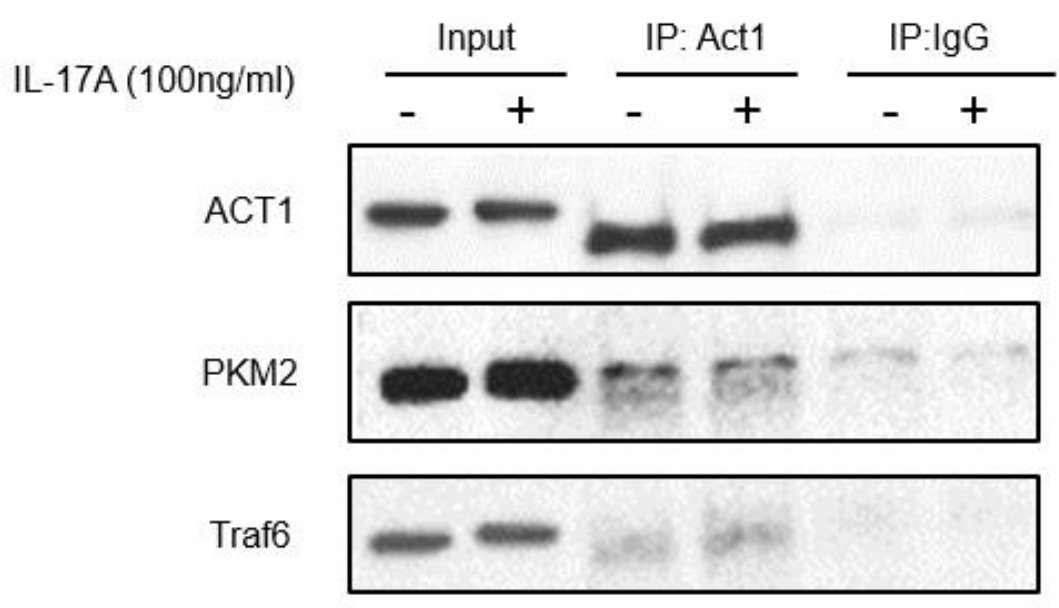

b)

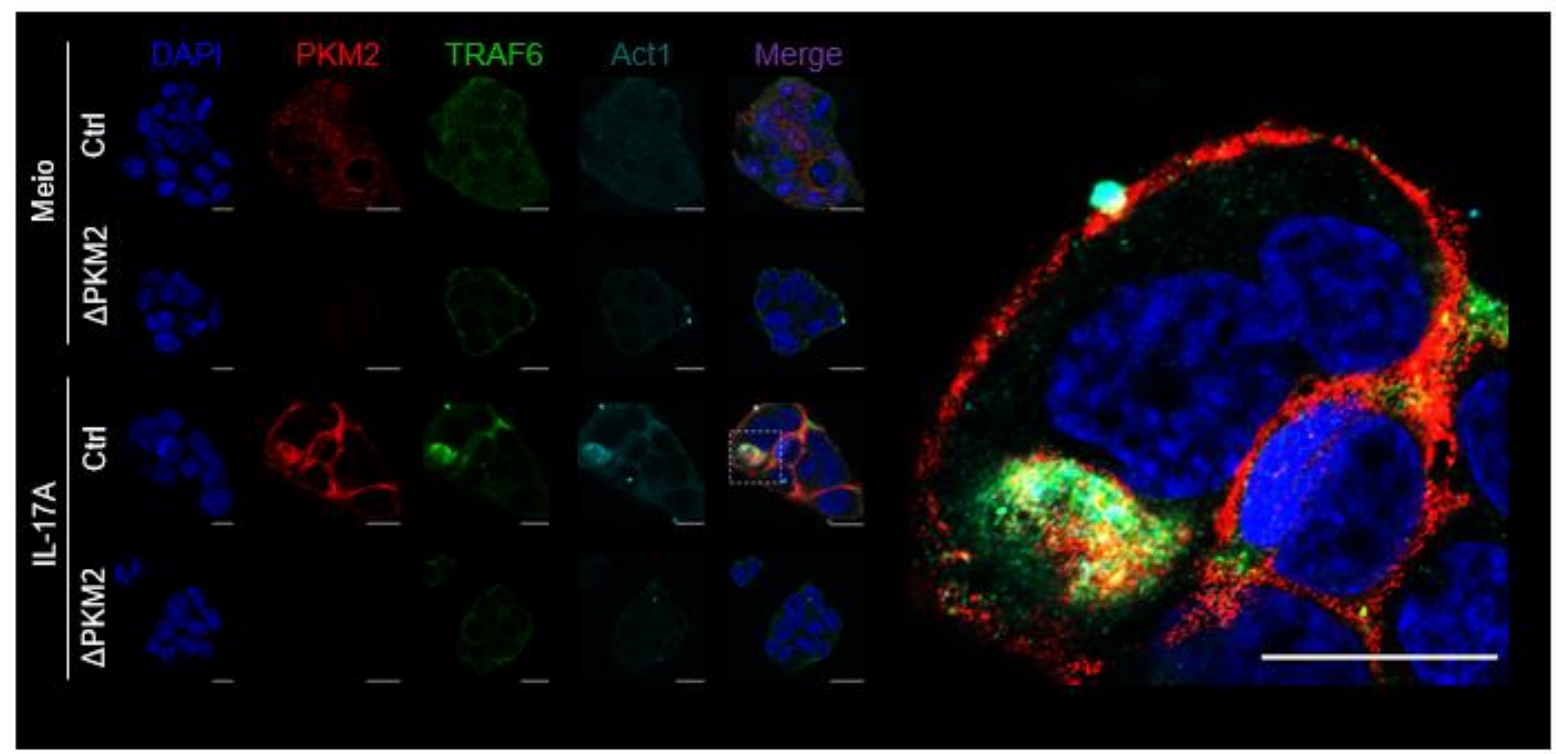

Figura 15 - PKM2 é importante para a formação da plataforma molecular TRAF6Act1 em queratinócitos ativados por IL-17A. (a) Imunoprecipitado por Act1 de extrato proteico de células Hacat estimuladas ou não por IL-17A. Marcado por Imunoblot de Act1, PKM2 e Traf6, para avaliar a interação da plataforma molecular. Anti-IgG foi utilizado como controle do experimento (b) Imunofluorescência das células HaCat após estimulo com IL-17A, marcadas por PKM2 (vermelho), Traf6 (verde), Act1 (ciano) e Dapi (Azul). Barra de escala $50 \mu \mathrm{m}$. 


\section{Discussão}

No presente estudo avaliamos a participação de PKM2 no processo de ativação de queratinócitos pela citocina IL-17A, com o intuído de determinar a importância dessa enzima durante esse processo e inferindo em sua importância na patogênese da psoríase. Isso se torna relevante na busca de terapias alternativas para o tratamento dessa doença, uma vez que as drogas utilizadas atualmente na clínica se baseiam no uso de anti-inflamatórios tópicos, como glicocorticoides, que apresentam efeitos colaterais quando usados cronicamente, e mais recentemente no uso de imunobiológicos, os quais apresentam um custo elevado.

Uma das principais citocinas encontradas na pele psoriásica é a IL-17A (Johansen et al., 2009; Harper et al., 2009; Steinman, 2010). Essa citocina é secretada na pele principalmente por dois subtipos de células T, as T CD4+ auxiliares Th17 e os linfócitos inatos T үס (Albanesi C, 1999; Harrington LE, 2005; Yihua Cai, 2011). Os níveis de IL-17A se encontram elevados tanto no soro como na pele de pacientes com psoríase, quando comparadas aos de indivíduos saudáveis, e atualmente está bem estabelecido a importância dessa citocina durante a patogênese da psoríase e é proposto a inibição dessa citocina como forma de tratamento dessa doença (Lowes et al., 2008; Lee FEH, 2010; Amy C Foulkes, 2019). Essa citocina foi relacionada com o processo e ativação de queratinócitos, levando os a produzirem diversas moléculas relacionadas a psoríase, como um aumento na expressão de K17, Stat3, Ikb-z, ERK5 (Shi, X, 2011; Ling Wu, 2015; Muromoto R, 2016; Pfaff, CM, 2017; Wang M, 2018). No presente estudo, nós confirmamos o aumento da expressão de enzima PKM2 frente ao estímulo de IL-17A (Figura 5), bem como em sua ausência pode impactar na ativação de queratinócitos frente a esse e outros estimulo (Figura 8 e 13). 
A PKM2 tem se mostrado importante para a produção de mediadores inflamatórios em diferentes contextos, regulando tanto a imunidade inata como a adaptativa. Isso é evidente em macrófagos ativados por LPS, no qual a inibição de PKM2 levou a uma menor produção de IL-1ß e HMGB1 (Palsson-McDermoot, 2015; Yang L, 2014; Tannahil G. M. 2013). Nessas células PKM2 também possuí a capacidade de se translocar para o núcleo e interagir como co-fator transcricional para HIF1- $\alpha$, assim como promover atividade de proteína quinase ativando STAT3 (Palsson-McDermoot, 2015; Shirai T, 2016). Além disso foi demonstrado a participação de PKM2 também no processo de ativação de inflamassoma (Xie, M., 2016). Dados de nosso grupo de pesquisa também demonstraram a importância dessa enzima sobre a imunidade adaptativa, na qual participa no processo de diferenciação de linfócitos para o perfil Th17, tendo um papel determinante no desenvolvimento de encefalomielite autoimune experimental (Damasceno, 2018, tese de doutorado). Também reportamos a importância dessa enzima no desenvolvimento de psoríase experimental (Veras, 2018, tese de doutorado). Esse papel emergente da PKM2 na imunidade também foi visto no presente trabalho, no qual se mostrou importante para a produção dos mediadores inflamatórios, visto na expressão de genes relacionados a ativação de queratinócitos (Figura 8a), na produção de proteínas de diferenciação (Figura $\mathbf{8 b}$ ) e na produção de quimiocinas TNF-a e IL-8 (Figura 8c). O que impacta na participação dos queratinócitos tanto na gênese e na manutenção da psoríase, tornando a PKM2 como um alvo interessante para o tratamento de psoríase.

Mostramos o impacto da ausência de PKM2 funcionalmente na ativação de queratinócitos, visto em sua capacidade reduzida de recrutar neutrófilos na ausência da enzima (Figura 9), possível reflexo da menor produção de IL-8 mencionada 
anteriormente, a qual é importante para o recrutamento desse tipo celular (Hammond et al., 1995). Foi descrito o uso tópico de anti-IL-8 no tratamento de lesões psoriasicas, o qual se mostrou efetivo no controle dessas lesões (Tsai Y.C, 2017), dando evidências de uma participação importante dos neutrófilos durante a patogênese da psoríase. Ainda não está bem descrito o papel dos neutrófilos durante a psoríase, porém existem trabalhos que mostram que esses perturbam a homeostasia da epiderme, estimulando a proliferação e ativação de queratinócitos (Henry et al., 2016;Tonello, 2017). Além disso, foi demonstrado em modelo de psoríse induzida por imiquimode que a inibição dessas celulas com anti-Ly6G levava a um menor desenvolvimento da doença (Sumida et al., 2014).

Para a realização desse trabalho utilizamos da tecnologia CRISPR/Cas9 para a geração de uma linhagem HaCat deficiente na produção de PKM2, a escolha dessa abordagem para o estudo da participação dessa enzima durante o processo de ativação de queratinócitos foi feita pelas vantagens apresentadas desse método sobre as alternativas, como o uso de fármacos que podem apresentar atividade off-target dificultando a interpretação dos resultados, ou de outras abordagens moleculares como o silenciamento gênico por RNAs de interferência, que não é capaz de gerar uma linhagem estável em sua utilização (Chen J, 2011; Po-Lin Liao, 2017; Boettcher M, 2015; Wei Gao, 2017). Embora a tecnologia CRISPR/Cas9 seja considerada atualmente como uma das mais eficiente para a edição gênica para a geração de modelos experimentais, o sistema possui algumas ressalvas importantes que devem ser consideradas, como o potencial efeito off-target. O RNA guia que direciona a Cas9 para um determinado local pode reagir de forma inespecífica com outras sequências presentes no genoma. Por esse motivo, é de extrema importância pesquisar cuidadosamente por sequências-guia que apresentem alta especificidade para o alvo. 
Os softwares que realizam essa análise de especificidade de RNAs guia vem se modernizando, minimizando o desenho de guias com esses potenciais off-targets, a ferramenta de desenho do guia realizado nesse trabalho (Optimized Crispr Desing: http://crispr.mit.edu), já não se encontra disponível sendo recomendado o uso de outras ferramentas para esse propósito como o software CRISPOR (Maximilian Haeussler, 2016). No entanto, escolhemos in silico uma sequência guia que se liga perfeitamente a um único alvo de 23 pb (incluindo a sequência PAM) no genoma, minimizando o reconhecimento inespecífico do RNA guia com outra sequência do genoma humano, para confirmar a especificidade dessa reação analisamos a expressão proteica da célula, assim como de suas isoforma, que por similaridade pode ser um possível alvo inespecífico do silenciamento (Figura 7a), assim como por sequenciamento observamos o tipo de mutação ocorrida em nosso gene de interesse (Figura 7b), nos dando segurança que os fenômenos observados em nossa célula gerada são produtos desse silenciamento.

Em nosso estudo buscamos a razão pela qual os queratinócitos deficientes para PKM2 não respondiam ao estimulo de IL-17A, uma possível explicação seria por alterações metabólicas que tornariam essa célula menos competente. Existem dados na literatura que demonstram que a ativação de queratinócitos por compostos oxidantes promove aumento de PKM2 e outros marcadores da via glicolítica (Xiao et al., 2014). Além disso, foi descrita a importância dessa enzima no processo de adesão e proliferação celular (He Y, 2015). Ainda se observa aumento na produção de lactato, resultante do efeito Warburg, pode por si só aumentar o metabolismo celular assim como promover a ativação de células do sistema imune (Ratter JM, 2018). Porém, nossos dados mostram que não houve alterações na proliferação dessas células na ausência de PKM2 (Figura 10a), assim como não observamos diferenças no consumo 
de glicose e produção de lactato comparando os queratinócitos Ctrl com os deficientes para PKM2 (Figura 10b), dando evidencias que o papel da PKM2 nesse tipo celular não por alterações no metabolismo glicolítico.

Como não observamos alterações metabólicas nos queratinócitos na ausência de PKM2, procuramos verificar se essa estava participando de alguma forma na via de sinalização de IL-17A. Vimos que os queratinócitos deficientes a PKM2 não alteravam a expressão do receptor para IL-17A (Figura 14), portanto investigamos se a enzima participa em sua via de sinalização. Em queratinócitos IL-17A pode induzir três vias de sinalização intracelular, ativando JAK/STAT, ativando a via das MAP quinases e ativando a via de NF-кB (Gaffen, 2008; Shen, 2008; Ivanov, 2009). Uma

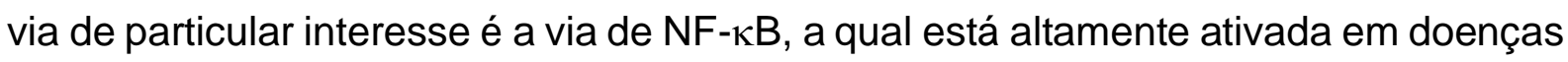
inflamatórias como a psoríase. Isso se torna interessante, uma vez que já foi

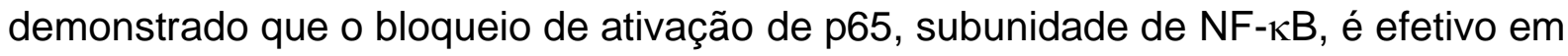
modelo de colite induzida por DSS, além de demonstrado participação direta dessa via associada a inflamação sistêmica na psoríase, mostrando um potencial terapêutico de se inibir essa via (Murano et al., 2000; Sebastian Lorscheid, 2019). Demonstramos no trabalho que os queratinócitos deficientes para PKM2 não translocam a subunidade p65 para o núcleo (Figura 11), e de maneira quantitativa mostramos que temos menos transcrição dos genes comandados pelo NF-kB na ausência de PKM2, por meio da geração de células repórter para sua ativação (Figura 12). Após a interação de IL17A com seu receptor temos o recrutamento da proteína Act1, que se incorpora com TRAF6, formando uma plataforma molecular permitindo a sinalização de IL-17A ativar NF-кB (Qian Y, 2007; Song X, 2013; Gaffen SL, 2014). De maneira interessante, moléculas dessa via de ativação de NF-אB, em células epiteliais são compartilhadas durante ativação por diferentes receptores, sendo TRAF6 importante para a 
sinalização dos receptores da família Toll, NLR, IL-1R e até receptores mitocondriais (Dainichi T, 2019). Durante o trabalho observamos que os queratinócitos deficientes para PKM2 não respondiam a diversos estímulos inflamatórios além de IL-17A, como IL-22, Imiquimode (Toll 7/8), Zymozan (Toll 2), LPS (Toll 4), todos dos quais compartilham vias de sinalização dependentes de TRAF6, porém frente ao estímulo independente dessa via PMA/l, observamos atividade de NF-kB mesmo na ausência de PKM2 (Figura 13). Portanto supomos que PKM2 devesse interagir com essa parte da via de sinalização, e confirmamos a interação de PKM2 com essas moléculas adaptadoras por imunoprecipitação de ACT1 e imunofluorescência, na qual PKM2 parece interagir com o complexo ACT1-TRAF6, sendo necessário para sua sinalização (Figura 15).

Assim, mostramos com nossos resultados, pela primeira vez, a participação da enzima PKM2, em um efeito citoplasmático durante o processo de ativação de queratinócitos, desvendando seu mecanismo. O entendimento dessas vias moleculares nos ajuda na maior compreensão do papel dos queratinócitos na patogênese da psoríase, além disso desvendar esse papel não canônico apresentado por proteínas metabólicas também são interessantes para o desenvolvimento de terapias alternativas para doenças inflamatórias. 


\section{Conclusão}

Tiramos como conclusão desse trabalho que a PKM2 é uma importante enzima durante a ativação de queratinócitos frente a estímulos inflamatórios. Num contexto de psoríase temos então a ativação inicial de queratinócitos, qual dá início a inflamação recrutando principalmente células produtoras de IL-17A as quais as ativam, levando a sua proliferação e maior recrutamento de células do sistema imune como neutrófilos (Figura 16a).

Mecanisticamente, a IL-17A ativa os queratinócitos levando a um aumento de expressão de PKM2, e a própria enzima participa no processo de transdução de sinal de sua via de sinalização, interagindo com o complexo ACT1-TRAF6, sendo necessária para a translocação de NF-kB para o núcleo e transcrição de genes próinflamatórios (Figura 16b). 


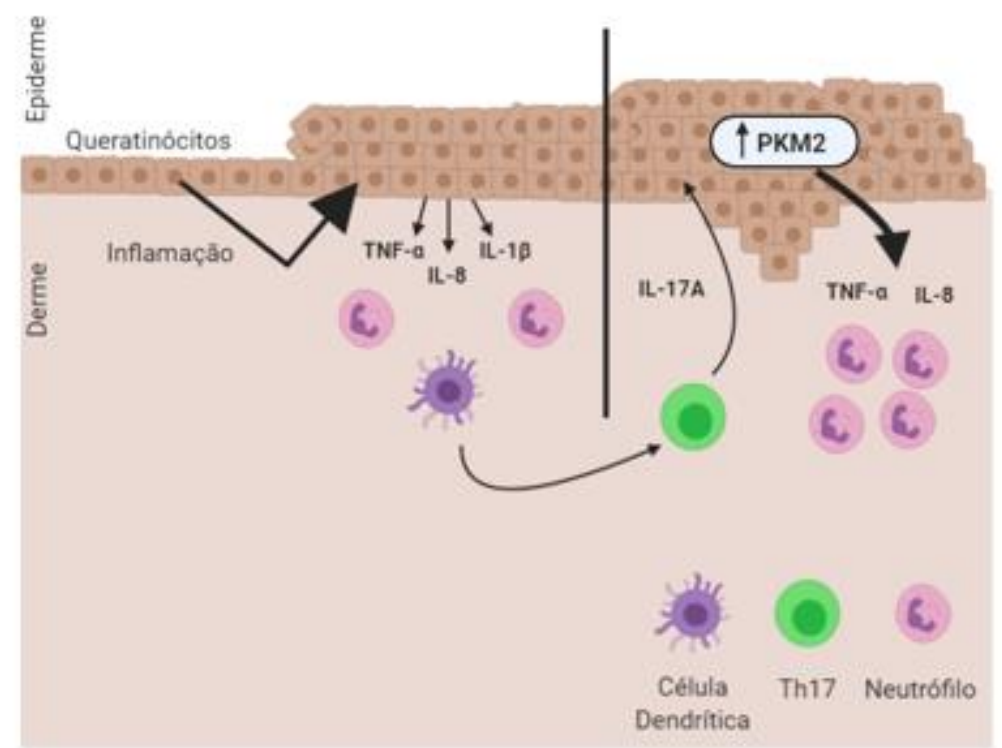

b)

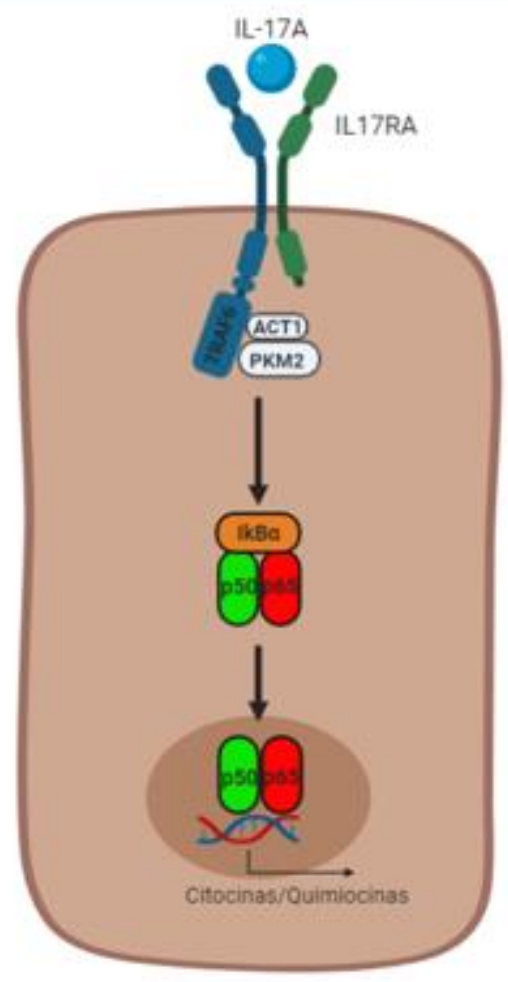

Figura 16 - Participação da PKM2 durante o processo de ativação de queratinócitos. Ativação inicial de queratinócitos os levam a produzir mediadores inflamatórios dando início a inflamação e consequentemente temos o recrutamento de células produtoras de IL-17A, que ativam os queratinócitos promovendo um aumento de PKM2, de sua proliferação e maior produção de mediadores inflamatórios (a). Após o contato de IL-17A com seu receptor, temos o recrutamento de moléculas adaptadoras como ACT1, formando o complexo com TRAF6 e PKM2, permitindo sua sinalização e ativação da via do NF-kB. 


\section{REFERÊNCIAS BIBLIOGRÁFICAS}

1. Aggarwal S, Gurney AL. IL-17: A prototype member of an emerging family. J. Leukoc. Biol 2002;71:1-8.

2. Alam H, Sehgal L, Kundu ST, Dalal SN, Vaidya MM. Novel function of keratins 5 and 14 in proliferation and differentiation of stratified epithelial cells. Mol Biol Cell. 2011;22:4068-4078. doi: 10.1091/mbc.E10-08-0703.

3. Albanesi C, Cavani A, Girolomoni G (1999) IL-17 is produced by nickel- specific T lymphocytes and regulates ICAM-1 expression and chemokine production in human keratinocytes: synergistic or antagonist effects with IFN-gamma and TNF-alpha. J Immunol 162:494-502

4. Albanesi C, De Pità O, Girolomoni G. Resident skin cells in psoriasis: a special look at the pathogenetic functions of keratinocytes. Clin Dermatol(2007) 25(6):581-8. doi:10.1016/j.clindermatol.2007.08.013

5. Alves-Filho, J. C., \& Palsson-McDermott, E. M. (2016). Pyruvate kinase M2: A potential target for regulating inflammation. Frontiers in Immunology.

6. Amy C Foulkes e Richard B Warren. Brodalumab in psoriasis: evidence to date and clinical potential. Drugs Context. 2019; 8: 212570

7. Anastasiou D., Yu Y., Israelsen W.J., Jiang J.-K., Boxer M.B., Hong B.S., Tempel W., Dimov S., Shen M., Jha A., et al. Pyruvate kinase M2 activators promote tetramer formation and suppress tumorigenesis. Nat. Chem. Biol. 2012;8:839-847. doi: 10.1038/nchembio.1060.

8. Anoopkumar-Dukie $S$, et al. Resazurin assay of radiation response in cultured cells. Br J Radiol 78, 945-947 (2005).

9. Baeuerle P, Baltimore D. I kappa B: a specific inhibitor of the NF-kB transcription factor. Science. 1988;242:540-46. 
10. Barker, J. N. W. N. (1991). The pathophysiology of psoriasis. The Lancet, 338(8761), 227-230. http://doi.org/10.1016/0140-6736(91)90357Uhttp://doi.org/10.1016/0140-6736(91)90357-U

11. Bhardwaj A, Das S. SIRT6 deacetylates PKM2 to suppress its nuclear localization and oncogenic functions. Proc Natl Acad Sci USA. 2016;113(5): E538-E547. doi: 10.1073/pnas.1520045113.

12. Boehncke W. H., Schön M. P. Psoriasis. Lancet. 2015;386(9997):983-994. doi: 10.1016/S0140-6736(14)61909-7.

13. Boettcher M., McManus M. T. (2015). Choosing the right tool for the job: RNAi, TALEN, or CRISPR. Mol. Cell. 58 575-585. 10.1016/j.molcel.2015.04.028

14. Boiteux, A. \& Hess, B. (1981) Design of glycolysis. Philos. Trans. R. Soc. Lond. Ser. B Biol. Sci. 293, 5-22.

15. Boukamp, P. (1988). Normal Keratinization in a Spontaneously Immortalized, 106(March), 761-771.

16. C. Albanesi, C. Scarponi, A. Cavani, M. Fedrici, F. Nasorri, G. Girolomonilnterl eukin-17 is produced by both Th1 and Th2 lymphocytes, and modulates interferon-gamma and interleukin-4-induced activation of human keratinocytes J. Invest. Dermatol., 115 (2000), pp. 81-87

17. Cai $Y$, Shen X, Ding C, et al. Pivotal role of dermal IL-17-producing gammadelta T cells in skin inflammation. Immunity. 2011;35:596-610.

18. Cai Y, Shen X, Ding C, Qi C, Li K, Li X et al. Pivotal role of dermal IL-17producing cd T cells in skin inflammation. Immunity 2011; 35:596-610

19. Cai, Y., Shen, X., Ding, C., Qi, C., Li, K., Li, X., .. Yan, J. (2011). Pivotal role of dermal IL-17-producing үס T cells in skin inflammation. Immunity, 35(4), 596610. https://doi.org/10.1016/j.immuni.2011.08.001 
20. Carrier Y, Ma HL, Ramon HE, Napierata L, Small C, O'Toole M, et al. Interregulation of Th17 cytokines and the IL-36 cytokines in vitro and in vivo: implications in psoriasis pathogenesis. J Invest Dermatol (2011) 131(12):242837. doi:10.1038/jid.2011.234

21. Chaneton B, Hillmann $P$, Zheng L, Martin AC, Maddocks OD, Chokkathukalam A, Coyle JE, Jankevics A, Holding FP, Vousden $\mathrm{KH}$, et al: Serine is a natural ligand and allosteric activator of pyruvate kinase M2. Nature. 491:458-462. 2012.

22. Chen FE, Huang DB, Chen YQ and Ghosh G. 1998. Crystal structure of p50/p65 heterodimer of transcription factor NF-B bound to DNA Nature, 391:410- 413.

23. Chen J, et al. Shikonin and its analogs inhibit cancer cell glycolysis by targeting tumor pyruvate kinase-M2. Oncogene. 2011;30:4297-4306. doi: 10.1038/onc.2011.137.

24. Chiricozzi, A., Guttman-Yassky, E., Suárez-Farĩas, M., Nograles, K. E., Tian, S., Cardinale, I., ... Krueger, J. G. (2011). Integrative responses to IL-17 and TNF- $\alpha$ in human keratinocytes account for key inflammatory pathogenic circuits in psoriasis. Journal of Investigative Dermatology, 131(3), 677-687. https://doi.org/10.1038/jid.2010.340

25. Cho, J.-L., Allanson, M., \& Reeve, V. E. (2012). Hypoxia inducible factor-1a contributes to UV radiation-induced inflammation, epidermal hyperplasia and immunosuppression in mice. Photochemical \& Photobiological Sciences : Official Journal of the European Photochemistry Association and the European Society for Photobiology, 11(2), 309-17. http://doi.org/10.1039/c1pp05265a

26. Christofk HR, Van der Heiden MG, Harris MH, Ramanathan A, Gerszten RE, Wei R, Fleming MD, Schreiber SL and Cantley LC: The M2 splice isoform of 
pyruvate kinase is important for cancer metabolism and tumour growth. Nature. 452:230-233. 2008.

27. Christophers, E. (2001). Psoriasis--epidemiology and clinical spectrum. Clinical and Experimental Dermatology, 26(4), 314-20. http://doi.org/10.1046/j.13652230.2001.00832.x

28. Coimbra, S., Figueiredo, A., Castro, E., Rocha-Pereira, P., \& Santos-Silva, A. (2012). The roles of cells and cytokines in the pathogenesis of psoriasis. International Journal of Dermatology. https://doi.org/10.1111/j.13654632.2011.05154.x

29. Cong L, Ran FA, Cox D, Lin S, Barretto R, Habib N, Hsu PD, Wu X, Jiang W, Marraffini LA, et al. Multiplex genome engineering using CRISPR/Cas systems. Science. 2013;339(6121):819-823. doi: 10.1126/science.1231143.

30. Cua DJ, Tato CM. Innate IL-17-producing cells: the sentinels of the immune system. Nat Rev Immunol 2010; 10:479-89.

31. Cua DJ, Tato CM. Innate IL-17-producing cells: the sentinels of the immune system. Nat Rev Immunol 2010; 10:479-89.

32. Dainichi T, Matsumoto R, Mostafa A, Kabashima K. Immune Control by TRAF6Mediated Pathways of Epithelial Cells in the EIME (Epithelial Immune Microenvironment). Front Immunol. 2019 May 16;10:1107.

33. Damasceno, LE. (2018) Envolvimento da enzima piruvato quinase M2 (PKM2) na diferenciação de linfócitos Th17 e patogênese da encefalomielite autoimune experimental. Tese de Mestrado - Programa de Imunologia Básica de Aplicada da Faculdade de Medicina de Ribeirão Preto - Universidade de São Paulo, Ribeirão Preto, SP 
34. Dandekar, T., Schuster, S., Snel, B., Huynen, M., \& Bork, P. (1999) Pathway alignment: application to the comparative analysis of glycolytic enzymes. Biochem. J. 343, 115-124.

35. Dong G, Mao Q, Xia W, Xu Y, Wang J, Xu L, Jiang F. (2016). PKM2 and cancer: The function of PKM2 beyond glycolysis. Oncol Lett. 2016;11:1980-1986.

36. Eckert, R. L., \& Rorke, E. a. (1989). Molecular biology of keratinocyte differentiation. Environmental Health Perspectives, 80, 109-116. http://doi.org/10.1289/ehp.8980109

37. Erlandsen, H., Abola, E.E., \& Stevens, R.C. (2000) Combining structural genomics and enzymology: completing the picture in metabolic pathways and enzyme active sites. Curr. Opin. Struct. Biol. 10, 719-730.

38. Freedberg, I. M., Eisen, A. Z., Wolff, K., Austen, K. F., Goldsmith, L. A., \& Katz, S. I. (2003). Fitzpatrick's Dermatology In General Medicine. General Medicine, 2900

39. Fukuoka $M$, Ogino $Y$, Sato $H$, et al. RANTES expression in psoriatic skin and regulation of RANTES and IL-8 production in cultured epider- mal keratinocytes by active vitamin D3 (tacalcitol). Br J Dermatol 1998;138:63-70.

40. Gaffen S.L. Structure and signalling in the IL-17 receptor family. Nat. Rev. Immunol. 2009; 9: 556-567

41. Gaffen SL (2008) An overview of IL-17 function and signaling. Cytokine 43:4027

42. Gaffen SL, Jain R, Garg AV, Cua DJ. The IL-23-IL-17 immune axis: from mechanisms to therapeutic testing. Nat Rev Immunol. (2014) 14:585-600. doi: 10.1038/nri3707

43. Galkowska H, Wojewodska U, Olszewski WL. Che- mokines, cytokines and 
growth factors in keratino- cytes and dermal endothelial cells in the margin of chronic diabetic foot ulcers. Wound Repair Regen 2006;14:558-65.

44. Galván-Peña, S., \& O’Neill, L. A. J. (2014). Metabolic Reprograming in Macrophage Polarization. Frontiers in Immunology, 5(September), 1-6. http://doi.org/10.3389/fimmu.2014.00420

45. Galván-Peña, S., \& O’Neill, L. A. J. (2014). Metabolic Reprograming in Macrophage Polarization. Frontiers in Immunology, 5(September), 1-6. http://doi.org/10.3389/fimmu.2014.00420

46. Gao X, Wang H, Yang JJ, Liu X and Liu ZR. (2012) Pyruvate kinase M2 regulates gene transcription by acting as a protein kinase. Mol Cell 45: 598-609, 2012

47. Gao X, Wang H, Yang JJ, Chen J, et al. 2013. Reciprocal regulation of protein kinase and pyruvate kinase activities of pyruvate kinase M2 by growth signals. $J$ Biol Chem 288: 15971-9.

48. Girolomoni G, Strohal R, Puig L, Bachelez H, Barker J, Boehncke WH, et al. The role of IL-23 and the IL-23/TH17 immune axis in the pathogenesis and treatment of psoriasis. J Eur Acad Dermatol Venereol (2017) 31(10):1616-26. doi:10.1111/jdv.14433

49. Griffiths, C. E. M. C., \& Barker, J. J. N. W. N. (2007). Pathogenesis and clinical features of psoriasis. The Lancet, 370(9583), 263-271. https://doi.org/10.1016/S0140-6736(07)61128-3

50. Griffiths, C. E. M., Christophers, E., Barker, J. N. W. N., Chalmers, R. J. G., Chimenti, S., Krueger, G. G., ... Fry, L. (2007). A classification of psoriasis vulgaris according to phenotype. In British Journal of Dermatology (Vol. 156, pp. 258-262). https://doi.org/10.1111/j.1365-2133.2006.07675.x 
51. Haeussler M., Schonig K., Eckert H., Eschstruth A., Mianne J., Renaud J. B., Schneider-Maunoury S., Shkumatava A., Teboul L., Kent J., Joly J. S., Concordet J.-P., Evaluation of off-target and on-target scoring algorithms and integration into the guide RNA selection tool CRISPOR. Genome Biol. 17, 148 (2016).

52. Hammond ME, Lapointe GR, Feucht PH, Hilt S, Gallegos CA, Gordon CA, et al. IL-8 induces neutrophil chemotaxis predominantly via type I IL-8 receptors. $J$ Immunol. 1995; 155: 1428-33.

53. Hao JQ. Targeting interleukin-22 in psoriasis. Inflammation. (2014) 37:94-9. $10.1007 / \mathrm{s} 10753-013-9715-y$

54. Harper EG, Guo C, Rizzo H, Lillis JV, Kurtz SE, Skorcheva I, Purdy D, Fitch E, lordanov M, Blauvelt A. Th17 cytokines stimulate CCL20 expression in keratinocytes in vitro and in vivo: implications for psoriasis pathogenesis. $\mathrm{J}$ Invest Dermatol. 2009;129:2175-2183.

55. Harrington LE, Hatton RD, Mangan PR et al. (2005) Interleukin-17-producing CD4+ effector T cells develop via a lineage distinct from the Thelper type 1 and 2 lineages. Nat Immunol 6:1123-32

56. He Y, Wang Y, Liu H, Xu X, He S, Tang J, Huang Y, Miao X, Wu Y, Wang $\mathrm{Q}$, Cheng C. Pyruvate kinase isoform M2 (PKM2) participates in multiple myeloma cell proliferation, adhesion and chemoresistance. Leuk Res. 2015 Dec;39(12):1428-36.

57. Imamura K, Tanaka T. (1972) Multimolecular forms of pyruvate kinase from rat and other mammalian tissues. I. Electrophoretic studies. J Biochem 1972;71:1043-51. 
58. Ivanov S, Linde'n A (2009) Interleukin-17 as a drug target in human disease. Trends Pharmacol Sci 30:95-103

59. Jinek M, Chylinski K, Fonfara I, Hauer M, Doudna JA, Charpentier E. A programmable dual-RNA-guided DNA endonuclease in adaptive bacterial immunity. Science. 2012;337(6096):816-821. doi: 10.1126/science.1225829.

60. Johansen C, Usher PA, Kjellerup RB, Lundsgaard D, Iversen L, Kragballe K. Characterization of the interleukin-17 isoforms and receptors in lesional psoriatic skin. Br J Dermatol. 2009;160(2):319-324. doi: 10.1111/j.13652133.2008.08902.x.

61. Juráňová, J., Franková, J., \& Ulrichová, J. (2017). The role of keratinocytes in inflammation. Journal of Applied Biomedicine. https://doi.org/10.1016/j.jab.2017.05.003

62. Kierszenbaum, Abraham L. o Editor Hislologia e biologia celular: uma introdução à patologia / Abraham L. Kierszenbaum ; [revisão científica Marcelo Sampaio Narciso; tradução Adriana Paulino do Nascimenlo .. etal.[. - Rio de Janeiro: Elsevier, 2008.

63. Korn, T., Bettelli, E., Oukka, M., \& Kuchroo, V. K. (2009). IL-17 and Th17 Cells. Annual Review of Immunology, 27(1), 485-517. https://doi.org/10.1146/annurev.immunol.021908.132710

64. Krueger JG, Bowcock A. (2005) Psoriasis pathophysiology: current concepts of pathogenesis. Ann Rheum Dis. 2005;64(Suppl 2):30-36.

65. Lande, R., Gregorio, J., Facchinetti, V., Chatterjee, B., Wang, Y.-H., Homey, B., ... Gilliet, M. (2007). Plasmacytoid dendritic cells sense self-DNA coupled with antimicrobial peptide. Nature, 449(7162), 564-569. https://doi.org/10.1038/nature06116 
66. Lee FEH, Georas SN, Beck LA (2010) IL-17: Important for host defense, autoimmunity, and allergy? J Invest Dermatol 130:2540-2

67. Lehninger, A. L., Nelson, D. L., \& Cox, M. M. (2000). Lehninger principles of biochemistry. 4. ed. cap. 1, p. 3-31

68. Li N, Yamasaki K, Saito R, Fukushi-Takahashi S, Shimada-Omori R, Asano M, et al. Alarmin function of cathelicidin antimicrobial peptide LL37 through IL-36y induction in human epidermal keratinocytes. J Immunol (2014) 193(10):51408. doi:10.4049/jimmunol.1302574

69. Li XB, Gu JD, Zhou QH. Review of aerobic glycolysis and its key enzymes new targets for lung cancer therapy. Thorac Cancer 2015; 6: 17-24.

70. Lorscheid S, Müller A, Löffler J, Resch C, Bucher P, Kurschus FC, Waisman A, Schäkel K, Hailfinger S, Schulze-Osthoff K, Kramer D. Keratinocyte-derived IKB $\zeta$ drives psoriasis and associated systemic inflammation. JCI Insight. 2019 Nov 14;4(22). pii: 130835

71. Lowes MA, Kikuchi T, Fuentes-Duculan J, Cardinale I, Zaba LC, Haider AS, Bowman EP, Krueger JG. Psoriasis vulgaris lesions contain discrete populations of Th1 and Th17 T cells. J Invest Dermatol. 2008;128:1207-1211.

72. Lowes, M. A., Russell, C. B., Martin, D. A., Towne, J. E., \& Krueger, J. G. (2013). The IL-23/T17 pathogenic axis in psoriasis is amplified by keratinocyte responses. Trends in Immunology. https://doi.org/10.1016/j.it.2012.11.005

73. Lu KQ, Brenneman S, Burns R, et al. Thalidomide inhibits UVB induced mouse keratinocyte apoptosis by bothTNFa independent pathways. Photoderma- tol Photoimmunol Photomed 2003;19:272-80.

74. M. Akaiwa, B. Yu, R. Umeshita,Suyama, N. Terada, H. Suto, T. Koga, K. Arim a, S. Matsushita, H. Saito, H. Ogawa, M. Furue, N. Hamasaki, K. Ohshima, K. 
IzuharaLocalization of human interleukin 13 receptor in non-haematopoietic cells Cytokine, 13 (2001), pp. 75-84

75. Ma Y., Zhang L., Huang X. (2014). Genome modification by CRISPR/Cas9. FEBS J. 281, 5186-5193. 10.1111/febs.13110

76. McKee PH, Calonje E, Granter SR. (2005) Pathologyof the Skin :With Clinical Correlations.Philadelphia: Elsevier Mosby; 2005. 195 p

77. Murano M, Maemura K, Hirata I et al. (2000) Therapeutic effect of intracolonically administered nuclear factor kappa B (p65) antisense oligonucleotide on mouse dextran sulphate sodium (DSS)-induced colitis. Clin Exp Immunol 120:51-8

78. Muromoto R, Hirao T, Tawa K, Hirashima K, Kon S, Kitai Y, et al. IL-17A plays a central role in the expression of psoriasis signature genes through the induction of IKB- $\zeta$ in keratinocytes. Int Immunol (2016) 28(9):443-52. doi:10.1093/intimm/dxw011

79. Nestle F. O., Di Meglio P., Qin J. Z., Nickoloff B. J. (2009) Skin immune sentinels in health and disease. Nat. Rev. Immunol. 9, 679-691.

80. O'Neill, L. A. J., Kishton, R. J., \& Rathmell, J. (2016). A guide to immunometabolism for immunologists. Nature Reviews Immunology. https://doi.org/10.1038/nri.2016.70

81. Palsson-McDermott, E. M., \& O'Neill, L. A. J. (2013). The Warburg effect then and now: From cancer to inflammatory diseases. BioEssays, 35(11), 965-973. http://doi.org/10.1002/bies.201300084

82. Palsson-McDermott, E. M., Curtis, A. M., Goel, G., Lauterbach, M. A. R., Sheedy, F. J., Gleeson, L. E., ... O’Neill, L. A. J. (2015). Pyruvate Kinase M2 Regulates Hif-1 $\alpha$ Activity and IL-1 $\beta$ Induction and Is a Critical Determinant of 
the Warburg Effect in LPS-Activated Macrophages. Cell Metabolism, 21(1), 6580. http://doi.org/10.1016/j.cmet.2014.12.005

83. Pfaff, CM, Marquardt, Y, Fietkau, K. The psoriasis-associated IL-17A induces and cooperates with IL-36 cytokines to control keratinocyte differentiation and function. Sci Rep 2017; 7: 15631.

84. Po-Lin Liao, Cheng-Hui Lin, Ching-Hao Li, Chi-Hao Tsai, Jau-Der Ho, George C. Y. Chiou, Jaw-Jou Kang, and Yu-Wen Cheng. (2017) Anti-inflammatory properties of shikonin contribute to improved early-stage diabetic retinopathy. Sci Rep. Sci Rep. 2017; 7: 44985. doi: 10.1038/srep44985

85. Pouyssegur J, Dayan F, Mazure NM. 2006. Hypoxia signalling in cancer and approaches to enforce tumour regression. Nature 441: 437-43.

86. Qian Y, Liu C, Hartupee J, Altuntas CZ, Gulen MF, Jane-Wit D, Xiao J, Lu Y, Giltiay N, Liu J, Kordula T, Zhang QW, Vallance B, Swaidani S, Aronica M, Tuohy VK, Hamilton T, Li X. The adaptor Act1 is required for interleukin 17dependent signaling associated with autoimmune and inflammatory disease. Nat Immunol. 2007 Mar; 8(3):247-56.

87. Ran FA, Hsu PD, Wright J, Agarwala V, Scott DA, Zhang F. (2013) Genome engineering using the CRISPR-Cas9 system. Nat Protoc. 2013;8:2281-308. https://doi.org/10.1038/nprot.2013.143

88. Ratter JM, Rooijackers HMM, Hooiveld GJ, Hijmans AGM, de Galan BE, Tack $\mathrm{CJ}$, et al. . In vitro and in vivo effects of lactate on metabolism and cytokine production of human primary PBMCs and monocytes. Front Immunol. (2018) 9:2564. 10.3389/fimmu.2018.02564

89. Robinson P. J. (1992). Differential stimulation of protein kinase C activity by phorbol ester or calcium/phosphatidylserine in vitro and in intact 
synaptosomes. J. Biol. Chem. 267, 21637-21644.

90. S. Mazurek Pyruvate kinase type M2: A key regulator of the metabolic budget system in tumor cells Int. J. Biochem. Cell Biol., 43 (2011), pp. 969-980

91. Samira Tamoutounour et al (2019) Keratinocyte-intrinsic MHCII expression controls microbiota-induced Th1 cell responses Proc Natl Acad Sci U S A.Proc Natl Acad Sci U S A. 2019 Oct 31. pii: $201912432 . \quad$ doi: 10.1073/pnas.1912432116.

92. Schoop, V. M., Mirancea, N., \& Fusenig, N. E. (1999). Epidermal organization and differentiation of HaCat keratinocytes in organotypic coculture with human dermal fibroblasts. Journal of Investigative Dermatology, 112(3), 343-353. http://doi.org/10.1046/j.1523-1747.1999.00524.x

93. Schwandner R, Yamaguchi K, Cao Z Requirement of tumor necrosis factor receptor-associated factor (TRAF)6 in interleukin 17 signal transduction. J Exp Med. 2000 Apr 3; 191(7):1233-40.

94. Sen R, Baltimore D. Inducibility of kappa immunoglobulin enhancer-binding protein NF-kappa B by a posttranslational mechanism. Cell. 1986;47:921-928.

95. Shen F, Gaffen SL (2008) Structure-function relationships in the IL-17 receptor: implications for signal transduction and therapy. Cytokine 41:92-104

96. Shi $\mathrm{X}$, et al. IL-17A upregulates keratin 17 expression in keratinocytes through STAT1- and STAT3-dependent mechanisms. J. Invest. Dermatol. 2011;131:2401-2408. doi: 10.1038/jid.2011.222.

97. Shi, L. Z., Wang, R., Huang, G., Vogel, P., Neale, G., Green, D. R., \& Chi, H. (2011). HIF1 -dependent glycolytic pathway orchestrates a metabolic checkpoint for the differentiation of $\mathrm{TH} 17$ and Treg cells. Journal of 
Experimental $\quad$ Medicine, $\quad$ 208(7), 1367-1376. http://doi.org/10.1084/jem.20110278

98. Shibata K, Yamada H, Nakamura R, Sun X, Itsumi M, Yoshikai Y. Identification of CD25+cd T cells as fetal thymus-derived naturally occurring IL-17 producers. J Immunol 2008; 181:5940-7

99. Shirai T, Nazarewicz RR, Wallis BB, et al. The glycolytic enzyme PKM2 bridges metabolic and inflammatory dysfunction in coronary artery disease. J Exp Med. 2016:jem.20150900. doi:10.1084/jem.20150900.

100. Song X, Qian Y. The activation and regulation of IL-17 receptor mediated signaling. Cytokine. (2013) 62:175-82. doi: 10.1016/j.cyto.2013.03.014

101. Steffan NM, Bren GD, Frantz B, Tocci MJ, O'Neill EA, Paya CV. Regulation of IkB alpha phosphorylation by PKC- and $\mathrm{Ca}(2+)$-dependent signal transduction pathways. J Immunol. (1995) 155:4685-91.

102. Steinman L. Mixed results with modulation of $\mathrm{TH}-17$ cells in human autoimmune diseases. Nat Immunol. 2010;11:41-44.

103. Sumida H, Yanagida K, Kita Y, Abe J, Matsushima K, Nakamura M, et al. . Interplay between CXCR2 and BLT1 facilitates neutrophil infiltration and resultant keratinocyte activation in a murine model of imiquimod-induced psoriasis. J Immunol. (2014) 192:4361-9. 10.4049/jimmunol.1302959

104. Sutton CE, Lalor SJ, Sweeney CM, Brereton CF, Lavelle EC, Mills KHG. Interleukin-1 and IL-23 induce innate IL-17 production from cd T cells, amplifying Th17 responses and autoimmunity. Immunity 2009; 31:331-41

105. Takagi $\mathrm{H}$, Arimura K, Uto T, Fukaya T, Nakamura T, Choijookhuu N, et al. Plasmacytoid dendritic cells orchestrate TLR7-mediated innate and adaptive 
immunity for the initiation of autoimmune inflammation. Sci Rep (2016) 14(6):24477-95. doi:10.1038/srep24477

106. Tannahill G. M. et al. Succinate is an inflammatory signal that induces IL-1beta through HIF-1alpha. Nature 496, 238-242 (2013).

107. Tonel, G., \& Conrad, C. (2009). Interplay between keratinocytes and immune cells-Recent insights into psoriasis pathogenesis. International Journal of Biochemistry and Cell Biology. https://doi.org/10.1016/j.biocel.2008.10.022

108. Tonello, S., Rizzi, M., Migliario, M., Rocchetti, V., \& Renò, F. (2017). Low concentrations of neutrophil extracellular traps induce proliferation in human keratinocytes via NF-kB activation. Journal of Dermatological Science, 88(1), 110-116. https://doi.org/10.1016/j.jdermsci.2017.05.010

109. Torales-cardeña, A., Martínez-torres, I., Rodríguez-martínez, S., Gómez-chávez, F., Cancino-díaz, J. C., Vázquez-sánchez, E. A., \& Cancinodíaz, M. E. (2015). Cross Talk between Proliferative, Angiogenic , and Cellular Mechanisms Orchestred by HIF-1a in Psoriasis, 2015. http://doi.org/10.1155/2015/607363

110. Tsai Y.C., Tsai T.F. Anti-interleukin and interleukin therapies for psoriasis: Current evidence and clinical usefulness. Ther. Adv. Musculoskelet. Dis. 2017;9:277-294. doi: 10.1177/1759720X17735756.

111. Tüzün, Y., Antonov, M., Dolar, N., \& Wolf, R. (2007). Keratinocyte Cytokine and Chemokine Receptors. Dermatologic Clinics, 25(4), 467-476. http://doi.org/10.1016/j.det.2007.06.003

112. V. Junghans, T. Jung, C. NeumannHuman keratinocytes constitutively express IL-4 receptor molecules and respond to IL-4 with an increase in B7/BB1 expression Exp. Dermatol., 5 (1996), pp. 316-324 
113. Vander Heiden MG, Locasale JW, Swanson KD, et al. Evidence for an alternative glycolytic pathway in rapidly proliferating cells. Science. 2010;329:1492-99.

114. Veras, F.P. (2018) Investigação dos mecanismos moleculares da patogênese da psoríase: participação da enzima glicolítica Piruvato Quinase M2 (PKM2). Tese de Doutorado - Departamento de Farmacologia da Faculdade de Medicina de Ribeirão Preto - Universidade de São Paulo, Ribeirão Preto, SP.

115. W. Zwerschke, S. Mazurek, P. Stockl, E. Hutter, E. Eigenbrodt, P. Jans en-DurrMetabolic analysis of senescent human fibroblasts reveals a role for AMP in cellular senescence Biochem. J., 376 (2003), pp. 403-411

116. W.J. Israelsen, M.G. Vander HeidenPyruvate kinase: Function, regulation and role in cancer Semin. Cell Dev. Biol., 43 (2015), pp. 43-51

117. Wang M, Zhang S, Zheng G, Huang J, Songyang Z, Zhao X, Lin X. Gainof-function mutation of Card14 leads to spontaneous psoriasis-like skin inflammation through enhanced keratinocyte response to IL17A. Immunity. 2018;49(1):66-79. doi: 10.1016/j.immuni.2018.05.012.

118. Warburg O, Wind F and Negelein E.(1927) The metabolism of tumors in the body. J Gen Physiol 8: 519-530, 1927.

119. Wei Gao, Lu Long, Xinquan Tian, Fuchun Xu, Ji Liu, Prashant K. Singh, Jose R. Botella, and Chunpeng Song. (2017) Genome Editing in Cotton with the CRISPR/Cas9 System. Plant Sci. 2017; 8: 1364.

120. West AP, Brodsky IE, Rahner C, Woo DK, Erdjument-Bromage $\mathrm{H}$, Tempst P, Walsh MC, Choi Y, Shadel GS, Ghosh S. (2011) TLR signalling 
augments macrophage bactericidal activity through mitochondrial ROS. Nature. 2011;472(7344):476-480

121. Wickersham M, Wachtel S, Wong Fok Lung $T$, Soong G, Jacquet R, et al. (2017) Metabolic Stress Drives Keratinocyte Defenses against Staphylococcus aureus Infection. Cell Rep 18: 2742-2751. doi: 10.1016/j.celrep.2017.02.055

122. Wu L et al. A novel IL-17 signaling pathway controlling keratinocyte proliferation and tumorigenesis via the TRAF4-ERK5 axis. J Exp Med 212, 1571-1587 (2015).

123. Xie, M., Yu, Y., Kang, R., Zhu, S., Yang, L., Zeng, L., ... Tang, D. (2016). PKM2-Dependent glycolysis promotes NLRP3 and AIM2 inflammasome activation. Nature Communications, 7. https://doi.org/10.1038/ncomms13280

124. Yang and Lu, 2015 W. Yang, Z. LuPyruvate kinase M2 at a glance J. Cell Sci., 128 (2015), pp. 1655-1660

125. Yang W, Lu Z. (2013) Regulation and function of pyruvate kinase M2 in cancer. Cancer. Lett. 2013;339:153-158. doi: 10.1016/j.canlet.2013.06.008.

126. Yang $\mathrm{W}$, Zheng $\mathrm{Y}$, Xia $\mathrm{Y}$, Ji $\mathrm{H}$, et al. 2012. ERK1/2-dependent phosphorylation and nuclear translocation of PKM2 promotes the Warburg effect. Nat Cell Biol 14: 1295-304.

127. Yao Z, Fanslow WC, Seldin MF, Rousseau AM, Painter SL, Comeau MR, et al. Herpesvirus Saimiri encodes a new cytokine, IL-17, which binds to a novel cytokine receptor. Immunity. 1995;3:811-821.

128. Y-C Yang. Cytosolic PKM2 stabilizes mutant EGFR protein expression through regulating HSP90-EGFR association Oncogene volume 35, pages3387-3398(2016) 
129. Zhang Z, Zi Z, Lee EE, Zhao J, Contreras DC, South AP, et al. . Differential glucose requirement in skin homeostasis and injury identifies a therapeutic target for psoriasis. Nat Med. (2018) 24:617-27. 10.1038/s41591018-0003-0

130. Zhou CF, Li XB, Sun H, et al. Pyruvate kinase type M2 is upregulated in colorectal cancer and promotes proliferation and migration of colon cancer cells. IUBMB Life. 2012;64:775-82.

131. Zhu, S., Pan, W., Shi, P., Gao, H., Zhao, F., Song, X., ... Qian, Y. (2010). Modulation of experimental autoimmune encephalomyelitis through TRAF3mediated suppression of interleukin 17 receptor signaling. The Journal of Experimental Medicine, 207(12), 2647-2662. https://doi.org/10.1084/jem.20100703 


\section{APÊNDICE}

\section{APÊNDICE A - Comitê de ética no uso de animais para experimentação}

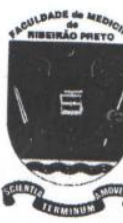

\section{UNIVERSIDADE DE SÃO PAULO \\ FACULDADE DE MEDICINA DE RIBEIRÃO PRETO \\ COMISSÃO DE ÉTICA NO USO DE ANIMAIS

\section{E R T I F I C A D O}

Certificamos que o Protocolo intitulado "O papel da enzima glicolitica piruvato quinase M2 (PKM2) na sinalização via IL-17A em queratinócitos", registrado com o número 081/2019, sob a responsabilidade do Prof. Dr. José Carlos Farias Alves Filho, envolvendo a produção, manutenção ou utilização de animais pertencentes ao filo Chordata, subfilo Vertebrata (exceto humanos) para fins de pesquisa científica, encontra-se de acordo com os preceitos da Lei $n^{\circ} 11.794$ de 8 de outubro de 2008, do Decreto $n^{\circ} 6.899$ de 15 de julho de 2009 e com as normas editadas pelo Conselho Nacional de Controle de Experimentação Animal (CONCEA), e foi APROVADO pela Comissão de Ética no Uso de Animais da Faculdade de Medicina de Ribeirão Preto da Universidade de São Paulo em reunião de 27 de maio de 2019.

Este Protocolo prevê a utilização de 28 camundongos K14-Cre+/ ERT PKM2fl/fl (C57bl/6) machos pesando $20 \mathrm{~g}$ e 28 camundongos PKM2fl/fl (C57bl/6) machos pesando $20 \mathrm{~g}$ oriundos do Serviço de Biotério da Prefeitura do Campus de Ribeirão Preto da Universidade de São Paulo. Vigência da autorização: 27/05/2019 a 20/01/2020.

We certify that the Protocol $n^{\circ} \mathbf{0 8 1} / 2019$, entitled "The Role of PKM2 on IL-17A pathway in keratinocytes", is in accordance with the Ethical Principles in Animal Research adopted by the National Council for the Control of Animal Experimentation (CONCEA) and was approved by the Local Animal Ethical Committee from Ribeirão Preto Medical School of the University of São Paulo in 05/27/2019. This protocol involves the production, maintenance or use of animals from phylumChordata, subphylumVertebrata (except humans) for research purposes, and includes the use of 28 male K14-Cre+/ ERT PKM2fl/fl (C57bl/6) mice weighing 20g and 28 male $\mathrm{PKM} 2 \mathrm{fl} / \mathrm{fl}(\mathrm{C} 57 \mathrm{bl} / 6)$ mice weighing $20 \mathrm{~g}$ from the Central Animal House of Ribeirão Preto Medical School, University of São Paulo. This certificate is valid until 01/20/2020. 